\title{
Refashioning Italian Theatrical and Dramatic Conventions: Prologues, Epilogues and Inductions in Early Modern English Drama
}

\author{
Fernando Cioni , University of Florence
}

Elizabethan drama used a variety of introductory scenes which can be defined as inductions, [1] provided that we distinguish their dramatic and theatrical functions. In the theatre, the induction is a dramatic device, metatheatrical and metadramatic, which emphasizes the nature of the play. Richard Hosley argues that it is "a short dramatic action introducing a full-length play, normally performed by two or more actors and creating a fictional situation different from that of the play itself." [2] According to Harbage,[3] before 1594 twenty-one plays with introductory scenes were performed or simply entered in the Stationer's register. Eight of these plays, such as George Gascoigne's Jocasta (1566) and George Peele's The Battle of Alcazar (1597), present a dumb-show[4] as introductory scene; the other eight plays have what Thelma Greenfield defines as "occasional inductions," [5] such as that of The Spanish Tragedy (1582-92). Only four plays have the induction as a frame play: the anonymous The Taming of a Shrew (1594), William Shakespeare's The Taming of the Shrew (1592), George Peele's The Old Wives Tale (1588-1594), and Robert Greene's The Scottish History of James IV (1590-1591). After 1594, the forms of induction registered by Harbage are forty-nine: eight in a dumb show form (such as John Marston's Sophonisba or the Wonder of Women, 1605-1606), and only three in the form of frame play, Beaumont's The Knight of the Burning Pestle (1607-1610), Beaumont and Fletcher and Field's Four Moral Representations (1608-1613), and Thomas Randolph's The Muses Looking-Glass (1630). Seventeen inductions have mainly an introductory function, presenting the play, and sometimes with its characters appearing throughout the play. One example is Thomas Dekker's If This Be Not a Good Play the Devil Is in It (1611-1612), where the characters in the induction open and close the play. This kind of induction, is similar to the frame play, but it lacks the dramatic development of it - see, for instance, the induction to Thomas Middleton's Michaelmas Term (1604-1606) and that to Laelia (1595), an adaptation in Latin of the French translation of Gli Ingannati and Charles Estienne's Les Abusez (1540), performed at Queen's College, Cambridge, in 1595. The other inductions after 1594 to the Restoration have been classified as "critical inductions," where "human spectators appear on stage to watch a play and criticize it. Actors and tiremen rush about it in a last minute flurry before the play opens"[6] (Greenfield [1969]: 67).

The induction as dramatic and theatrical device was a way to overcome the gap between stage and audience, between make-believe and actuality, aiming at making the audience accept dramatic illusion. The induction, even though it possibly followed the Italian custom of turning prologues into a conversation, seems to gather and develop the characteristics of other introductory forms such as prologue and dumb show. The former, normally, does not contain dramatic action, whereas the latter lacks dialogue. The induction could have been influenced by the Italian prologues and epilogues, in particular by the dialogical prologues, such as Bibbiena's La Calandria, even though in Italian Renaissance plays prologues were mainly used to disclose sources and plot, in the Terencian and Plautine traditions. Until the end of $16^{\text {th }}$ century, prologues and epilogues of the Plautine and Terencian kind model themselves after Italian comedy, if not through a physical contact or a direct borrowing, then through what Louise George Clubb calls "theatergrams," that is, "a common process based on the principle of contamination of sources, genres, and accumulated stage-structures".[7]

\section{Prologues and Epilogues. The Italian Comedic Tradition.}


In the Italian Renaissance, the imitation of Latin literature became a principle of literary composition. Renaissance dramatists considered Plautus and Terence the supreme degree of perfection to be imitated. Not only were Latin comedies the sources for the dramatic composition (structure, plot, and characters), but also for their prologues. Both Plautus and Terence use extensively a variety of prologues:[8] four of Plautus's comedies[9] have an expository dialogue and no narrative prologue, eight have a narrative prologue,[10] six open with a prologue, $[11]$ which deals mainly with the "argumentum". Unlike Plautus, Terence made the prologue independent of the play and gradually eliminated the argumentum. The prologues of commedie erudite have many similarities with those of the two Latin dramatists.

Giraldi Cinthio, in his essay Intorno al comporre delle commedie e delle tragedie (1543), emphasized how the prologue is independent of the fabula:

non si può dire tal prologo parte della favola; perché non ha legamento alcuno coll'azione che nella favola si tratta, né a quel modo si recita che si recitano l'altre parti; perocché colui che fa il prologo il fa "o" in persona del poeta, "o in commendazione della favola", il quale non si può né si dee introdurre nell'azione.[12]

[The prologue cannot be considered part of the fabula, because it has no connections with the action treated in it; and it is not acted in the same manner as the other parts of the play. Therefore, whoever reads the prologue does it either to praise the fabula, or to act as the poet himself, who cannot and must not intrude in the action]

Whoever reads the prologue must not intrude in the action, as he speaks on behalf of the poet. The prologue is an addition made by the Romans to draw the attention of the audience and to favour their appreciation of the poet:

non imitando il prologo l'azione, riman chiarissimo ch'egli della favola non è parte, ma è una giunta postavi da' Romani per disporre gli animi degli spettatori alla attenzione, o per conciliare insieme benevolenza al poeta: "o per le altre cagioni già dette", il che mostra il voltar del parlare che fa colui "che ha la cura" del prologo agli spettatori, la qual cosa non si può fare negli atti della favola, se non con riprensione.[13]

[as the prologue does not imitate the action, it is clear that it is not part of the fabula, but it is an addition made by the Romans to draw the attention of the spectators' minds, or to give the poet their benevolence, or for the reasons I have already given. This is shown by the address to the audience made by the reader of the Prologue, something that cannot be done in the action of the fabula, without disapproval]

In that spirit, Ariosto prepared two different prologues to the Negromante, one for the performance to be given in Rome in $1520, \stackrel{[14]}{a}$ and another for the performance at Carnival in Ferrara in 1528, as if the circumstances affected the way the prologue had to be written and spoken. The Rome prologue contains direct references to the Pope ("De la soma virtù di Leon decimo," "The high virtues of Leo 10th" and the city ("[Ferrara] sen'era sin qui in Roma venuta integra," "[Ferrara] had arrived intact here in Rome");[15] the prologue for the Ferrara performance contains both references to Ariosto's hometown and to his plays, which were very popular at the court of Ferrara ("Autor da chi Ferrara ebbe di prossimo / La Lena; e già son quindici anni o sedeci,/ Ch'ella ebbe la Cassaria and li Suppositi," "The author from whom recently Ferrara had La Lena, and la Cassaria e li Suppositi fifteen or sixteen years ago". [16] Giovanni Francesco Loredano in Lo Incendio (1597) was more explicit about it 
when he wrote that it is a good thing to vary the Prologue according to the circumstances in which the play is given:

Sopra questa scena qual volta è accaduto far più rappresentationi di una favola, si è osservati variar prologo, sapendo che in tal materia ogni novità fatta con disegno suole apportare grandezza alla Commedia, diletto al popolo, \& lode ai recitanti, \& per mantenere questo buon ordine, sempre habbiamo usato diligenza di trovare invenzioni meritevoli di essere ascoltate, di ciò ne sete certi, quanto nella prova di questa, che è intitolata lo INCENDIO, vi si recitò Prologo non ingrato, \& hora ne havereste un'altro, che di stile, $\&$ di materia saria stato non meno vago del primo se al nostro buon volere non si fosse opposta la presunzione di un maligno Pedagogo.[17]

[When on stage it happened that a fabula had to be performed more than once, we had also to change the prologue, knowing that in doing this every change made on purpose would bring greatness to the Comedy, amusement to the people, and praise to the players; in order to keep this order we have always tried to find inventions worthy of being heard, be sure of this; as far as this play entitled The Fire is concerned, a pleasant Prologue was performed, and now you will have another one, which, for the style and the subject, would be no less vague than the first if a spiteful Pedagogue's presumption had not opposed to our good intentions.]

The prologue was, in the majority of cases, spoken by an actor - sometimes by the author himself, as in the prose version of Ariosto's I Suppositi or Machiavelli's Mandragola. Nevertheless, the prologue could be also given by two or more actors. This is the case of Pietro Aretino's Ipocrito and La Cortigiana; or Ludovico Dolce's Fabritia, where "due fanciulli fanno il prologo" ("two children say the prologue"),[18] or Alessandro Piccolomini's $L$ 'amor costante. It could happen that the characters of the prologue were abstract characters, such as "la gelosia" ("Jelousy"), "il Riso" ("The Laugh"), "L'ubbidienza" ("The Obedience"), "La verità" ("The Truth"), "Tragedia" and "Commedia" ("Tragedy" and "Comedy"), "Prologo" and "Argomento" ("Prologue" and "Argument").[19]

English Renaissance dramatists seem to have followed this two-actors kind of induction, which has been defined as allegorical,[20] which developed also from the late moralities. The Italian Renaissance prologue was an excellent inducement for English dramatists to introduce in their plays allegorical figures.[21] Between 1582 and 1604, we have a good number of plays beginning with an allegorical induction. For instance, in the anonymous $A$ Warning to Fair Women (1599) History, Comedy, and Tragedy appear in bodily form on the stage discussing about the theme of the play.[22] In the anonymous The True Tragedy of Richard III (1594), the speakers are Truth and Poetrie who, starting from the appearance of the ghost of Clarence, first give the historical frame, then inform the audience about the events which brought Richard to the crown, and finally they present Richard. [23]

In Middleton's Michaelmas Term (1604), allegorical representatives of the four terms of the legal year ${ }^{[24]}$ are present in the induction, explaining the general purpose of the play. The induction ends with Michaelmas Term's address to the audience.[25]

It was principally before 1600 that this kind of introductory scene was very popular.

Afterwards, starting from Marston's Antonio and Mellida and Jonson's Every Man Out of His Humour they had mainly the form of satirical inductions, a vehicle of criticism and satire 
which contributed to the so called "war of the theatres". For example in the induction to Every Man Out of His Humour, Ben Jonson first attacks the audience:

Now gentlemen I goe

To turne an Actor, and a Humorist,

Where (ere I doe resume my present person)

We hope to make the circles of your eies

Flow with distilled laughter: if we faile,

We must impute it to this onely chance,

Art hath an enemie cal'd Ignorance.[26]

Then he considers the theory of comedy, illustrating its development:

Mit. Does he observe all the lawes of Comedie in it?

Card. Wathe lawes meane you?

Mit. Why the equall devision of it into Actas and Scenes,

According to the Terentian manner, his true number of Actors: the furnishing of the scene with Grex or Chorus, and that the whole Argument fall within compasse of a daies efficience powee: but 'tis extant, that that which wee call Comedia, was at first nothing but a simple and continues Satyre, sung by one only person, till Susario, invented a second, after him Epicharmus a third, Phormus (long after) added a fifth and sixt: Eupolis more, Aristophane more than they: every man in the dignitie of his spirit and judgement, supplied something: and (though that in him this kind of Poeme appeared absolute, and fully perfected) yet how is the face of it chang'd since, in Menander, Philemon, Cecilius, Plautus, and the rest; who have utterly excluded the Chorus, altered the propertie of the persons, their names, and natures, and augmented it with all libertie, according to the elegancie and disposition of those times wherein they wrote. I see not then but we should enjoy the same Licentia or free power, to illustrate and heighten our invention as they did; and not to be tied to those strict and regular forms, which the nicenesse of a fewe (who are nothing but Forme) would thrust upon us.[27] (STC 14767, B4 ${ }^{\mathrm{v}}$ )

Another kind of induction is the framing induction. It developed partly from the allegorical kind, and partly from the framed tale and the play-within-the play. These inductions differ from the allegorical ones, as the characters which appear in it are not allegorical but human. In general, these inductions provide a framework for the presentation of the play. Among them the anonymous The Taming of a Shrew; Robert Greene's The Scottish History of James $I V$, with the return of Bohan from tomb, his conversation with Oberon and his invitation to the King of Fairies to see a play he has written about King James IV, which explains why he hates all the world; and George Peele's The Old Wives Tale, where Frolick, Antick and Fantastic lost in the wood meet an old woman, Madge, who is asked to tell a story, but she cannot remember it and the characters of the story act it out for her; Anthony Munday's The 
Downfall of Robert Earl of Huntington, with an induction which starts from the idea that the play is a rehearsal for a performance to be given before Henry VIII. The function of the induction in all these plays is that of providing a framework to the main plot of the play.

The induction seems to have some relationship with Italian prologues, both from a dramatic and theatrical perspective. It is in the dialogic prologue that we can find a kind of relation with the theatrical form of the induction. The above quoted prologues to Piccolomini's $L$ 'amor costante, with a Spaniard commenting the on organization of the performance and his involvement in the production, and the prologue to Pietro Aretino's La cortigiana with a Forestiero and a Gentiluomo discussing the "pomposo apparato" could have offered more than a mere example to Early Modern English drama. Also the introductory part to Lasca's La strega, as Marvin Herrick has noted, has an introduction-like structure "similar to those later used by Ben Jonson, Shakespeare, and other Elizabethan playwrights".[28] (Herrick [1960]: 137).

The popularity of these introductory scenes is witnessed also by University[29] drama and by the so called "closet plays", never published or never performed. The importance of the University plays[30] in the transition of the Italianate comedic tradition goes beyond their aesthetical value. These plays, amateurish and duly imitative, extensively used prologues, choruses, songs, and epilogues.

The anonymous Laelia, which is extant in MS.,[31] was acted at Queen's College, Cambridge probably on March $1^{\text {st }}, 1595$. Even if it is a translation, in Latin, of Charles Estienne's French translation of Gli Ingannati, Les Abusez, the prologue is not that of the Italian play, nor is the epilogue. The prologue, probably written for the performance before the noble visitors of 1595, is a dialogue between Panneus and Sericus. It is meant to introduce the plot of the play: "Pan. Prologus sum. Venio narratum argumentum fabulae" (1.3) ("Pan. I am the Prologue. I come to tell the argument of the play").[32] The epilogue, spoken by Petrus is the classical Plautus-like epilogue meant to invite the audience to applaud:

"Petrus Nostrae extremum iam actum tanquam Audiuisti comediae [...] (Honoratissimi viri, onoratissimi, inquam, et grauissimi viri)/ Cum meo Cicerone plausum date,/ Vel potius cum Plauto, plaudite" $(1.78,81-83)$

["Petrus You have heard the final act of this comedy, most noble men, most noble I say, and most notable men, give your applause with my Cicero, or rather applaud with Plautus"].[33]

Another example is the anonymous Philomela, performed on $29^{\text {th }}$ December 1607, at St. John's College, Oxford, which survives only in MS.34] The St. John's anonymous dramatist took his material directly from Book VI of Ovid's Metamorphosis. The play, a comedy of the neo-Plautine type, is set in Athens and Megara, a university town, a transparent disguise for Oxford. The first act is preceded by an "Induction Fortunae" and by a chorus (Terra and Unda). The plays ends with a speech by Fortuna (not headed as epilogue).

William Percy's plays, which survive only in a Ms, $[35]$ housed at the Huntington Library, present both prologues and epilogues. Among them is A Country Tragedy in Vacunium or Cupid's Sacrifice (ca. 1602), which was probably privately acted. The play opens with a chorus of eight lovers, who sing a hymn to Cupid. Then the Presenter addresses a prayer to Cupid. The Chorus sits on either side of the stage, and the Presenter speaks the prologue, a 
mere plea for favour towards the play. The chorus intervenes at the end of each act with a song. The play ends with an epilogue divided into two parts: the argument between the Presenter and the Chorus whether the classical rules have been violated or not, and the songs sung by the Chorus.

Periander [36] is a tragedy based at first hand on a Greek original, such as Herodotus or Diogenes Laertius. The play opens with a chorus, a dialogue between The Master of the Revels, The Master of the Revels boy, Detraction and Resolution. The Master of the revels asks the boy "What's your play nowe", and the boy presents the play as a tragedy in English. Detraction, seated among the spectators shouts "Hisses" in disapproval (and continues: "Poxe: begin your play, and leaue your pratinge"). The Master of Revels and Detraction start to argue:

D. I haue heard your play repeated man, tis not so worshipfull stuffe as is expected

$M^{r}$. T'is to good for you sir.

D. And to bad for this Audience.[37]

Then Resolution intervenes, sent by His Lord ("My lorde sends to knowe what noyse this is."). The Master of Revels accuses Detraction not to let the play begin, but Resolution says that "He is indeed an Epitome of all the fowle mouthe's in a whole vniversity". Then The Master of Revels exits. Resolution invites Detraction to act with him as chorus: "Thou and I wil be Chorus, they shall not hold: they'l speake to gravely for vs, and to wisely for the tyme".

These introductory scenes seem to have been influenced by the allegorical prologues of Italian comedy. The University plays, but also the closet plays, which should be seen as a sort of cultural phenomenon, had an important role in the diffusion of Italian Renaissance dramatic and theatrical conventions. Both professional and academic playwrights were, in large number, coming from Oxford and Cambridge, where, both as spectator and as actors, when not as dramatists, they had experienced college plays.

What I have tried to show in this essay is how also theatrical conventions such as prologues and inductions can be indebted to Italian theatre. Even though the introductory scenes so popular in Early modern English drama such as prologues and inductions (along with epilogues and choruses), have certainly developed from a medieval tradition, they represent a device which derives also from Italianate comedic conventions.

\section{WORKS CITED}

Anonymous, The True Tragedy of Richard III, London, 1594.

Anonymous, A Warning to Fair Women, London, 1599.

Anonymous, Laelia, edited by George C. Moore Smith, Cambridge, Cambridge University Press, 1910.

Anonymous, Laelia edited by Horst-Dieter Blume, Georg Olms Verlag, Hildesheim 1991. 
Ariosto, Ludovico, Opere minori, edited by Luigi Polidori, Firenze, Le Monnier, 1857.

Ariosto, Ludovico, Opere Minori, edited by Cesare Segre, Milano-Napoli, Ricciardi, 1964.

Boas, Frederick S., University drama in the Tudor age, Oxford, Oxford University Press, 1914.

Boas Frederick S., The Christmas Prince, The Malone Society reprints, Oxford, Oxford University Press, 1922.

Cioni, Fernando, "Stages at the University of Cambridge in Tudor England", in English Renaissance Scenes, edited by Paola Pugliatti and Alessandro Serpieri, Oxford, Peter Lang, 2006, pp. 127-154.

Clubb, Louise George, Italian Drama in Shakespeare's Time, New Haven and London, Yale University Press, 1989.

Creizenach, Willheim, The English drama in the age of Shakespeare, London, Sidwick \& Jackson, 1916, pp. 276-277.

Dolce, Ludovico, Fabritia, Venezia, 1549.

Fabia, Philippe, Les Prologues de Terence, Ernest Thorin, Paris 1888.

Giraldi Cinthio, Giovan Battista, Intorno al comporre delle commedie e delle tragedie (1543), in Commedie del Cinquecento, edited by Aldo Borlenghi, Rizzoli, Milano 1959, vol. I.

Goggio, Emilio, "The Prologue in the Commedie Erudite of the Sixteenth Century", Italica, 18 (1941) pp. 124-132.

Greenfield, Thelma, The Induction in Elizabethan Drama, Eugene, The University of Oregon Press, 1969.

Harbage, Alfred, Annals of English Drama, Philadelphia, University of Pennsylvania Press, 1940.

Herrick, Marvin T., Italian comedy in the Renaissance, Urbana, Illinois University Press, 1960.

Hillebrand, Harold N., "William Percy: An Elizabethan Amateur", The Huntington Library Quarterly 1 (1938), pp. 391-416.

Hosley, Richard, “Was There a 'Dramatic Epilogue' to The Taming of the Shrew?, Studies in English Literature, 1500-1900, 1 (1961), pp. 17-34.

Jonson, Ben, Every Man Out of His Humour, London 1600.

Loredano, Giovanni Francesco, Lo Incendio, Venezia, 1597. 
Mehl, Dieter, The Elizabethan Dumb Show, Cambridge (Mass.), Harvard University Press, 1966.

Middleton, Thomas, Michaelmas Term, edited by Theodore B. Leinwand, in The Collected Works, edited by Gary Taylor and John Lavagnino, Oxford, Clarendon Press, 2007.

Moore Smith, George C., College plays performed in the university of Cambridge, Cambridge, Cambridge University Press, 1923.

Taylor, Michael, "Notes", in Thomas Middleton, A Mad World, My Master and other plays, edited by Michael Taylor, Oxford, Oxford University Press, 1995, p. 318).

\section{APPENDIX}

The following table summarizes the presence of introductory scenes (such as inductions, dumb shows, choruses, prologues, epilogues, etc.) in early modern English drama from 1516 to 1642: 308 plays written and/or performed before the closing of the theatres (including ten manuscripts, seventeen Latin plays, and a play not classified by Greg, Shakespeare's The Taming of the Shrew, that have the same entry of the anonymous The Taming of a Shrew), from a total of 836 plays in English - including manuscripts - and 22 in Latin.

The first column is devoted to the name of the author, or the authors. When is a collaborative play the names are indicated with surname and the initials. When an author has the main hand, he is placed in the first place, followed by "with" (i.e. "Fletcher, with Beaumont"). Anonymous is used when the authorship is unknown.

The second column is devoted to title as they appear on the front page of a published playtext, or on the first page of a manuscript. When a play is an adaptation of another play, the title of the adapted play is given in brackets.

The third column supplies the year of publication (or the only extant early edition) and of the first performance (A). When a play was not published individually, "collection" follows the year of publication. When a play has been revised, the date is supplied after the date of the first publication and performance. For manuscripts, the approximate date of the manuscript is given.

The fourth column supplies a rough classification of the play as classified in Alfred Harbage's Annals of English Drama, University of Pennsylvania Press, Philadelphia 1940;

The fifth column supplies the place of the first performance (theatre, college, etc.), or the name of the professional company that performed the play; "closet" means the plays was not written to be performed;

The sixth column gives the entry in the "Short title catalogue", the catalogue of printed texts published in England until 1700.

The seventh column gives the entry as in W.W. Greg's A Bibliography of the English Printed Drama to the Restoration, The Bibliographical Society, London 1939-59, 4 vol. (MS stands for manuscript, L for plays in Latin); 
The eight column describes the kind of introductory scene in each play; "conclusion" means a not headed epilogue; "in form of a dialogue" means a prologue or epilogue with more than one actor performing them.

Prologues, inductions, choruses, dumb shows in Early Modern English drama (15121642)

\begin{tabular}{|c|c|c|c|c|c|c|c|c|}
\hline & Author & Title & Year & $\begin{array}{l}\text { Dramatic } \\
\text { genre }\end{array}$ & $\begin{array}{l}\text { Place of } \\
\text { performanc } \\
\text { e }\end{array}$ & STC & $\begin{array}{l}\text { Gr } \\
\text { eg }\end{array}$ & Notes \\
\hline 1. & $\begin{array}{l}\text { Merbury, } \\
\text { Francis } \\
(?)\end{array}$ & $\begin{array}{l}\text { The } \\
\text { Marriage } \\
\text { between } \\
\text { Wit and } \\
\text { Wisdom }\end{array}$ & 1579 & $\begin{array}{l}\text { Moral } \\
\text { Interlude }\end{array}$ & Unknown & & $\begin{array}{l}M \\
S\end{array}$ & $\begin{array}{l}\text { Prologue } \\
\text { and } \\
\text { epilogue }\end{array}$ \\
\hline 2. & Anon. & $\begin{array}{l}\text { Revival of } \\
\text { Three } \\
\text { Plays in } \\
\text { One? } \\
\text { (Seven } \\
\text { deadly sin) }\end{array}$ & $1590 \mathrm{c}$. & Moral & Strange's & & $\begin{array}{l}M \\
S\end{array}$ & $\begin{array}{l}\text { Two } \\
\text { introducto } \\
\text { ry scenes, } \\
\text { conclusion } \\
\text { and } \\
\text { epilogue }\end{array}$ \\
\hline 3. & Anon. & Laelia & $\begin{array}{l}1595 \\
\text { MS }\end{array}$ & $\begin{array}{l}\text { Latin } \\
\text { comedy }\end{array}$ & $\begin{array}{l}\text { Queen's } \\
\text { College, } \\
\text { Cambridg } \\
\text { e }\end{array}$ & & $\begin{array}{l}M \\
S\end{array}$ & $\begin{array}{l}\text { Prologue } \\
\text { (dialogue } \\
\text { between } \\
\text { Penneus } \\
\text { and } \\
\text { Sericus), } \\
\text { Epilogue } \\
\text { (not } \\
\text { headed) }\end{array}$ \\
\hline 4. & Anon. & Philomela & $\begin{array}{l}1607 \\
\text { A } 29 \\
\text { Dic. } \\
1607\end{array}$ & $\begin{array}{l}\text { Latin } \\
\text { tragedy }\end{array}$ & $\begin{array}{l}\text { St. John's } \\
\text { College, } \\
\text { Oxford }\end{array}$ & & $\begin{array}{l}M \\
S\end{array}$ & $\begin{array}{l}\text { Induction } \\
\text { and } \\
\text { conclusion } \\
\text { by Fortuna }\end{array}$ \\
\hline 5. & $\begin{array}{l}\text { Percy } \\
\text { William }\end{array}$ & $\begin{array}{l}\text { A Country } \\
\text { Tragedy in } \\
\text { Vacunium } \\
\text { or Cupid's } \\
\text { Sacrifice }\end{array}$ & 1602 & Tragedy & $\begin{array}{l}\text { Privately } \\
\text { acted? }\end{array}$ & & $\begin{array}{l}M \\
S\end{array}$ & $\begin{array}{l}\text { Chorus, } \\
\text { prologue, } \\
\text { chorus at } \\
\text { the end of } \\
\text { each act, } \\
\text { epilogue } \\
\text { in form of } \\
\text { a dialogue }\end{array}$ \\
\hline 6. & $\begin{array}{l}\text { Sansbury, } \\
\text { John }\end{array}$ & Periander & 1608 & Tragedy & $\begin{array}{l}\text { St. John's } \\
\text { Col., } \\
\text { Oxford }\end{array}$ & & $\begin{array}{l}\mathrm{M} \\
\mathrm{S}\end{array}$ & $\begin{array}{l}\text { Induction } \\
\text { (Chorus), } \\
\text { chorus at } \\
\text { the end of } \\
\text { each act, }\end{array}$ \\
\hline
\end{tabular}




\begin{tabular}{|c|c|c|c|c|c|c|c|c|}
\hline & & & & & & & & $\begin{array}{l}\text { with } \\
\text { epilogue } \\
\text { an } \\
\text { conclusion }\end{array}$ \\
\hline 7. & $\begin{array}{l}\text { Willmot, } \\
\text { R. } \\
\text { Stalford, } \\
\text { Hatton, } \\
\text { Noel, G. } \\
\text { Al. }\end{array}$ & $\begin{array}{l}\text { Gismond } \\
\text { of Salerne }\end{array}$ & $\begin{array}{l}1566 \\
\text { or } \\
1568 \\
\text { P } 1591\end{array}$ & Tragedy & $\begin{array}{l}\text { Inner } \\
\text { Temple }\end{array}$ & & $\begin{array}{l}M \\
S\end{array}$ & $\begin{array}{l}\text { Prologue } \\
\text { spoken by } \\
\text { Cupid, } \\
\text { epilogue }\end{array}$ \\
\hline 8. & $\begin{array}{l}\text { Anonymo } \\
\text { us }\end{array}$ & $\begin{array}{l}\text { Narcissus. } \\
\text { A Twelfth } \\
\text { Night } \\
\text { Merriment }\end{array}$ & 1603 & Farce & $\begin{array}{l}\text { St. John } \\
\text { College, } \\
\text { Oxford }\end{array}$ & & $\begin{array}{l}M \\
S\end{array}$ & $\begin{array}{l}\text { Induction, } \\
\text { song, } \\
\text { prologue, } \\
\text { epilogue }\end{array}$ \\
\hline 9. & $\begin{array}{l}\text { Anonymo } \\
\text { us }\end{array}$ & $\begin{array}{l}\text { The Dead } \\
\text { Man's } \\
\text { Fortune }\end{array}$ & $1590 \mathrm{c}$. & $\begin{array}{l}\text { Romantic } \\
\text { Comedy }\end{array}$ & Admiral's & & $\begin{array}{l}M \\
S\end{array}$ & Prologue \\
\hline 10 & $\begin{array}{l}\text { Anonymo } \\
\text { us }\end{array}$ & $\begin{array}{l}\text { Frederick } \\
\text { and } \\
\text { Basilea }\end{array}$ & 1597 & Romance & $\begin{array}{l}\text { Admiral's } \\
\text { performed } \\
\text { at the } \\
\text { Rose }\end{array}$ & & $\begin{array}{l}M \\
S\end{array}$ & $\begin{array}{l}\text { Prologue } \\
\text { and } \\
\text { epilogue } \\
\text { spoken by } \\
\text { Richard } \\
\text { Alleyn }\end{array}$ \\
\hline 11 & $\begin{array}{l}\text { Gager, } \\
\text { William }\end{array}$ & Meleager & $\begin{array}{l}1592 \\
\text { A } 1582\end{array}$ & $\begin{array}{l}\text { Latin } \\
\text { Tragedy }\end{array}$ & $\begin{array}{l}\text { Christ } \\
\text { Church, } \\
\text { Oxford }\end{array}$ & $\begin{array}{l}\text { STC } \\
11515\end{array}$ & L2 & $\begin{array}{l}\text { Chorus at } \\
\text { the end of } \\
\text { each act, } \\
\text { two } \\
\text { prologues } \\
\text { and one } \\
\text { epilogue } \\
\text { (+ two } \\
\text { prologues } \\
\text { for the } \\
\text { performan } \\
\text { ce before } \\
\text { Queen } \\
\text { Elizabeth } \\
\text { in 1592) }\end{array}$ \\
\hline $\begin{array}{l}12 \\
.\end{array}$ & $\begin{array}{l}\text { Gager, } \\
\text { William }\end{array}$ & $\begin{array}{l}\text { Ulysses } \\
\text { Redux }\end{array}$ & $\begin{array}{l}1592 \\
\text { A } 1592\end{array}$ & $\begin{array}{l}\text { Latin } \\
\text { Tragedy }\end{array}$ & $\begin{array}{l}\text { Christ } \\
\text { Church, } \\
\text { Oxford }\end{array}$ & $\begin{array}{l}\text { STC } \\
11516\end{array}$ & L4 & $\begin{array}{l}\text { Chorus, } \\
\text { Prologue } \\
\text { and } \\
\text { epilogue }\end{array}$ \\
\hline 13 & $\begin{array}{l}\text { Gwinne, } \\
\text { Matthew }\end{array}$ & $\begin{array}{l}\text { Nero } \\
\text { Tragoedia } \\
\text { Nova }\end{array}$ & $\begin{array}{l}1603 \\
\text { A } 1603\end{array}$ & $\begin{array}{l}\text { Latin } \\
\text { tragedy }\end{array}$ & $\begin{array}{l}\text { St. John's } \\
\text { Col., } \\
\text { Oxford }\end{array}$ & $\begin{array}{l}\text { STC } \\
12553\end{array}$ & L5 & $\begin{array}{l}\text { Prologue } \\
\text { and } \\
\text { epilogue } \\
\text { spoken by } \\
\text { Nemesis, } \\
\text { chorus and } \\
\text { introducto }\end{array}$ \\
\hline
\end{tabular}




\begin{tabular}{|c|c|c|c|c|c|c|c|c|}
\hline & & & & & & & & $\begin{array}{l}\text { ry dumb } \\
\text { show }\end{array}$ \\
\hline 14 & $\begin{array}{l}\text { Gwinne, } \\
\text { Matthew }\end{array}$ & Vertumnus & $\begin{array}{l}1607 \\
\text { A } 1605\end{array}$ & $\begin{array}{l}\text { Latin } \\
\text { Play }\end{array}$ & $\begin{array}{l}\text { St John's } \\
\text { men at } \\
\text { Christ } \\
\text { Church, } \\
\text { Oxford }\end{array}$ & $\begin{array}{l}\text { STC } \\
12555\end{array}$ & L6 & $\begin{array}{l}\text { Epilogue } \\
\text { and a } \\
\text { dialogue } \\
\text { for the } \\
\text { King's } \\
\text { entrance }\end{array}$ \\
\hline 15 & $\begin{array}{l}\text { Ruggle, } \\
\text { George }\end{array}$ & Ignoramus & $\begin{array}{l}1630 \\
\text { A } 1615\end{array}$ & $\begin{array}{l}\text { Civic } \\
\text { pageant }\end{array}$ & London & $\begin{array}{l}\text { STC } \\
21445\end{array}$ & L8 & $\begin{array}{l}\text { Two } \\
\text { prologues } \\
\text { in form of } \\
\text { a } \\
\text { dialogue, } \\
\text { epilogue }\end{array}$ \\
\hline $\begin{array}{l}16 \\
.\end{array}$ & $\begin{array}{l}\text { Stub, } \\
\text { Edmund }\end{array}$ & $\begin{array}{l}\text { Fraus } \\
\text { Honesta }\end{array}$ & $\begin{array}{l}1632 \\
\text { A } 1619\end{array}$ & $\begin{array}{l}\text { Latin } \\
\text { Comedy }\end{array}$ & $\begin{array}{l}\text { Trinity } \\
\text { College, } \\
\text { Cambridg } \\
\text { e }\end{array}$ & $\begin{array}{l}\text { STC } \\
23374\end{array}$ & $\begin{array}{l}\text { L1 } \\
0\end{array}$ & $\begin{array}{l}\text { Prologue } \\
\text { and } \\
\text { epilogue }\end{array}$ \\
\hline 17 & $\begin{array}{l}\text { Alabaster, } \\
\text { William }\end{array}$ & $\begin{array}{l}\text { Roxana } \\
\text { (Adapt. } \\
\text { Groto La } \\
\text { Dalida) }\end{array}$ & $\begin{array}{l}1632 \\
\text { A } 1592\end{array}$ & $\begin{array}{l}\text { Latin } \\
\text { Tragedy }\end{array}$ & $\begin{array}{l}\text { Trinity } \\
\text { College, } \\
\text { Cambridg } \\
\text { e }\end{array}$ & $\begin{array}{l}\text { STC } \\
249\end{array}$ & $\begin{array}{l}\mathrm{L} 1 \\
1\end{array}$ & $\begin{array}{l}\text { Chorus in } \\
\text { each act }\end{array}$ \\
\hline 18 & $\begin{array}{l}\text { Hausted, } \\
\text { Peter }\end{array}$ & $\begin{array}{l}\text { Senile } \\
\text { Odiu, }\end{array}$ & $\begin{array}{l}1633 \\
\text { A } 1631\end{array}$ & $\begin{array}{l}\text { Latin } \\
\text { Comedy }\end{array}$ & $\begin{array}{l}\text { Queen's } \\
\text { College, } \\
\text { Cambridg } \\
\text { e }\end{array}$ & $\begin{array}{l}\text { STC } \\
12936\end{array}$ & $\begin{array}{l}\mathrm{L} 1 \\
2\end{array}$ & $\begin{array}{l}\text { Prologue } \\
\text { and } \\
\text { epilogue }\end{array}$ \\
\hline $\begin{array}{l}19 \\
.\end{array}$ & $\begin{array}{l}\text { Hutton, } \\
\text { Leonard } \\
(?)\end{array}$ & $\begin{array}{l}\text { Bellum } \\
\text { Grammati } \\
\text { cale }\end{array}$ & $\begin{array}{l}1635 \\
\text { A } 1582\end{array}$ & $\begin{array}{l}\text { Latin } \\
\text { Allegory }\end{array}$ & $\begin{array}{l}\text { Christ } \\
\text { Church, } \\
\text { Oxford in } \\
1592\end{array}$ & $\begin{array}{l}\text { STC } \\
12418\end{array}$ & $\begin{array}{l}\mathrm{L} 1 \\
3\end{array}$ & $\begin{array}{l}\text { Prologue } \\
\text { and } \\
\text { epilogue }\end{array}$ \\
\hline 20 & $\begin{array}{l}\text { Hawkesw } \\
\text { orth, } \\
\text { Walter }\end{array}$ & $\begin{array}{l}\text { Labyrinthu } \\
\text { s (adap. } \\
\text { Della } \\
\text { Porta La } \\
\text { Cintia) }\end{array}$ & $\begin{array}{l}1636 \\
\text { A } 1603\end{array}$ & $\begin{array}{l}\text { Latin } \\
\text { Comedy }\end{array}$ & $\begin{array}{l}\text { Trinity } \\
\text { College, } \\
\text { Cambridg } \\
\text { e }\end{array}$ & $\begin{array}{l}\text { STC } \\
12956\end{array}$ & $\begin{array}{l}\text { L1 } \\
4\end{array}$ & $\begin{array}{l}\text { Prologue } \\
\text { and } \\
\text { epilogue }\end{array}$ \\
\hline 21 & $\begin{array}{l}\text { Cowley, } \\
\text { Abraham }\end{array}$ & $\begin{array}{l}\text { Naufragiu } \\
\text { m Ioculare }\end{array}$ & $\begin{array}{l}1638 \\
\text { A } 1638\end{array}$ & $\begin{array}{l}\text { Latin } \\
\text { Comedy }\end{array}$ & $\begin{array}{l}\text { Trinity } \\
\text { College, } \\
\text { Cambridg } \\
\text { e }\end{array}$ & $\begin{array}{l}\text { STC } \\
5905\end{array}$ & $\begin{array}{l}\mathrm{L} 1 \\
5\end{array}$ & $\begin{array}{l}\text { Prologue } \\
\text { and } \\
\text { epilogue }\end{array}$ \\
\hline 22 & $\begin{array}{l}\text { Randolph, } \\
\text { Thomas } \\
\text { (?) } \\
\text { completat } \\
\text { a da } \\
\text { Richard } \\
\text { Brathwait } \\
\text { (?) }\end{array}$ & $\begin{array}{l}\text { Cornelian } \\
\text { um } \\
\text { Dolium }\end{array}$ & $\begin{array}{l}1638 \\
\text { A } 1638\end{array}$ & $\begin{array}{l}\text { Latin } \\
\text { Comedy }\end{array}$ & Unknown & $\begin{array}{l}\text { STC } \\
20691\end{array}$ & $\begin{array}{l}\text { L1 } \\
6\end{array}$ & $\begin{array}{l}\text { Prologue } \\
\text { and } \\
\text { epilogue }\end{array}$ \\
\hline
\end{tabular}




\begin{tabular}{|c|c|c|c|c|c|c|c|c|}
\hline 23 & $\begin{array}{l}\text { Snelling, } \\
\text { Thomas }\end{array}$ & $\begin{array}{l}\text { Thibaldus } \\
\text { (Pharamus } \\
\text { ) }\end{array}$ & $\begin{array}{l}1640 \\
\text { A } 1640\end{array}$ & $\begin{array}{l}\text { Latin } \\
\text { Tragedy }\end{array}$ & $\begin{array}{l}\text { St John's } \\
\text { College, } \\
\text { Oxford }\end{array}$ & $\begin{array}{l}\text { STC } \\
22888\end{array}$ & $\begin{array}{l}\mathrm{L} 1 \\
7\end{array}$ & $\begin{array}{l}\text { Chorus at } \\
\text { the end of } \\
\text { each act, } \\
\text { except the } \\
\text { last one }\end{array}$ \\
\hline 24 & $\begin{array}{l}\text { Brathwait } \\
\text {, Richard }\end{array}$ & $\begin{array}{l}\text { Mercurius } \\
\text { Britannicu } \\
\text { s }\end{array}$ & $\begin{array}{l}1641 \\
\text { A } 1641\end{array}$ & $\begin{array}{l}\text { Latin } \\
\text { Political } \\
\text { Comedy }\end{array}$ & Closet & $\begin{array}{l}\text { STC } \\
\text { B4269 }\end{array}$ & $\begin{array}{l}\text { L1 } \\
8\end{array}$ & Epilogue \\
\hline $\begin{array}{l}25 \\
.\end{array}$ & $\begin{array}{l}\text { Hacket, } \\
\text { John }\end{array}$ & Loyola & $\begin{array}{l}1648 \\
\text { A } 1623\end{array}$ & $\begin{array}{l}\text { Latin } \\
\text { Comedy }\end{array}$ & $\begin{array}{l}\text { Trinity } \\
\text { College, } \\
\text { Cambridg } \\
\text { e }\end{array}$ & $\mathrm{H} 170$ & $\begin{array}{l}\text { L1 } \\
9\end{array}$ & $\begin{array}{l}\text { Praeludiu } \\
\text { m, two } \\
\text { prologues }\end{array}$ \\
\hline $\begin{array}{l}26 \\
.\end{array}$ & $\begin{array}{l}\text { Anonymo } \\
\text { us }\end{array}$ & $\begin{array}{l}\text { Stoicus } \\
\text { Vapulans }\end{array}$ & $\begin{array}{l}1648 \\
\text { A } 1618\end{array}$ & $\begin{array}{l}\text { Latin } \\
\text { Moral }\end{array}$ & $\begin{array}{l}\text { St John's } \\
\text { College, } \\
\text { Cambridg } \\
\text { e }\end{array}$ & $\mathrm{H} 170$ & $\begin{array}{l}\mathrm{L} 2 \\
0\end{array}$ & $\begin{array}{l}\text { Prologue } \\
\text { and } \\
\text { epilogue }\end{array}$ \\
\hline 27 & $\begin{array}{l}\text { Anonymo } \\
\text { us }\end{array}$ & $\begin{array}{l}\text { Cancer } \\
\text { (adapt. . } \\
\text { Salviati Il } \\
\text { Granchio) }\end{array}$ & $\begin{array}{l}1648 \\
\text { A } 1612\end{array}$ & $\begin{array}{l}\text { Latin } \\
\text { Comedy }\end{array}$ & $\begin{array}{l}\text { Trinity } \\
\text { College, } \\
\text { Cambridg } \\
\text { e }\end{array}$ & $\mathrm{H} 170$ & $\begin{array}{l}\mathrm{L} 2 \\
1\end{array}$ & Prologue \\
\hline $\begin{array}{l}28 \\
.\end{array}$ & $\begin{array}{l}\text { Anonymo } \\
\text { us }\end{array}$ & Paria & $\begin{array}{l}1648 \\
\text { A } 1628\end{array}$ & $\begin{array}{l}\text { Latin } \\
\text { Comedy }\end{array}$ & $\begin{array}{l}\text { Trinity } \\
\text { College, } \\
\text { Cambridg } \\
\text { e }\end{array}$ & $\mathrm{H} 170$ & $\begin{array}{l}\mathrm{L} 2 \\
2\end{array}$ & $\begin{array}{l}\text { Two } \\
\text { prologues, } \\
\text { one } \\
\text { epilogue, } \\
\text { one } \\
\text { prologue- } \\
\text { like } \\
\text { argomentu } \\
\text { m }\end{array}$ \\
\hline 29 & $\begin{array}{l}\text { Medwall, } \\
\text { Henry }\end{array}$ & $\begin{array}{l}1 \text { Fulgens } \\
\text { and } \\
\text { Lucrece }\end{array}$ & 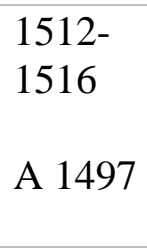 & $\begin{array}{l}\text { Romantic } \\
\text { interlude }\end{array}$ & $\begin{array}{l}\text { Morton's } \\
\text { house (?) }\end{array}$ & $\begin{array}{l}\text { STC } \\
17778\end{array}$ & 1 & $\begin{array}{l}\text { Dialogue } \\
\text { between } A \\
\text { and } B \text {, } \\
\text { probable } \\
\text { Induction }\end{array}$ \\
\hline 30 & $\begin{array}{l}\text { Medwall, } \\
\text { Henry }\end{array}$ & $\begin{array}{l}2 \text { Fulgens } \\
\text { and } \\
\text { Lucrece }\end{array}$ & $\begin{array}{l}1512- \\
1516 \\
\text { A } 1497\end{array}$ & $\begin{array}{l}\text { Romantic } \\
\text { interlude }\end{array}$ & $\begin{array}{l}\text { Morton's } \\
\text { house (?) }\end{array}$ & $\begin{array}{l}\text { STC } \\
17778\end{array}$ & 2 & $\begin{array}{l}\text { Dialogue } \\
\text { between } \mathrm{A} \\
\text { and } \mathrm{B} \text {, } \\
\text { probable } \\
\text { Induction }\end{array}$ \\
\hline 31 & $\begin{array}{l}\text { Rastell, } \\
\text { John }\end{array}$ & $\begin{array}{l}\text { The } \\
\text { Nature of } \\
\text { Four } \\
\text { Elements }\end{array}$ & $\begin{array}{l}1526- \\
1527 \\
\text { A } 1517\end{array}$ & $\begin{array}{l}\text { Didactic } \\
\text { interlude }\end{array}$ & Unknown & $\begin{array}{l}\text { STC } \\
20722\end{array}$ & 6 & Prologue \\
\hline 32 & $\begin{array}{l}\text { Rastell, } \\
\text { John }\end{array}$ & $\begin{array}{l}1 \\
\text { Gentleness } \\
\text { and } \\
\text { Nobility }\end{array}$ & $\begin{array}{l}1529 \\
\text { A } 1527\end{array}$ & Dialogue & $\begin{array}{l}\text { Rastel's } \\
\text { stage (?) }\end{array}$ & $\begin{array}{l}\text { STC } \\
20723\end{array}$ & 8 & Epilogue \\
\hline 33 & $\begin{array}{l}\text { Rastell, } \\
\text { John }\end{array}$ & $\begin{array}{l}2 \\
\text { Gentleness }\end{array}$ & 1529 & Dialogue & $\begin{array}{l}\text { Rastel's } \\
\text { stage (?) }\end{array}$ & $\begin{array}{l}\text { STC } \\
20723\end{array}$ & 9 & Epilogue \\
\hline
\end{tabular}




\begin{tabular}{|c|c|c|c|c|c|c|c|c|}
\hline & & $\begin{array}{l}\text { and } \\
\text { Nobility }\end{array}$ & A 1527 & & & & & \\
\hline 34 & $\begin{array}{l}\text { Anonymo } \\
\text { us }\end{array}$ & $\begin{array}{l}\text { Andria } \\
\text { (tr. } \\
\text { Terence) }\end{array}$ & $\begin{array}{l}1530 \mathrm{c} . \\
\text { A } 1520\end{array}$ & Comedy & Closet & $\begin{array}{l}\text { STC } \\
23894\end{array}$ & 12 & $\begin{array}{l}\text { Prologue } \\
\text { and } \\
\text { epilogue }\end{array}$ \\
\hline 35 & $\begin{array}{l}\text { Bale, } \\
\text { John }\end{array}$ & $\begin{array}{l}\text { The Chief } \\
\text { Promise of } \\
\text { God }\end{array}$ & $\begin{array}{l}1547- \\
1548 \\
\text { A } 1538\end{array}$ & $\begin{array}{l}\text { Anthi- } \\
\text { Catholic } \\
\text { Mystery }\end{array}$ & $\begin{array}{l}\text { St. } \\
\text { Stephen, } \\
\text { Canterbur } \\
\text { y }\end{array}$ & $\begin{array}{l}\text { STC } \\
1305\end{array}$ & 22 & $\begin{array}{l}\text { Prologue } \\
\text { and } \\
\text { epilogue }\end{array}$ \\
\hline 36 & $\begin{array}{l}\text { Bale, } \\
\text { John }\end{array}$ & $\begin{array}{l}\text { The } \\
\text { Temptatio } \\
\text { n of Christ }\end{array}$ & $\begin{array}{l}1547- \\
1548 \\
\text { A } 1538\end{array}$ & $\begin{array}{l}\text { Anthi- } \\
\text { Catholic } \\
\text { Mystery }\end{array}$ & $\begin{array}{l}\text { St. } \\
\text { Stephen, } \\
\text { Canterbur } \\
\text { y }\end{array}$ & $\begin{array}{l}\text { STC } \\
1279\end{array}$ & 23 & $\begin{array}{l}\text { Prologue } \\
\text { and } \\
\text { epilogue }\end{array}$ \\
\hline $\begin{array}{l}37 \\
.\end{array}$ & $\begin{array}{l}\text { Bale, } \\
\text { John }\end{array}$ & $\begin{array}{l}\text { The Three } \\
\text { Laws }\end{array}$ & $\begin{array}{l}1547- \\
1548 \\
\text { A } 1538\end{array}$ & $\begin{array}{l}\text { Anthi- } \\
\text { Catholic } \\
\text { Mystery }\end{array}$ & $\begin{array}{l}\text { St. } \\
\text { Stephen, } \\
\text { Canterbur } \\
\text { y }\end{array}$ & $\begin{array}{l}\text { STC } \\
1287\end{array}$ & 24 & Prologue \\
\hline 38 & $\begin{array}{l}\text { Heywood, } \\
\text { Jasper }\end{array}$ & Troas & 1559 & Tragedy & Closet & $\begin{array}{l}\text { STC } \\
22227\end{array}$ & 28 & $\begin{array}{l}\text { Chorus at } \\
\text { the end of } \\
\text { each act, } \\
\text { except the } \\
\text { last one, } \\
\text { Prologue }\end{array}$ \\
\hline $\begin{array}{l}39 \\
.\end{array}$ & $\begin{array}{l}\text { Heywood, } \\
\text { Jasper }\end{array}$ & Thyestes & $\begin{array}{l}1560 \\
\text { A } 1560\end{array}$ & Tragedy & Closet & $\begin{array}{l}\text { STC } \\
22227\end{array}$ & 29 & $\begin{array}{l}\text { Chorus at } \\
\text { the end of } \\
\text { each act, } \\
\text { except the } \\
\text { last one }\end{array}$ \\
\hline $\begin{array}{l}40 \\
.\end{array}$ & $\begin{array}{l}\text { Anonymo } \\
\text { us }\end{array}$ & $\begin{array}{l}\text { Nice } \\
\text { Wanton }\end{array}$ & $\begin{array}{l}1560 \\
\text { A } 1550\end{array}$ & Unknown & $\begin{array}{l}\text { Paul's at } \\
\text { Court }\end{array}$ & $\begin{array}{l}\text { STC } \\
25016\end{array}$ & 31 & Prologue \\
\hline $\begin{array}{l}41 \\
.\end{array}$ & $\begin{array}{l}\text { Anonymo } \\
\text { us }\end{array}$ & $\begin{array}{l}\text { Godly } \\
\text { Queen } \\
\text { Hester }\end{array}$ & $\begin{array}{l}1561 \\
\text { A } 1527\end{array}$ & $\begin{array}{l}\text { Biblical } \\
\text { Interlude }\end{array}$ & Unknown & $\begin{array}{l}\text { STC } \\
13251\end{array}$ & 33 & Prologue \\
\hline $\begin{array}{l}42 \\
.\end{array}$ & $\begin{array}{l}\text { Heywood, } \\
\text { Jasper }\end{array}$ & $\begin{array}{l}\text { Hercules } \\
\text { furens } \\
\text { (tr. } \\
\text { Seneca) }\end{array}$ & $\begin{array}{l}1561 \\
\text { A } 1561\end{array}$ & Tragedy & Closet & $\begin{array}{l}\text { STC } \\
22223\end{array}$ & 34 & $\begin{array}{l}\text { Chorus at } \\
\text { the end of } \\
\text { each act, } \\
\text { except the } \\
\text { last one }\end{array}$ \\
\hline $\begin{array}{l}43 \\
.\end{array}$ & $\begin{array}{l}\text { Neville, } \\
\text { Alexande } \\
\mathrm{r}\end{array}$ & $\begin{array}{l}\text { Oedipus } \\
\text { (tr. } \\
\text { Seneca) }\end{array}$ & $\begin{array}{l}1563 \\
\text { A } 1563\end{array}$ & Tragedy & Closet & $\begin{array}{l}\text { STC } \\
22225\end{array}$ & 36 & $\begin{array}{l}\text { Chorus at } \\
\text { the end of } \\
\text { act I, III, } \\
\text { IV }\end{array}$ \\
\hline $\begin{array}{l}44 \\
.\end{array}$ & $\begin{array}{l}\text { Sackwille } \\
\text { T. and } \\
\text { T. } \\
\text { Norton }\end{array}$ & $\begin{array}{l}\text { Gorboduc } \\
\text { (Ferrex } \\
\text { and } \\
\text { Porrex) }\end{array}$ & $\begin{array}{l}1565 \\
\text { A } 1562\end{array}$ & Tragedy & $\begin{array}{l}\text { Inner } \\
\text { Temple }\end{array}$ & $\begin{array}{l}\text { STC } \\
18684\end{array}$ & 39 & $\begin{array}{l}\text { dumb } \\
\text { show } \\
\text { before } \\
\text { each act, } \\
\text { Chorus at } \\
\text { the end of }\end{array}$ \\
\hline
\end{tabular}




\begin{tabular}{|c|c|c|c|c|c|c|c|c|}
\hline & & & & & & & & $\begin{array}{l}\text { each act, } \\
\text { except the } \\
\text { last one }\end{array}$ \\
\hline $\begin{array}{l}45 \\
.\end{array}$ & $\begin{array}{l}\text { Anonymo } \\
\text { us }\end{array}$ & $\begin{array}{l}\text { King } \\
\text { Darius }\end{array}$ & $\begin{array}{l}1565 \\
1565\end{array}$ & $\begin{array}{l}\text { Protestan } \\
\text { t Moral }\end{array}$ & Unknown & $\begin{array}{l}\text { STC } \\
6277\end{array}$ & 40 & $\begin{array}{l}\text { Prologue } \\
\text { and } \\
\text { epilogue }\end{array}$ \\
\hline $\begin{array}{l}46 \\
.\end{array}$ & Wever, R. & $\begin{array}{l}\text { Lusty } \\
\text { Juventus }\end{array}$ & $\begin{array}{l}1565 \mathrm{a} . \\
\text { A } 1550\end{array}$ & $\begin{array}{l}\text { Anti- } \\
\text { Catholic } \\
\text { moral } \\
\text { interlude }\end{array}$ & Unknown & $\begin{array}{l}\text { STC } \\
25149\end{array}$ & 41 & Prologue \\
\hline $\begin{array}{l}47 \\
.\end{array}$ & $\begin{array}{l}\text { Studley, } \\
\text { John }\end{array}$ & $\begin{array}{l}\text { Agamemn } \\
\text { on }\end{array}$ & $\begin{array}{l}1566 \\
\text { A } 1566\end{array}$ & Tragedy & Closet & $\begin{array}{l}\text { STC } \\
22222\end{array}$ & 42 & $\begin{array}{l}\text { Chorus at } \\
\text { the end of } \\
\text { each act, } \\
\text { except the } \\
\text { last one }\end{array}$ \\
\hline 48 & $\begin{array}{l}\text { Studely, } \\
\text { John }\end{array}$ & $\begin{array}{l}\text { Medea } \\
\text { (tr. } \\
\text { Seneca) }\end{array}$ & $\begin{array}{l}1566 \text { a. } \\
\text { A } 1566\end{array}$ & Tragedy & Closet & $\begin{array}{l}\text { STC } \\
22224\end{array}$ & 44 & $\begin{array}{l}\text { Chorus at } \\
\text { the end of } \\
\text { each act, } \\
\text { except the } \\
\text { last one }\end{array}$ \\
\hline 49 & $\begin{array}{l}\text { Nuce, } \\
\text { Thomas }\end{array}$ & $\begin{array}{l}\text { Octavia } \\
\text { (tr. } \\
\text { Seneca) }\end{array}$ & $\begin{array}{l}1566 \\
\text { A } 1566\end{array}$ & Tragedy & Closet & $\begin{array}{l}\text { STC } \\
22229\end{array}$ & 45 & $\begin{array}{l}\text { Chorus at } \\
\text { the end of } \\
\text { act I and } \\
\text { IV }\end{array}$ \\
\hline 50 & $\begin{array}{l}\text { Udall, } \\
\text { Nicholas }\end{array}$ & $\begin{array}{l}\text { Ralph } \\
\text { Roister } \\
\text { Doister }\end{array}$ & $\begin{array}{l}1566 ? \\
\text { A } 1552\end{array}$ & Comedy & $\begin{array}{l}\text { Unknown } \\
\text { (Windsor } \\
\text { Boys?) }\end{array}$ & $\begin{array}{l}\text { STC } \\
24508\end{array}$ & 46 & $\begin{array}{l}\text { Prologue, } \\
\text { final song }\end{array}$ \\
\hline $\begin{array}{l}51 \\
.\end{array}$ & $\begin{array}{l}\text { Wager, } \\
\text { Lewis }\end{array}$ & $\begin{array}{l}\text { The } \\
\text { Repentanc } \\
\text { e of Mary } \\
\text { Magdalen } \\
e\end{array}$ & $\begin{array}{l}1566 \\
\text { A } 1558\end{array}$ & $\begin{array}{l}\text { Moral- } \\
\text { biblical } \\
\text { interlude }\end{array}$ & Unknown & $\begin{array}{l}\text { STC } \\
24932\end{array}$ & 47 & Prologue \\
\hline 52 & $\begin{array}{l}\text { Wager, } \\
\text { W. (?) }\end{array}$ & $\begin{array}{l}\text { The Trial } \\
\text { of } \\
\text { Treasure }\end{array}$ & $\begin{array}{l}1567 \\
\text { A } 1567\end{array}$ & $\begin{array}{l}\text { Moral } \\
\text { interlude }\end{array}$ & Unknown & $\begin{array}{l}\text { STC } \\
24271\end{array}$ & 49 & Prologue \\
\hline $\begin{array}{l}53 \\
.\end{array}$ & $\begin{array}{l}\text { Fulwell, } \\
\text { Ulpian }\end{array}$ & $\begin{array}{l}\text { Like Will } \\
\text { to Like }\end{array}$ & $\begin{array}{l}1568 \mathrm{a} . \\
\text { A } 1568\end{array}$ & $\begin{array}{l}\text { Moral } \\
\text { interlude }\end{array}$ & Unknown & $\begin{array}{l}\text { STC } \\
11473\end{array}$ & 50 & $\begin{array}{l}\text { Prologue, } \\
\text { final song }\end{array}$ \\
\hline $\begin{array}{l}54 \\
.\end{array}$ & $\begin{array}{l}\text { Udall, } \\
\text { Nicholas } \\
\text { (?) or } \\
\text { Hunnis, } \\
\text { W. (?) }\end{array}$ & $\begin{array}{l}\text { Jacob and } \\
\text { Esau }\end{array}$ & $\begin{array}{l}1568 \\
\text { A } 1554\end{array}$ & $\begin{array}{l}\text { Biblical } \\
\text { interlude }\end{array}$ & $\begin{array}{l}\text { Unknown } \\
\text { (boys) }\end{array}$ & $\begin{array}{l}\text { STC } \\
14327\end{array}$ & 51 & $\begin{array}{l}\text { Prologue } \\
\text { and } \\
\text { epilogue }\end{array}$ \\
\hline $\begin{array}{l}55 \\
.\end{array}$ & $\begin{array}{l}\text { Phillip, } \\
\text { John }\end{array}$ & $\begin{array}{l}\text { Patient } \\
\text { and Meek } \\
\text { Grissil }\end{array}$ & $\begin{array}{l}1569 \\
\text { A } 1559\end{array}$ & Comedy & Unknown & $\begin{array}{l}\text { STC } \\
19865\end{array}$ & 52 & $\begin{array}{l}\text { Prologue } \\
\text { and } \\
\text { epilogue }\end{array}$ \\
\hline $\begin{array}{l}56 \\
.\end{array}$ & $\begin{array}{l}\text { Wager, } \\
\text { W. }\end{array}$ & $\begin{array}{l}\text { The } \\
\text { Longer } \\
\text { thou Livest }\end{array}$ & $\begin{array}{l}1569 \\
\text { A } 1559\end{array}$ & $\begin{array}{l}\text { Protestan } \\
\text { t Moral }\end{array}$ & Unknown & $\begin{array}{l}\text { STC } \\
24935\end{array}$ & 53 & Prologue \\
\hline
\end{tabular}




\begin{tabular}{|c|c|c|c|c|c|c|c|c|}
\hline & & $\begin{array}{l}\text { the More } \\
\text { Fool thou } \\
\text { Art }\end{array}$ & & & & & & \\
\hline $\begin{array}{l}57 \\
.\end{array}$ & $\begin{array}{l}\text { Ingeland, } \\
\text { Thomas }\end{array}$ & $\begin{array}{l}\text { The } \\
\text { Disobedie } \\
\text { nt Child }\end{array}$ & $\begin{array}{l}1569 \\
\text { A } 1560\end{array}$ & Interlude & Unknown & $\begin{array}{l}\text { STC } \\
14085\end{array}$ & 54 & $\begin{array}{l}\text { Prologue } \\
\text { and } \\
\text { epilogue }\end{array}$ \\
\hline $\begin{array}{l}58 \\
.\end{array}$ & $\begin{array}{l}\text { Preston, } \\
\text { Thomas }\end{array}$ & Cambises & $\begin{array}{l}1569 \\
\text { A } 1561\end{array}$ & Tragedy & Corte (?) & $\begin{array}{l}\text { STC } \\
20287\end{array}$ & 56 & $\begin{array}{l}\text { Prologue } \\
\text { and } \\
\text { epilogue }\end{array}$ \\
\hline $\begin{array}{l}59 \\
.\end{array}$ & $\begin{array}{l}\text { Wager, } \\
\text { W. }\end{array}$ & $\begin{array}{l}\text { Enough is } \\
\text { as Good } \\
\text { as a Feast }\end{array}$ & $\begin{array}{l}1565- \\
1570 \\
\text { A } 1560\end{array}$ & $\begin{array}{l}\text { Protestan } \\
\text { t moral }\end{array}$ & Unknown & $\begin{array}{l}\text { STC } \\
24933\end{array}$ & 57 & Prologue \\
\hline 60 & $\begin{array}{l}\text { Edwards, } \\
\text { Richard }\end{array}$ & $\begin{array}{l}\text { Damon } \\
\text { and } \\
\text { Pithias }\end{array}$ & $\begin{array}{l}1571 \\
\text { A } 1564\end{array}$ & $\begin{array}{l}\text { Tragicom } \\
\text { edy }\end{array}$ & $\begin{array}{l}\text { Merton } \\
\text { College } \\
\text { Oxford }\end{array}$ & $\begin{array}{l}\text { STC } \\
7514\end{array}$ & 58 & $\begin{array}{l}\text { Prologue, } \\
\text { final song }\end{array}$ \\
\hline 61 & $\begin{array}{l}\text { Anonymo } \\
\text { us }\end{array}$ & $\begin{array}{l}\text { New } \\
\text { Custom }\end{array}$ & $\begin{array}{l}1573 \\
\text { A } 1571\end{array}$ & $\begin{array}{l}\text { Protestan } \\
\text { t moral }\end{array}$ & Unknown & $\begin{array}{l}\text { STC } \\
6150\end{array}$ & 59 & Prologue \\
\hline 62 & $\begin{array}{l}\text { Gascoign } \\
\text { e, George }\end{array}$ & Supposes & $\begin{array}{l}1573 \\
\text { collecti } \\
\text { on } \\
\text { A } 1566\end{array}$ & Comedy & Gray's Inn & $\begin{array}{l}\text { STC } \\
11635\end{array}$ & 60 & Prologue \\
\hline 63 & $\begin{array}{l}\text { Gascoign } \\
\text { e, George } \\
\text { Kinwelm } \\
\text { ershe, F. }\end{array}$ & Jocasta & $\begin{array}{l}1573 \\
\text { collecti } \\
\text { on } \\
\text { A } 1566\end{array}$ & Tragedy & Gray's Inn & $\begin{array}{l}\text { STC } \\
11635\end{array}$ & 61 & $\begin{array}{l}\text { Each act is } \\
\text { preceded } \\
\text { by a dumb } \\
\text { show and } \\
\text { followed } \\
\text { by a } \\
\text { chorus, } \\
\text { epilogue }\end{array}$ \\
\hline 64 & Anon. & $\begin{array}{l}\text { Comoedia. } \\
\text { A work in } \\
\text { ryme } \\
\text { contayning } \\
\text { an } \\
\text { Interlude } \\
\text { of Minds }\end{array}$ & $\begin{array}{l}1574 \mathrm{c} . \\
\text { A c } \\
1574\end{array}$ & $\begin{array}{l}\text { Protestan } \\
\text { t moral }\end{array}$ & Closet & $\begin{array}{l}\text { STC } \\
18550\end{array}$ & 64 & $\begin{array}{l}\text { Seventeen } \\
\text { chapters, } \\
\text { the first } \\
\text { one } \\
\text { headed as } \\
\text { prologue, } \\
\text { and the } \\
\text { last three } \\
\text { form the } \\
\text { conclusion } \\
\text {. }\end{array}$ \\
\hline 65 & $\begin{array}{l}\mathrm{B} \text { [ower?], } \\
\mathrm{R} \text { [ichard] }\end{array}$ & $\begin{array}{l}\text { Appius } \\
\text { and } \\
\text { Virginia }\end{array}$ & $\begin{array}{l}1575 \\
\text { A } 1564\end{array}$ & $\begin{array}{l}\text { Classical } \\
\text { moral }\end{array}$ & $\begin{array}{l}\text { Westminst } \\
\text { er boys (?) }\end{array}$ & $\begin{array}{l}\text { STC } \\
1059\end{array}$ & 65 & $\begin{array}{l}\text { Prologue } \\
\text { and } \\
\text { epilogue }\end{array}$ \\
\hline 66 & $\begin{array}{l}\text { Stevenson } \\
\text {, W. (?) }\end{array}$ & $\begin{array}{l}\text { Gammer } \\
\text { Gurton's } \\
\text { Needle }\end{array}$ & $\begin{array}{l}1575 \\
\text { A } 1553\end{array}$ & Comedy & $\begin{array}{l}\text { Christ's } \\
\text { College }\end{array}$ & $\begin{array}{l}\text { STC } \\
23263\end{array}$ & 67 & Prologue \\
\hline
\end{tabular}




\begin{tabular}{|c|c|c|c|c|c|c|c|c|}
\hline & & & & & $\begin{array}{l}\text { Cambridg } \\
\text { e }\end{array}$ & & & \\
\hline 67 & $\begin{array}{l}\text { Gascoign } \\
\text { e, George }\end{array}$ & $\begin{array}{l}\text { The Glass } \\
\text { of } \\
\text { Governme } \\
n t\end{array}$ & $\begin{array}{l}1575 \\
\text { A } 1575\end{array}$ & $\begin{array}{l}\text { Moral } \\
\text { allegory }\end{array}$ & Closet & $\begin{array}{l}\text { STC } \\
11643\end{array}$ & 68 & $\begin{array}{l}\text { Prologue } \\
\text { and } \\
\text { epilogue, } \\
\text { chorus } \\
\text { after each } \\
\text { act except } \\
\text { the last } \\
\text { one }\end{array}$ \\
\hline 68 & $\begin{array}{l}\text { Anonymo } \\
\text { us }\end{array}$ & $\begin{array}{l}\text { Common } \\
\text { Conditions }\end{array}$ & $\begin{array}{l}1576 \\
\text { A } 1576\end{array}$ & $\begin{array}{l}\text { Heroical } \\
\text { moral }\end{array}$ & Unknown & $\begin{array}{l}\text { STC } \\
5592\end{array}$ & 69 & $\begin{array}{l}\text { Prologue } \\
\text { and } \\
\text { epilogue }\end{array}$ \\
\hline 69 & $\begin{array}{l}\text { Wapull, } \\
\text { George }\end{array}$ & $\begin{array}{l}\text { The Tide } \\
\text { Tarrieth } \\
\text { no Man }\end{array}$ & $\begin{array}{l}1576 \\
\text { A } 1576\end{array}$ & Moral & Unknown & $\begin{array}{l}\text { STC } \\
25018\end{array}$ & 70 & Prologue \\
\hline $\begin{array}{l}70 \\
.\end{array}$ & $\begin{array}{l}\text { Golding, } \\
\text { Arthur }\end{array}$ & $\begin{array}{l}\text { Abraham's } \\
\text { Sacrifice }\end{array}$ & $\begin{array}{l}1577 \\
\text { A } 1575\end{array}$ & Tragedy & Closet & $\begin{array}{l}\text { STC } \\
2047\end{array}$ & 71 & $\begin{array}{l}\text { Prologue } \\
\text { and } \\
\text { epilogue }\end{array}$ \\
\hline $\begin{array}{l}71 \\
.\end{array}$ & $\begin{array}{l}\text { Lupton, } \\
\text { Thomas }\end{array}$ & $\begin{array}{l}\text { All for } \\
\text { Money }\end{array}$ & $\begin{array}{l}1578 \\
\text { A } 1577\end{array}$ & $\begin{array}{l}\text { Satirical } \\
\text { moral }\end{array}$ & Unknown & $\begin{array}{l}\text { STC } \\
16949\end{array}$ & 72 & $\begin{array}{l}\text { Prologue } \\
\text { and } \\
\text { epilogue }\end{array}$ \\
\hline 72 & $\begin{array}{l}\text { Woodes, } \\
\text { Nathaniel }\end{array}$ & $\begin{array}{l}\text { The } \\
\text { Conflict of } \\
\text { Conscienc } \\
e\end{array}$ & $\begin{array}{l}1581 \\
\text { A } 1572\end{array}$ & $\begin{array}{l}\text { Protestan } \\
\text { t moral }\end{array}$ & Unknown & $\begin{array}{l}\text { STC } \\
25966\end{array}$ & 78 & $\begin{array}{l}\text { Prologue, } \\
\text { act VI as a } \\
\text { sort of } \\
\text { chorus/epi } \\
\text { logue, } \\
\text { single } \\
\text { speech by } \\
\text { Nuntius }\end{array}$ \\
\hline $\begin{array}{l}73 \\
.\end{array}$ & $\begin{array}{l}\text { Studley, } \\
\text { John }\end{array}$ & Hyppolitus & $\begin{array}{l}1581 \\
\text { (collect } \\
\text { ion) } \\
\text { A } 1567\end{array}$ & Tragedy & Closet & $\begin{array}{l}\text { STC } \\
22221\end{array}$ & 80 & $\begin{array}{l}\text { Chorus at } \\
\text { the end of } \\
\text { each act, } \\
\text { except the } \\
\text { last one }\end{array}$ \\
\hline $\begin{array}{l}74 \\
.\end{array}$ & $\begin{array}{l}\text { Studley, } \\
\text { John }\end{array}$ & $\begin{array}{l}\text { Hercules } \\
\text { Oeataeus }\end{array}$ & $\begin{array}{l}1581 \\
\text { (collect } \\
\text { ion) } \\
\text { A } 1566\end{array}$ & Tragedy & Closet & $\begin{array}{l}\text { STC } \\
22221\end{array}$ & 81 & Chorus \\
\hline 75 & $\begin{array}{l}\text { Lyly, } \\
\text { John }\end{array}$ & $\begin{array}{l}\text { Sappho } \\
\text { and Phao }\end{array}$ & $\begin{array}{l}1584 \\
\text { A } 1583\end{array}$ & $\begin{array}{l}\text { Classical } \\
\text { legend } \\
\text { (comedy) }\end{array}$ & $\begin{array}{l}\text { Oxford's } \\
\text { boys }\end{array}$ & $\begin{array}{l}\text { STC } \\
17086\end{array}$ & 82 & $\begin{array}{l}\text { Two } \\
\text { prologues } \\
\text { and one } \\
\text { epilogue }\end{array}$ \\
\hline $\begin{array}{l}76 \\
.\end{array}$ & $\begin{array}{l}\text { Peele, } \\
\text { George }\end{array}$ & $\begin{array}{l}\text { The } \\
\text { Arraignme } \\
\text { nt of Paris }\end{array}$ & $\begin{array}{l}1584 \\
\text { A } 1581\end{array}$ & $\begin{array}{l}\text { Classical } \\
\text { legend } \\
\text { (pastoral) }\end{array}$ & $\begin{array}{l}\text { Chapel at } \\
\text { Court }\end{array}$ & $\begin{array}{l}\text { STC } \\
19530\end{array}$ & 83 & $\begin{array}{l}\text { Prologue } \\
\text { and } \\
\text { epilogue. }\end{array}$ \\
\hline
\end{tabular}




\begin{tabular}{|c|c|c|c|c|c|c|c|c|}
\hline & & & & & & & & $\begin{array}{l}\text { Epilogue } \\
\text { in Latin }\end{array}$ \\
\hline $\begin{array}{l}77 \\
.\end{array}$ & $\begin{array}{l}\text { Lyly, } \\
\text { John }\end{array}$ & Campaspe & $\begin{array}{l}1584 \\
\text { A } 1583\end{array}$ & $\begin{array}{l}\text { Classical } \\
\text { legend } \\
\text { (comedy) }\end{array}$ & $\begin{array}{l}\text { Oxford's } \\
\text { boys }\end{array}$ & $\begin{array}{l}\text { STC } \\
17047 . \\
5\end{array}$ & 84 & $\begin{array}{l}\text { Prologue } \\
\text { and } \\
\text { epilogue }\end{array}$ \\
\hline $\begin{array}{l}78 \\
.\end{array}$ & $\begin{array}{l}\text { R.W. } \\
\text { (Robert } \\
\text { Wilson) }\end{array}$ & $\begin{array}{l}\text { The Three } \\
\text { Ladies of } \\
\text { London }\end{array}$ & $\begin{array}{l}1584 \\
\text { A } 1581\end{array}$ & Moral & Unknown & $\begin{array}{l}\text { STC } \\
25784\end{array}$ & 85 & Prologue \\
\hline $\begin{array}{l}79 \\
.\end{array}$ & $\begin{array}{l}\text { Munday, } \\
\text { Anthony }\end{array}$ & $\begin{array}{l}\text { Fedele e } \\
\text { Fortunio }\end{array}$ & $\begin{array}{l}1585 \\
\text { A } 1584\end{array}$ & Comedy & At Court & $\begin{array}{l}\text { STC } \\
19447\end{array}$ & 86 & $\begin{array}{l}\text { Prologue } \\
\text { and } \\
\text { epilogue }\end{array}$ \\
\hline 80 & $\begin{array}{l}\text { Hughes } \\
\text { T. with } \\
\text { Bacon, } \\
\text { Trotte, } \\
\text { Fullwek, } \\
\text { Lancaster, } \\
\text { Yelverton } \\
\text { Penroodo } \\
\text { cke and } \\
\text { Flower }\end{array}$ & $\begin{array}{l}\text { The } \\
\text { Misfortune } \\
\text { s of Arthur }\end{array}$ & $\begin{array}{l}1587 \\
\text { A } \\
1588\end{array}$ & Tragedy & $\begin{array}{l}\text { Gray's Inn } \\
\text { at Court }\end{array}$ & $\begin{array}{l}\text { STC } \\
13921\end{array}$ & 89 & $\begin{array}{l}\text { Epilogue, } \\
\text { chorus at } \\
\text { the end of } \\
\text { each act } \\
\text { except the } \\
\text { last one, } \\
\text { dumb } \\
\text { show } \\
\text { before } \\
\text { each act }\end{array}$ \\
\hline $\begin{array}{l}81 \\
.\end{array}$ & $\begin{array}{l}\text { Anonymo } \\
\text { us }\end{array}$ & $\begin{array}{l}\text { Love and } \\
\text { Fortune }\end{array}$ & $\begin{array}{l}1589 \\
\text { A } 1582\end{array}$ & $\begin{array}{l}\text { Mytholog } \\
\text { ical } \\
\text { moral }\end{array}$ & $\begin{array}{l}\text { Derby's at } \\
\text { Court }\end{array}$ & $\begin{array}{l}\text { STC } \\
24286\end{array}$ & 92 & $\begin{array}{l}\text { First act } \\
\text { has the } \\
\text { structure } \\
\text { of an } \\
\text { induction, } \\
\text { its } \\
\text { characters } \\
\text { act as a } \\
\text { sort of } \\
\text { chorus at } \\
\text { the end of } \\
\text { the next } \\
\text { three acts } \\
\text { and join } \\
\text { the other } \\
\text { characters } \\
\text { in the last } \\
\text { one }\end{array}$ \\
\hline 82 & $\begin{array}{l}\text { R.W. } \\
\text { (Robert } \\
\text { Wilson) }\end{array}$ & $\begin{array}{l}\text { The Three } \\
\text { Lords of } \\
\text { London }\end{array}$ & $\begin{array}{l}1590 \\
\text { A } 1588\end{array}$ & Moral & Queen's & $\begin{array}{l}\text { STC } \\
25783\end{array}$ & 93 & Prologue \\
\hline 83 & $\begin{array}{l}\text { Marlowe, } \\
\text { Christoph } \\
\text { er }\end{array}$ & $\begin{array}{l}1 \\
\text { Tamburlai } \\
\text { ne }\end{array}$ & $\begin{array}{l}1590 \\
\text { A } 1587\end{array}$ & $\begin{array}{l}\text { Heroical } \\
\text { romance }\end{array}$ & Admiral's & $\begin{array}{l}\text { STC } \\
17425\end{array}$ & 94 & Prologue \\
\hline 84 & $\begin{array}{l}\text { Marlowe, } \\
\text { Christoph } \\
\text { er }\end{array}$ & $\begin{array}{l}2 \\
\text { Tamburlai } \\
\text { ne }\end{array}$ & $\begin{array}{l}1590 \\
\text { A } 1588\end{array}$ & $\begin{array}{l}\text { Heroical } \\
\text { romance }\end{array}$ & Admiral's & $\begin{array}{l}\text { STC } \\
17425\end{array}$ & 95 & Prologue \\
\hline
\end{tabular}




\begin{tabular}{|c|c|c|c|c|c|c|c|c|}
\hline 85 & $\begin{array}{l}\text { Fraunce, } \\
\text { Abraham }\end{array}$ & $\begin{array}{l}\text { Amynta's } \\
\text { Pastoral } \\
\text { (tr. Tasso) }\end{array}$ & $\begin{array}{l}1591 \\
\text { A } 1591\end{array}$ & Pastoral & Closet & $\begin{array}{l}\text { STC } \\
11340\end{array}$ & 97 & $\begin{array}{l}\text { Chorus } \\
\text { and } \\
\text { epilogue }\end{array}$ \\
\hline 86 & $\begin{array}{l}\text { Lyly, } \\
\text { John }\end{array}$ & Endymion & $\begin{array}{l}1591 \\
\text { A } 1588\end{array}$ & $\begin{array}{l}\text { Classical } \\
\text { legend } \\
\text { (comedy) }\end{array}$ & $\begin{array}{l}\text { Paul's at } \\
\text { Court }\end{array}$ & $\begin{array}{l}\text { STC } \\
17050\end{array}$ & 99 & $\begin{array}{l}\text { Prologue } \\
\text { and } \\
\text { epilogue }\end{array}$ \\
\hline 87 & $\begin{array}{l}\text { Anonymo } \\
\text { us }\end{array}$ & $\begin{array}{l}1 \text { The } \\
\text { Troubleso } \\
\text { me Raigne } \\
\text { of King } \\
\text { John }\end{array}$ & $\begin{array}{l}1591 \\
\text { A } 1588\end{array}$ & History & Queen's & $\begin{array}{l}\text { STC } \\
14644\end{array}$ & $\begin{array}{l}10 \\
1\end{array}$ & Prologue \\
\hline $\begin{array}{l}88 \\
.\end{array}$ & $\begin{array}{l}\text { Anonymo } \\
\text { us }\end{array}$ & $\begin{array}{l}2 \text { The } \\
\text { Troubleso } \\
\text { me Raigne } \\
\text { of King } \\
\text { John }\end{array}$ & $\begin{array}{l}1591 \\
\text { A } 1591\end{array}$ & History & Queen's & $\begin{array}{l}\text { STC } \\
14645\end{array}$ & $\begin{array}{l}10 \\
2\end{array}$ & Prologue \\
\hline $\begin{array}{l}89 \\
\cdot\end{array}$ & $\begin{array}{l}\text { Wilmot } \\
\text { R., } \\
\text { Stafford, } \\
\text { Hatton, } \\
\text { Noel, } \\
\text { Al.,G. }\end{array}$ & $\begin{array}{l}\text { Tancred } \\
\text { and } \\
\text { Gismund }\end{array}$ & $\begin{array}{l}1591 \\
\text { A } 1566\end{array}$ & $\begin{array}{l}\text { Senecan } \\
\text { Tragedy }\end{array}$ & $\begin{array}{l}\text { Innert } \\
\text { Temple }\end{array}$ & $\begin{array}{l}\text { STC } \\
25764\end{array}$ & $\begin{array}{l}10 \\
4\end{array}$ & $\begin{array}{l}\text { Two } \\
\text { prologues, } \\
\text { one } \\
\text { epilogue, } \\
\text { chorus at } \\
\text { the end of } \\
\text { each act } \\
\text { except the } \\
\text { last one }\end{array}$ \\
\hline 90 & $\begin{array}{l}\text { Lyly, } \\
\text { John }\end{array}$ & Gallathea & $\begin{array}{l}1592 \\
\text { A1585 }\end{array}$ & $\begin{array}{l}\text { Classical } \\
\text { legend } \\
\text { (comedy) }\end{array}$ & Paul's & $\begin{array}{l}\text { STC } \\
17080\end{array}$ & $\begin{array}{l}10 \\
5\end{array}$ & $\begin{array}{l}\text { Prologue } \\
\text { and } \\
\text { epilogue }\end{array}$ \\
\hline $\begin{array}{l}91 \\
\cdot\end{array}$ & $\begin{array}{l}\text { Lyly, } \\
\text { John }\end{array}$ & Midas & $\begin{array}{l}1592 \\
\text { A } 1589\end{array}$ & Comedy & Paul's & $\begin{array}{l}\text { STC } \\
17083\end{array}$ & $\begin{array}{l}10 \\
6\end{array}$ & Prologue \\
\hline 92 & $\begin{array}{l}\text { Anonymo } \\
\text { us }\end{array}$ & $\begin{array}{l}\text { Arden of } \\
\text { Feversham }\end{array}$ & $\begin{array}{l}1592 \\
\text { A } 1591\end{array}$ & $\begin{array}{l}\text { Realistic } \\
\text { tragedy }\end{array}$ & Unknown & $\begin{array}{l}\text { STC } \\
733\end{array}$ & $\begin{array}{l}10 \\
7\end{array}$ & Epilogue \\
\hline $\begin{array}{l}93 \\
\cdot\end{array}$ & $\begin{array}{l}\text { Herbert, } \\
\text { Mary }\end{array}$ & Antonius & $\begin{array}{l}1592 \\
\text { A } \\
1590\end{array}$ & Tragedy & Closet & $\begin{array}{l}\text { STC } \\
18138\end{array}$ & $\begin{array}{l}10 \\
8\end{array}$ & $\begin{array}{l}\text { Chorus at } \\
\text { the end of } \\
\text { each act } \\
\text { except the } \\
\text { last one }\end{array}$ \\
\hline $\begin{array}{l}94 \\
.\end{array}$ & $\begin{array}{l}\text { Anon. (T. } \\
\text { Kyd?) }\end{array}$ & $\begin{array}{l}\text { The } \\
\text { Tragedy of } \\
\text { Soliman } \\
\text { and } \\
\text { Perseda }\end{array}$ & $\begin{array}{l}1592 \\
\text { A } 1589\end{array}$ & Tragedy & Unknown & $\begin{array}{l}\text { STC } \\
22894\end{array}$ & $\begin{array}{l}10 \\
9\end{array}$ & Chorus \\
\hline 95 & $\begin{array}{l}\text { Kyd, } \\
\text { Thomas }\end{array}$ & $\begin{array}{l}\text { The } \\
\text { Spanish } \\
\text { Tragedy }\end{array}$ & $\begin{array}{l}1592 \\
\text { A } 1587\end{array}$ & Tragedy & $\begin{array}{l}\text { Strange's, } \\
\text { Admiral's }\end{array}$ & $\begin{array}{l}\text { STC } \\
15086\end{array}$ & $\begin{array}{l}11 \\
0\end{array}$ & $\begin{array}{l}\text { Chorus in } \\
\text { form of a } \\
\text { dialogue } \\
\text { between } \\
\text { Revenge }\end{array}$ \\
\hline
\end{tabular}




\begin{tabular}{|c|c|c|c|c|c|c|c|c|}
\hline & & & & & & & & $\begin{array}{l}\text { and the } \\
\text { ghost of } \\
\text { Andrea at } \\
\text { the } \\
\text { beginning } \\
\text { and at the } \\
\text { end of } \\
\text { each act. }\end{array}$ \\
\hline 96 & $\begin{array}{l}\text { Kyd, } \\
\text { Thomas }\end{array}$ & Cornelia & $\begin{array}{l}1594 \\
\text { A } 1594\end{array}$ & Tragedy & Closet (?) & $\begin{array}{l}\text { STC } \\
11622\end{array}$ & $\begin{array}{l}11 \\
6\end{array}$ & $\begin{array}{l}\text { Chorus at } \\
\text { the } \\
\text { beginning } \\
\text { and at the } \\
\text { end of } \\
\text { each act } \\
\text { except the } \\
\text { last one. }\end{array}$ \\
\hline $\begin{array}{l}97 \\
.\end{array}$ & $\begin{array}{l}\text { Lodge, } \\
\text { Thomas, } \\
\text { Greene, } \\
\text { Robert }\end{array}$ & $\begin{array}{l}\text { A } \\
\text { Looking- } \\
\text { Glass for } \\
\text { London } \\
\text { and } \\
\text { England }\end{array}$ & $\begin{array}{l}1594 \\
\text { A } 1590\end{array}$ & $\begin{array}{l}\text { Biblical } \\
\text { moral }\end{array}$ & $\begin{array}{l}\text { Queen's } \\
\text { (?) }\end{array}$ & $\begin{array}{l}\text { STC } \\
16679\end{array}$ & $\begin{array}{l}11 \\
8\end{array}$ & Chorus \\
\hline $\begin{array}{l}98 \\
.\end{array}$ & $\begin{array}{l}\text { Shakespe } \\
\text { are, } \\
\text { William }\end{array}$ & $\begin{array}{l}\text { The } \\
\text { Taming of } \\
\text { the Shrew }\end{array}$ & 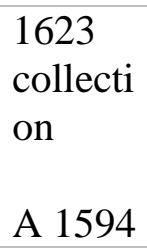 & Comedy & $\begin{array}{l}\text { Sussex's? } \\
\text { Chamberla } \\
\text { in's }\end{array}$ & $\begin{array}{l}\text { STC } \\
22273\end{array}$ & $\begin{array}{l}12 \\
0 \mathrm{a}\end{array}$ & Induction \\
\hline $\begin{array}{l}99 \\
.\end{array}$ & $\begin{array}{l}\text { Anonymo } \\
\text { us }\end{array}$ & $\begin{array}{l}\text { The } \\
\text { Taming of } \\
\text { a Shrew }\end{array}$ & 1594 & Comedy & Queen's? & $\begin{array}{l}\text { STC } \\
23667\end{array}$ & $\begin{array}{l}12 \\
0\end{array}$ & $\begin{array}{l}\text { Induction, } \\
\text { interludes, } \\
\text { conclusion }\end{array}$ \\
\hline $\begin{array}{l}10 \\
0 .\end{array}$ & Anon. & $\begin{array}{l}\text { The True } \\
\text { Tragedy of } \\
\text { Richard } \\
\text { the Third }\end{array}$ & $\begin{array}{l}1594 \\
\text { A } 1591\end{array}$ & History & Queen's & $\begin{array}{l}\text { STC } \\
21009\end{array}$ & $\begin{array}{l}12 \\
6\end{array}$ & $\begin{array}{l}\text { Induction } \\
\text { and } \\
\text { conclusion }\end{array}$ \\
\hline $\begin{array}{l}10 \\
1 .\end{array}$ & $\begin{array}{l}\text { Peele, } \\
\text { George }\end{array}$ & $\begin{array}{l}\text { The Battle } \\
\text { of Alcazar }\end{array}$ & $\begin{array}{l}1594 \\
\text { A } 1589\end{array}$ & $\begin{array}{l}\text { Foreign } \\
\text { History }\end{array}$ & Admiral's & $\begin{array}{l}\text { STC } \\
19531\end{array}$ & $\begin{array}{l}12 \\
7\end{array}$ & $\begin{array}{l}\text { Prologue } \\
\text { and dumb } \\
\text { show }\end{array}$ \\
\hline $\begin{array}{l}10 \\
2 .\end{array}$ & $\begin{array}{l}\text { Greene, } \\
\text { Robert (?) }\end{array}$ & 1 Selimus & $\begin{array}{l}1594 \\
\text { A } 1592\end{array}$ & $\begin{array}{l}\text { Heroical } \\
\text { romance }\end{array}$ & Unknown & $\begin{array}{l}\text { STC } \\
2310 \mathrm{a}\end{array}$ & $\begin{array}{l}13 \\
0\end{array}$ & $\begin{array}{l}\text { Prologue } \\
\text { and } \\
\text { epilogue }\end{array}$ \\
\hline $\begin{array}{l}10 \\
3 .\end{array}$ & $\begin{array}{l}\text { Anonymo } \\
\text { us }\end{array}$ & $\begin{array}{l}\text { The Wars } \\
\text { of Cyrus }\end{array}$ & $\begin{array}{l}1594 \\
\text { A } 1588\end{array}$ & $\begin{array}{l}\text { Classical } \\
\text { history }\end{array}$ & Chapel & $\begin{array}{l}\text { STC } \\
6160\end{array}$ & $\begin{array}{l}13 \\
1\end{array}$ & $\begin{array}{l}\text { Prologue } \\
\text { (misplace } \\
\text { d ten } \\
\text { pages after } \\
\text { the } \\
\text { beginning } \\
\text { of the } \\
\text { play) }\end{array}$ \\
\hline $\begin{array}{l}10 \\
4 .\end{array}$ & $\begin{array}{l}\text { Daniel, } \\
\text { Samuel }\end{array}$ & Cleopatra & 1594 & Tragedy & Closet & $\begin{array}{l}\text { STC } \\
6254\end{array}$ & $\begin{array}{l}13 \\
2\end{array}$ & $\begin{array}{l}\text { Chorus at } \\
\text { the end of }\end{array}$ \\
\hline
\end{tabular}




\begin{tabular}{|c|c|c|c|c|c|c|c|c|}
\hline & & & $\begin{array}{l}\text { A } 1593 \\
\text { Revise } \\
\text { d } 1607\end{array}$ & & & & & $\begin{array}{l}\text { each act, } \\
\text { except the } \\
\text { last one }\end{array}$ \\
\hline $\begin{array}{l}10 \\
5 .\end{array}$ & $\begin{array}{l}\text { Anonymo } \\
\text { us }\end{array}$ & $\begin{array}{l}\text { Pedlar's } \\
\text { Prophecy }\end{array}$ & $\begin{array}{l}1595 \\
\text { A } 1561\end{array}$ & $\begin{array}{l}\text { Protestan } \\
\text { t Moral }\end{array}$ & Unknown & $\begin{array}{l}\text { STC } \\
25782\end{array}$ & $\begin{array}{l}13 \\
4\end{array}$ & $\begin{array}{l}\text { Prologue } \\
\text { and } \\
\text { epilogue }\end{array}$ \\
\hline $\begin{array}{l}10 \\
6 .\end{array}$ & $\begin{array}{l}\text { W. S.” } \\
\text { (Peele? } \\
\text { Greene?) }\end{array}$ & Locrine & $\begin{array}{l}1591 \\
\text { A } 1594\end{array}$ & $\begin{array}{l}\text { Pseudo-h } \\
\text { istory }\end{array}$ & Unknown & $\begin{array}{l}\text { STC } \\
21528\end{array}$ & $\begin{array}{l}13 \\
6\end{array}$ & $\begin{array}{l}\text { Prologue } \\
\text { and } \\
\text { epilogue }\end{array}$ \\
\hline $\begin{array}{l}10 \\
7 .\end{array}$ & $\begin{array}{l}\text { Peele, } \\
\text { George }\end{array}$ & $\begin{array}{l}\text { The Old } \\
\text { Wives Tale }\end{array}$ & $\begin{array}{l}1595 \\
\text { A } 1590\end{array}$ & Romance & Queen's & $\begin{array}{l}\text { STC } \\
19545\end{array}$ & $\begin{array}{l}13 \\
7\end{array}$ & Induction \\
\hline $\begin{array}{l}10 \\
8 .\end{array}$ & $\begin{array}{l}\text { Shakespe } \\
\text { are, } \\
\text { William }\end{array}$ & $\begin{array}{l}\text { Romeo } \\
\text { and Juliet }\end{array}$ & $\begin{array}{l}1597 \\
\text { A } 1595\end{array}$ & Tragedy & $\begin{array}{l}\text { Chamberla } \\
\text { in's }\end{array}$ & $\begin{array}{l}\text { STC } \\
22322\end{array}$ & $\begin{array}{l}14 \\
3\end{array}$ & $\begin{array}{l}\text { Prologue } \\
\text { and chorus }\end{array}$ \\
\hline $\begin{array}{l}10 \\
9 .\end{array}$ & $\begin{array}{l}\text { Lyly, } \\
\text { John }\end{array}$ & $\begin{array}{l}\text { The } \\
\text { Woman in } \\
\text { the Moon }\end{array}$ & $\begin{array}{l}1597 \\
\text { A } 1593\end{array}$ & Comedy & Unknown & $\begin{array}{l}\text { STC } \\
17090\end{array}$ & $\begin{array}{l}14 \\
4\end{array}$ & Prologue \\
\hline $\begin{array}{l}11 \\
0 .\end{array}$ & $\begin{array}{l}\text { Brandon, } \\
\text { Samuel }\end{array}$ & $\begin{array}{l}\text { The } \\
\text { Virtuous } \\
\text { Octavia }\end{array}$ & $\begin{array}{l}1598 \\
\text { A } 1598\end{array}$ & $\begin{array}{l}\text { Tragicom } \\
\text { edy }\end{array}$ & Closet & $\begin{array}{l}\text { STC } \\
3544\end{array}$ & $\begin{array}{l}14 \\
7\end{array}$ & $\begin{array}{l}\text { Chorus at } \\
\text { the end of } \\
\text { each act } \\
\text { except the } \\
\text { last one }\end{array}$ \\
\hline $\begin{array}{l}11 \\
1 .\end{array}$ & $\begin{array}{l}\text { Greene, } \\
\text { Robert }\end{array}$ & $\begin{array}{l}\text { The } \\
\text { Scottish } \\
\text { History of } \\
\text { James I V }\end{array}$ & $\begin{array}{l}1598 \\
\text { A } 1590\end{array}$ & History & Queen's? & $\begin{array}{l}\text { STC } \\
12308\end{array}$ & $\begin{array}{l}14 \\
9\end{array}$ & $\begin{array}{l}\text { Induction } \\
\text { and chorus }\end{array}$ \\
\hline $\begin{array}{l}11 \\
2 .\end{array}$ & Anon. & $\begin{array}{l}\text { Mucedoru } \\
\text { s and } \\
\text { Amadine }\end{array}$ & $\begin{array}{l}1598 \\
\text { rev. } \\
1610 \\
\text { A } 1590\end{array}$ & $\begin{array}{l}\text { Romantic } \\
\text { comedy }\end{array}$ & $\begin{array}{l}\text { Unknown } \\
\text { (Queen's } \\
\text { men? } \\
\text { Pembroke' } \\
\text { s ? } \\
\text { Sussex's } \\
? \text { ) } \\
\text { (King's } \\
\text { 1610) }\end{array}$ & $\begin{array}{l}\text { STC } \\
18230\end{array}$ & $\begin{array}{l}15 \\
1\end{array}$ & $\begin{array}{l}\text { Induction } \\
\text { and } \\
\text { epilogue, } \\
\text { Prologue } \\
\text { added } \\
\text { later }\end{array}$ \\
\hline $\begin{array}{l}11 \\
3 .\end{array}$ & $\begin{array}{l}\text { Heywood, } \\
\text { Thomas } \\
\text { (?) and } \\
\text { others (?) }\end{array}$ & $\begin{array}{l}1 \text { Edward } \\
\text { IV }\end{array}$ & $\begin{array}{l}1599 \\
\text { A } 1599\end{array}$ & History & Derby's & $\begin{array}{l}\text { STC } \\
13341\end{array}$ & $\begin{array}{l}15 \\
3\end{array}$ & Chorus \\
\hline $\begin{array}{l}11 \\
4 .\end{array}$ & $\begin{array}{l}\text { Heywood, } \\
\text { Thomas } \\
(?) \text { and } \\
\text { others (?) }\end{array}$ & $\begin{array}{l}2 \text { Edward } \\
I V\end{array}$ & $\begin{array}{l}1599 \\
\text { A } 1599\end{array}$ & History & Derby's & $\begin{array}{l}\text { STC } \\
13341\end{array}$ & $\begin{array}{l}15 \\
4\end{array}$ & Chorus \\
\hline
\end{tabular}




\begin{tabular}{|c|c|c|c|c|c|c|c|c|}
\hline $\begin{array}{l}11 \\
5 .\end{array}$ & $\begin{array}{l}\text { Anon. (T. } \\
\text { Heywood } \\
\text { ?) }\end{array}$ & $\begin{array}{l}\text { A Warning } \\
\text { for Fair } \\
\text { Women }\end{array}$ & $\begin{array}{l}1599 \\
\text { A } 1599\end{array}$ & Tragedy & $\begin{array}{l}\text { Chamberla } \\
\text { in's }\end{array}$ & $\begin{array}{l}\text { STC } \\
25089\end{array}$ & $\begin{array}{l}15 \\
5\end{array}$ & $\begin{array}{l}\text { Induction, } \\
\text { prologue, } \\
\text { dumb } \\
\text { show, } \\
\text { epilogue }\end{array}$ \\
\hline $\begin{array}{l}11 \\
6 .\end{array}$ & $\begin{array}{l}\text { Greene, } \\
\text { Robert }\end{array}$ & $\begin{array}{l}\text { Alphonsus } \\
\text { King of } \\
\text { Aragon }\end{array}$ & $\begin{array}{l}1599 \\
\text { A } 1587\end{array}$ & $\begin{array}{l}\text { Heroical } \\
\text { romance }\end{array}$ & Unknown & $\begin{array}{l}\text { STC } \\
12233\end{array}$ & $\begin{array}{l}15 \\
6\end{array}$ & $\begin{array}{l}\text { Induction } \\
\text { and } \\
\text { conclusion }\end{array}$ \\
\hline $\begin{array}{l}11 \\
7 .\end{array}$ & $\begin{array}{l}\text { Anonymo } \\
\text { us (T. } \\
\text { Preston?) } \\
\text { Peele }\end{array}$ & $\begin{array}{l}\text { Clymon } \\
\text { and } \\
\text { Clamydes }\end{array}$ & $\begin{array}{l}1599 \\
\text { A } 1570\end{array}$ & $\begin{array}{l}\text { Heroical } \\
\text { romance }\end{array}$ & $\begin{array}{l}\text { Revived } \\
\text { by } \\
\text { Queen's } \\
\text { (?) }\end{array}$ & $\begin{array}{l}\text { STC } \\
5450 \mathrm{a}\end{array}$ & $\begin{array}{l}15 \\
7\end{array}$ & Prologue \\
\hline $\begin{array}{l}11 \\
8 .\end{array}$ & $\begin{array}{l}\text { Peele, } \\
\text { George }\end{array}$ & $\begin{array}{l}\text { The Love } \\
\text { of King } \\
\text { David and } \\
\text { Fair } \\
\text { Bethsabe }\end{array}$ & $\begin{array}{l}1599 \\
\text { A } 1587\end{array}$ & $\begin{array}{l}\text { Heroical } \\
\text { romance }\end{array}$ & Unknown & $\begin{array}{l}\text { STC } \\
19540\end{array}$ & $\begin{array}{l}16 \\
0\end{array}$ & $\begin{array}{l}\text { Prologue } \\
\text { and chorus }\end{array}$ \\
\hline $\begin{array}{l}11 \\
9 .\end{array}$ & $\begin{array}{l}\text { Porter, } \\
\text { Henry }\end{array}$ & $\begin{array}{l}\text { The Two } \\
\text { Angry } \\
\text { Women of } \\
\text { Abingdon }\end{array}$ & $\begin{array}{l}1599 \\
\text { A } 1598\end{array}$ & Comedy & Unknown & $\begin{array}{l}\text { STC } \\
20123\end{array}$ & $\begin{array}{l}16 \\
1\end{array}$ & Prologue \\
\hline $\begin{array}{l}12 \\
0 .\end{array}$ & $\begin{array}{l}\text { Dekker, } \\
\text { Thomas }\end{array}$ & $\begin{array}{l}\text { The } \\
\text { Pleasant } \\
\text { Comedy of } \\
\text { Old } \\
\text { Fortunatus }\end{array}$ & $\begin{array}{l}1600 \\
1599\end{array}$ & Comedy & Admiral's & $\begin{array}{l}\text { STC } \\
6517\end{array}$ & $\begin{array}{l}16 \\
2\end{array}$ & $\begin{array}{l}\text { Prologue } \\
\text { in forma } \\
\text { of a } \\
\text { dialogue } \\
\text { (at court), } \\
\text { final song, } \\
\text { epilogue } \\
\text { (at court) }\end{array}$ \\
\hline $\begin{array}{l}12 \\
1 .\end{array}$ & $\begin{array}{l}\text { Jonson, } \\
\text { Ben }\end{array}$ & $\begin{array}{l}\text { Every Man } \\
\text { out of his } \\
\text { Humour }\end{array}$ & $\begin{array}{l}1600 \\
\text { A } 1599\end{array}$ & Comedy & Chapel & $\begin{array}{l}\text { STC } \\
14767\end{array}$ & $\begin{array}{l}16 \\
3\end{array}$ & $\begin{array}{l}\text { Induction } \\
\text { (frame } \\
\text { play), } \\
\text { epilogue }\end{array}$ \\
\hline $\begin{array}{l}12 \\
2 .\end{array}$ & $\begin{array}{l}\text { Anonymo } \\
\text { us (Day?, } \\
\text { Lyly?) }\end{array}$ & $\begin{array}{l}\text { The } \\
\text { Maid's } \\
\text { Metamorp } \\
\text { hosis }\end{array}$ & $\begin{array}{l}1600 \\
\text { A } 1600\end{array}$ & Comedy & Paul's & $\begin{array}{l}\text { STC } \\
17188\end{array}$ & $\begin{array}{l}16 \\
4\end{array}$ & Prologue \\
\hline $\begin{array}{l}12 \\
3 .\end{array}$ & $\begin{array}{l}\text { Shakespe } \\
\text { are, } \\
\text { William }\end{array}$ & Henry V & $\begin{array}{l}1600 \\
\text { A } 1599\end{array}$ & History & $\begin{array}{l}\text { Chamberla } \\
\text { in's }\end{array}$ & $\begin{array}{l}\text { STC } \\
22289\end{array}$ & $\begin{array}{l}16 \\
5\end{array}$ & $\begin{array}{l}F_{1} 1623: \\
\text { Prologue } \\
\text { and chorus }\end{array}$ \\
\hline $\begin{array}{l}12 \\
4 .\end{array}$ & $\begin{array}{l}\text { Drayton, } \\
\text { Hathway, } \\
\text { Munday, } \\
\text { Wilson }\end{array}$ & $\begin{array}{l}\text { Sir John } \\
\text { Oldcastle }\end{array}$ & $\begin{array}{l}1600 \\
\text { A1599 }\end{array}$ & History & $\begin{array}{l}\text { Chamberla } \\
\text { in's }\end{array}$ & $\begin{array}{l}\text { STC } \\
18795\end{array}$ & $\begin{array}{l}16 \\
6\end{array}$ & Prologue \\
\hline $\begin{array}{l}12 \\
5 .\end{array}$ & $\begin{array}{l}\text { Shakespe } \\
\text { are, } \\
\text { William }\end{array}$ & 2 Henry IV & $\begin{array}{l}1600 \\
\text { A } 1597\end{array}$ & History & $\begin{array}{l}\text { Chamberla } \\
\text { in's }\end{array}$ & $\begin{array}{l}\text { STC } \\
22288\end{array}$ & $\begin{array}{l}16 \\
7\end{array}$ & Induction \\
\hline $\begin{array}{l}12 \\
6 .\end{array}$ & $\begin{array}{l}\text { Anon. (T. } \\
\text { Dekker in } \\
\text { part?) }\end{array}$ & $\begin{array}{l}\text { The } \\
\text { Weakest }\end{array}$ & $\begin{array}{l}1600 \\
\text { A } 1600\end{array}$ & $\begin{array}{l}\text { Pseudo-h } \\
\text { istory }\end{array}$ & Oxford's & $\begin{array}{l}\text { STC } \\
25144\end{array}$ & $\begin{array}{l}17 \\
1\end{array}$ & Prologue \\
\hline
\end{tabular}




\begin{tabular}{|c|c|c|c|c|c|c|c|c|}
\hline & & $\begin{array}{l}\text { Goeth to } \\
\text { the Wall }\end{array}$ & & & & & & \\
\hline $\begin{array}{l}12 \\
7 .\end{array}$ & $\begin{array}{l}\text { Nash, } \\
\text { Thomas }\end{array}$ & $\begin{array}{l}\text { Summer's } \\
\text { Last Will } \\
\text { and } \\
\text { Testament }\end{array}$ & $\begin{array}{l}1592 \\
\text { A } 1592\end{array}$ & Comedy & $\begin{array}{l}\text { Whitgift's } \\
\text { house (?) }\end{array}$ & $\begin{array}{l}\text { STC } \\
18376\end{array}$ & $\begin{array}{l}17 \\
3\end{array}$ & $\begin{array}{l}\text { Induction, } \\
\text { including } \\
\text { prologue, } \\
\text { and } \\
\text { epilogue, } \\
\text { with } \\
\text { conclusion } \\
\text {. Will } \\
\text { Summer } \\
\text { acts as a } \\
\text { chorus or } \\
\text { commenta } \\
\text { ry } \\
\text { throughou } \\
\mathrm{t} \text { the play }\end{array}$ \\
\hline $\begin{array}{l}12 \\
8 .\end{array}$ & $\begin{array}{l}\text { Dekker, } \\
\text { Thomas }\end{array}$ & $\begin{array}{l}\text { The } \\
\text { Shoemaker } \\
\text { 's Holiday }\end{array}$ & $\begin{array}{l}1600 \\
\text { A } 1599\end{array}$ & Comedy & Admiral's & $\begin{array}{l}\text { STC } \\
6523\end{array}$ & $\begin{array}{l}17 \\
5\end{array}$ & Prologue \\
\hline $\begin{array}{l}12 \\
9 .\end{array}$ & $\begin{array}{l}\text { Jonson, } \\
\text { Ben }\end{array}$ & $\begin{array}{l}\text { Everyman } \\
\text { in His } \\
\text { Humour }\end{array}$ & $\begin{array}{l}1601 \\
\text { A } 1598\end{array}$ & Comedy & $\begin{array}{l}\text { Chamberla } \\
\text { in's }\end{array}$ & $\begin{array}{l}\text { STC } \\
14766\end{array}$ & $\begin{array}{l}17 \\
6\end{array}$ & $\begin{array}{l}\text { F 1616: } \\
\text { Prologue }\end{array}$ \\
\hline $\begin{array}{l}13 \\
0 .\end{array}$ & $\begin{array}{l}\text { Marston, } \\
\text { John }\end{array}$ & $\begin{array}{l}\text { John/Jack } \\
\text { Drum's } \\
\text { Entertain } \\
\text { ment, or } \\
\text { Pasquil } \\
\text { and } \\
\text { Catherin }\end{array}$ & $\begin{array}{l}1601 \\
\text { A } 1600\end{array}$ & Comedy & Paul's & $\begin{array}{l}\text { STC } \\
7243\end{array}$ & $\begin{array}{l}17 \\
7\end{array}$ & $\begin{array}{l}\text { Induction, } \\
\text { Morris } \\
\text { dance, } \\
\text { music, and } \\
\text { songs }\end{array}$ \\
\hline $\begin{array}{l}13 \\
1 .\end{array}$ & $\begin{array}{l}\text { Munday, } \\
\text { Anthony } \\
\text { (\& } \\
\text { Chettle) }\end{array}$ & $\begin{array}{l}\text { The } \\
\text { Downfall } \\
\text { of Robert, } \\
\text { Earl of } \\
\text { Hunting }\end{array}$ & $\begin{array}{l}1601 \\
\text { A } 1598\end{array}$ & History & Admiral's & $\begin{array}{l}\text { STC18 } \\
721\end{array}$ & $\begin{array}{l}17 \\
9\end{array}$ & $\begin{array}{l}\text { Induction } \\
\text { and } \\
\text { conclusion } \\
\text {, Dumb } \\
\text { show } \\
\text { masque }\end{array}$ \\
\hline $\begin{array}{l}13 \\
2 .\end{array}$ & $\begin{array}{l}\text { Chettle, } \\
\mathrm{H}, \\
\text { Munday, } \\
\text { Anthony }\end{array}$ & $\begin{array}{l}\text { The Death } \\
\text { of Robert } \\
\text { Earl of } \\
\text { Huntingto } \\
n\end{array}$ & $\begin{array}{l}1601 \\
\text { A } 1598\end{array}$ & History & Admiral's & $\begin{array}{l}\text { STC } \\
18271\end{array}$ & $\begin{array}{l}18 \\
0\end{array}$ & Epilogue \\
\hline $\begin{array}{l}13 \\
3 .\end{array}$ & $\begin{array}{l}\text { Jonson, } \\
\text { Ben }\end{array}$ & $\begin{array}{l}\text { Cynthia's } \\
\text { Revels }\end{array}$ & $\begin{array}{l}1601 \\
\text { A } 1600\end{array}$ & Comedy & Chapel & $\begin{array}{l}\text { STC } \\
14773\end{array}$ & $\begin{array}{l}18 \\
1\end{array}$ & $\begin{array}{l}\text { Induction, } \\
\text { masque, } \\
\text { epilogue }\end{array}$ \\
\hline $\begin{array}{l}13 \\
4 .\end{array}$ & $\begin{array}{l}\text { Yarington } \\
\text {, R. }\end{array}$ & $\begin{array}{l}\text { Two } \\
\text { Lamentabl } \\
e \\
\text { Tragedies } \\
\text { in One }\end{array}$ & $\begin{array}{l}1601 \\
\text { A } 1594\end{array}$ & Tragedy & $\begin{array}{l}\text { Admiral's } \\
?\end{array}$ & $\begin{array}{l}\text { STC } \\
26076\end{array}$ & $\begin{array}{l}18 \\
2\end{array}$ & $\begin{array}{l}\text { Induction } \\
\text { and } \\
\text { conclusion }\end{array}$ \\
\hline
\end{tabular}




\begin{tabular}{|c|c|c|c|c|c|c|c|c|}
\hline $\begin{array}{l}13 \\
5 .\end{array}$ & $\begin{array}{l}\text { Dymock, } \\
\text { John (?) }\end{array}$ & $\begin{array}{l}\text { Il pastor } \\
\text { fido }\end{array}$ & $\begin{array}{l}1602 \\
\text { A } 1601\end{array}$ & Pastoral & Closet & $\begin{array}{l}\text { STC } \\
12415\end{array}$ & $\begin{array}{l}18 \\
3\end{array}$ & $\begin{array}{l}\text { Chorus at } \\
\text { the end of } \\
\text { each act }\end{array}$ \\
\hline $\begin{array}{l}13 \\
6 .\end{array}$ & $\begin{array}{l}\text { Marston, } \\
\text { John }\end{array}$ & $\begin{array}{l}\text { Antonio } \\
\text { and } \\
\text { Mellida }\end{array}$ & $\begin{array}{l}1602 \\
\text { A } 1599\end{array}$ & $\begin{array}{l}\text { Tragicom } \\
\text { edy }\end{array}$ & Paul's & $\begin{array}{l}\text { STC } \\
17473\end{array}$ & $\begin{array}{l}18 \\
4\end{array}$ & $\begin{array}{l}\text { Induction, } \\
\text { prologue } \\
\text { and } \\
\text { epilogue }\end{array}$ \\
\hline $\begin{array}{l}13 \\
7 .\end{array}$ & $\begin{array}{l}\text { Marston, } \\
\text { John }\end{array}$ & $\begin{array}{l}\text { Antonio's } \\
\text { revenge }\end{array}$ & $\begin{array}{l}1602 \\
\text { A } 1600\end{array}$ & Tragedy & Paul's & $\begin{array}{l}\text { STC } \\
17474\end{array}$ & $\begin{array}{l}18 \\
5\end{array}$ & Prologue \\
\hline $\begin{array}{l}13 \\
8 .\end{array}$ & $\begin{array}{l}\text { Jonson, } \\
\text { Ben }\end{array}$ & Poetaster & $\begin{array}{l}1601 \\
\text { A } 1601\end{array}$ & Comedy & Chapel & $\begin{array}{l}\text { STC } \\
14781\end{array}$ & $\begin{array}{l}18 \\
6\end{array}$ & $\begin{array}{l}\text { Induction } \\
\text { and } \\
\text { prologue }\end{array}$ \\
\hline $\begin{array}{l}13 \\
9 .\end{array}$ & $\begin{array}{l}\text { Anonymo } \\
\text { us (by } \\
\text { "W.S.") }\end{array}$ & $\begin{array}{l}\text { Thomas } \\
\text { Lord } \\
\text { Cromwell }\end{array}$ & $\begin{array}{l}1602 \\
\text { A } 1600\end{array}$ & History & $\begin{array}{l}\text { Chamberla } \\
\text { in's }\end{array}$ & $\begin{array}{l}\text { STC } \\
21532\end{array}$ & $\begin{array}{l}18 \\
9\end{array}$ & Chorus \\
\hline $\begin{array}{l}14 \\
0 .\end{array}$ & $\begin{array}{l}\text { Anonymo } \\
\text { us }\end{array}$ & $\begin{array}{l}\text { The } \\
\text { Contention } \\
\text { between } \\
\text { Liberality } \\
\text { and } \\
\text { Prodigalit } \\
y\end{array}$ & $\begin{array}{l}1602 \\
\text { A } 1601\end{array}$ & $\begin{array}{l}\text { Moral } \\
\text { interlude }\end{array}$ & Chapel & $\begin{array}{l}\text { STC } \\
5593\end{array}$ & $\begin{array}{l}19 \\
0\end{array}$ & $\begin{array}{l}\text { Prologue } \\
\text { and } \\
\text { epilogue }\end{array}$ \\
\hline $\begin{array}{l}14 \\
1 .\end{array}$ & $\begin{array}{l}\text { Anonymo } \\
\text { us }\end{array}$ & $\begin{array}{l}\text { A Larum } \\
\text { for } \\
\text { London }\end{array}$ & $\begin{array}{l}1602 \\
\text { A } 1599\end{array}$ & History & $\begin{array}{l}\text { Chamberla } \\
\text { in's }\end{array}$ & $\begin{array}{l}\text { STC } \\
16754\end{array}$ & $\begin{array}{l}19 \\
2\end{array}$ & $\begin{array}{l}\text { Prologue } \\
\text { and } \\
\text { epilogue }\end{array}$ \\
\hline $\begin{array}{l}14 \\
2 .\end{array}$ & $\begin{array}{l}\text { Dekker, } \\
\text { Thomas } \\
\text { (with } \\
\text { John } \\
\text { Marston?) }\end{array}$ & $\begin{array}{l}\text { Satiromast } \\
\text { ix }\end{array}$ & $\begin{array}{l}1602 \\
\text { A } 1601\end{array}$ & Comedy & $\begin{array}{l}\text { Chamberla } \\
\text { in's and } \\
\text { Paul's }\end{array}$ & $\begin{array}{l}\text { STC } \\
6521\end{array}$ & $\begin{array}{l}19 \\
5\end{array}$ & Epilogue \\
\hline $\begin{array}{l}14 \\
3 .\end{array}$ & $\begin{array}{l}\text { Alexande } \\
\text { r, William }\end{array}$ & Darius & $\begin{array}{l}1603 \\
\text { A } 1603\end{array}$ & Tragedy & Closet & $\begin{array}{l}\text { STC } \\
349\end{array}$ & $\begin{array}{l}19 \\
6\end{array}$ & $\begin{array}{l}\text { Chorus at } \\
\text { the end of } \\
\text { each act }\end{array}$ \\
\hline $\begin{array}{l}14 \\
4 .\end{array}$ & $\begin{array}{l}\text { Anonymo } \\
\text { us } \\
\text { (Montgo } \\
\text { mery?) }\end{array}$ & Philotus & $\begin{array}{l}1603 \\
\text { A } 1603\end{array}$ & Comedy & Closet (?) & $\begin{array}{l}\text { STC } \\
19888\end{array}$ & $\begin{array}{l}19 \\
9\end{array}$ & Epilogue \\
\hline $\begin{array}{l}14 \\
5 .\end{array}$ & $\begin{array}{l}\text { Marston, } \\
\text { John }\end{array}$ & $\begin{array}{l}\text { The } \\
\text { Malconten } \\
t\end{array}$ & $\begin{array}{l}1604 \\
\text { A1604 }\end{array}$ & $\begin{array}{l}\text { Tragicom } \\
\text { edy }\end{array}$ & $\begin{array}{l}\text { Queen's } \\
\text { revels e } \\
\text { King's }\end{array}$ & $\begin{array}{l}\text { STC } \\
17479\end{array}$ & $\begin{array}{l}20 \\
3\end{array}$ & $\begin{array}{l}\text { Induction } \\
\text { (by John } \\
\text { Webster), } \\
\text { dumb } \\
\text { show, } \\
\text { masque }\end{array}$ \\
\hline $\begin{array}{l}14 \\
6 .\end{array}$ & $\begin{array}{l}\text { Marlowe, } \\
\text { Christoph } \\
\text { er }\end{array}$ & $\begin{array}{l}\text { Dr } \\
\text { Faustus }\end{array}$ & $\begin{array}{l}1604 \\
\text { A } 1592\end{array}$ & Tragedy & Admirals & $\begin{array}{l}\text { STC } \\
17429\end{array}$ & $\begin{array}{l}20 \\
5\end{array}$ & $\begin{array}{l}\text { Prologue } \\
\text { and } \\
\text { epilogue }\end{array}$ \\
\hline $\begin{array}{l}14 \\
7 .\end{array}$ & $\begin{array}{l}\text { Anonymo } \\
\text { us }\end{array}$ & $\begin{array}{l}\text { The Wit of } \\
\text { a Woman }\end{array}$ & $\begin{array}{l}1604 \\
\text { A } 1604\end{array}$ & Comedy & $\begin{array}{l}\text { Not } \\
\text { performed } \\
(?)\end{array}$ & $\begin{array}{l}\text { STC } \\
25868\end{array}$ & $\begin{array}{l}20 \\
6\end{array}$ & $\begin{array}{l}\text { Prologue } \\
\text { and } \\
\text { epilogue }\end{array}$ \\
\hline
\end{tabular}




\begin{tabular}{|c|c|c|c|c|c|c|c|c|}
\hline $\begin{array}{l}14 \\
8 .\end{array}$ & $\begin{array}{l}\text { Alexande } \\
\text { r, William }\end{array}$ & Croesus & $\begin{array}{l}1604 \\
\text { collecti } \\
\text { on } \\
\text { A1604 }\end{array}$ & Tragedy & Closet & $\begin{array}{l}\text { STC } \\
343\end{array}$ & $\begin{array}{l}20 \\
9\end{array}$ & $\begin{array}{l}\text { Chorus at } \\
\text { the end of } \\
\text { each act }\end{array}$ \\
\hline $\begin{array}{l}14 \\
9 .\end{array}$ & $\begin{array}{l}\text { Marston, } \\
\text { John }\end{array}$ & $\begin{array}{l}\text { The Dutch } \\
\text { Courtesan }\end{array}$ & $\begin{array}{l}1605 \\
\text { A } 1605\end{array}$ & Comedy & $\begin{array}{l}\text { Queen's } \\
\text { Revels }\end{array}$ & $\begin{array}{l}\text { STC } \\
17475\end{array}$ & $\begin{array}{l}21 \\
4\end{array}$ & Prologue \\
\hline $\begin{array}{l}15 \\
0 .\end{array}$ & $\begin{array}{l}\text { Jonson, } \\
\text { Ben, } \\
\text { George } \\
\text { Chapman, } \\
\text { John } \\
\text { Marston }\end{array}$ & $\begin{array}{l}\text { Eastward } \\
\text { Ho }\end{array}$ & $\begin{array}{l}1605 \\
\text { A } 1605\end{array}$ & Comedy & $\begin{array}{l}\text { Queen's } \\
\text { Revels }\end{array}$ & $\begin{array}{l}\text { STC } \\
4970\end{array}$ & $\begin{array}{l}21 \\
7\end{array}$ & $\begin{array}{l}\text { Prologue } \\
\text { and } \\
\text { epilogue }\end{array}$ \\
\hline $\begin{array}{l}15 \\
1 .\end{array}$ & $\begin{array}{l}\text { Chapman, } \\
\text { George }\end{array}$ & All Fools & $\begin{array}{l}1605 \\
\text { A } 1601\end{array}$ & Comedy & $\begin{array}{l}\text { Queen's } \\
\text { Revels }\end{array}$ & $\begin{array}{l}\text { STC } \\
4963\end{array}$ & $\begin{array}{l}21 \\
9\end{array}$ & $\begin{array}{l}\text { Prologue } \\
\text { and } \\
\text { epilogue }\end{array}$ \\
\hline $\begin{array}{l}15 \\
2 .\end{array}$ & $\begin{array}{l}\text { Anon. } \\
\text { (Kyd?) }\end{array}$ & $\begin{array}{l}\text { The First } \\
\text { Part of } \\
\text { Ieronimo }\end{array}$ & $\begin{array}{l}1605 \\
\text { A } 1604\end{array}$ & $\begin{array}{l}\text { Pseudo-h } \\
\text { istory }\end{array}$ & King's? & $\begin{array}{l}\text { STC } \\
15085\end{array}$ & $\begin{array}{l}22 \\
1\end{array}$ & $\begin{array}{l}\text { Ieronimo } \\
\text { ends the } \\
\text { play } \\
\text { ("Enter } \\
\text { Ieronimo } \\
\text { Solus") }\end{array}$ \\
\hline $\begin{array}{l}15 \\
3 .\end{array}$ & $\begin{array}{l}\text { Daniel, } \\
\text { Samuel }\end{array}$ & Philotas & $\begin{array}{l}1605 \\
\text { collecti } \\
\text { on } \\
\text { A } 1604\end{array}$ & Tragedy & $\begin{array}{l}\text { Queen's } \\
\text { Revels }\end{array}$ & $\begin{array}{l}\text { STC } \\
6239\end{array}$ & $\begin{array}{l}22 \\
3\end{array}$ & Chorus \\
\hline $\begin{array}{l}15 \\
4 .\end{array}$ & $\begin{array}{l}\text { Heywood, } \\
\text { Thomas }\end{array}$ & $\begin{array}{l}\text { If you } \\
\text { Know Me } \\
\text { You Know } \\
\text { Nobody }\end{array}$ & $\begin{array}{l}1606 \\
\text { A } 1605\end{array}$ & History & $\begin{array}{l}\text { Queens' } \\
\text { Anne }\end{array}$ & $\begin{array}{l}\text { STC } \\
13336\end{array}$ & $\begin{array}{l}22 \\
4\end{array}$ & $\begin{array}{l}\text { 1633: } \\
\text { chorus }\end{array}$ \\
\hline $\begin{array}{l}15 \\
5 .\end{array}$ & $\begin{array}{l}\text { Anonymo } \\
\text { us } \\
\text { (Gwyn in } \\
\text { part?) }\end{array}$ & $\begin{array}{l}I \& 2 \\
\text { Return } \\
\text { from } \\
\text { Parnassus }\end{array}$ & $\begin{array}{l}1606 \\
\text { A } 1603\end{array}$ & $\begin{array}{l}\text { Satirical } \\
\text { comedy }\end{array}$ & $\begin{array}{l}\text { St. John's } \\
\text { College, } \\
\text { Cambridg } \\
\text { e }\end{array}$ & $\begin{array}{l}\text { STC } \\
19039\end{array}$ & $\begin{array}{l}22 \\
5\end{array}$ & $\begin{array}{l}\text { Induction } \\
\text { and } \\
\text { epilogue }\end{array}$ \\
\hline $\begin{array}{l}15 \\
6 .\end{array}$ & $\begin{array}{l}\text { Anonymo } \\
\text { us }\end{array}$ & $\begin{array}{l}\text { Nobody } \\
\text { and } \\
\text { somebody }\end{array}$ & $\begin{array}{l}1606 \\
\text { A } 1605\end{array}$ & $\begin{array}{l}\text { Pseudo- } \\
\text { history }\end{array}$ & $\begin{array}{l}\text { Queen's } \\
\text { Anne }\end{array}$ & $\begin{array}{l}\text { STC } \\
18597\end{array}$ & $\begin{array}{l}22 \\
9\end{array}$ & $\begin{array}{l}\text { Prologue } \\
\text { and } \\
\text { epilogue }\end{array}$ \\
\hline $\begin{array}{l}15 \\
7 .\end{array}$ & $\begin{array}{l}\text { Marston, } \\
\text { John }\end{array}$ & $\begin{array}{l}\text { Parasitast } \\
\text { er }\end{array}$ & $\begin{array}{l}1606 \\
\text { A } 1604\end{array}$ & Comedy & $\begin{array}{l}\text { Queen's } \\
\text { Revels }\end{array}$ & $\begin{array}{l}\text { STC } \\
17483\end{array}$ & $\begin{array}{l}23 \\
0\end{array}$ & $\begin{array}{l}\text { Prologue } \\
\text { and } \\
\text { epilogue }\end{array}$ \\
\hline $\begin{array}{l}15 \\
8 .\end{array}$ & $\begin{array}{l}\text { Marston, } \\
\text { John }\end{array}$ & $\begin{array}{l}\text { The } \\
\text { Wonder of } \\
\text { Women or } \\
\text { Sophonisb } \\
\text { a }\end{array}$ & $\begin{array}{l}1606 \\
\text { A } 1605\end{array}$ & Tragedy & $\begin{array}{l}\text { Queen's } \\
\text { Revels }\end{array}$ & $\begin{array}{l}\text { STC } \\
17488\end{array}$ & $\begin{array}{l}23 \\
1\end{array}$ & $\begin{array}{l}\text { Prologue } \\
\text { and } \\
\text { epilogue }\end{array}$ \\
\hline
\end{tabular}




\begin{tabular}{|c|c|c|c|c|c|c|c|c|}
\hline $\begin{array}{l}15 \\
9 .\end{array}$ & $\begin{array}{l}\text { Anon. } \\
\text { (probably } \\
\text { Simon } \\
\text { Rowley) }\end{array}$ & $\begin{array}{l}\text { Wily } \\
\text { Beguiled }\end{array}$ & $\begin{array}{l}1606 \\
\text { A } 1602\end{array}$ & Comedy & Paul's & $\begin{array}{l}\text { STC } \\
25818\end{array}$ & $\begin{array}{l}23 \\
4\end{array}$ & $\begin{array}{l}\text { Induction, } \\
\text { masque, } \\
\text { two } \\
\text { prologues, } \\
\text { epilogue }\end{array}$ \\
\hline $\begin{array}{l}16 \\
0 .\end{array}$ & Day, John & $\begin{array}{l}\text { The Isle of } \\
\text { Gulls }\end{array}$ & $\begin{array}{l}1606 \\
\text { A } 1606\end{array}$ & Comedy & $\begin{array}{l}\text { Queen's } \\
\text { Revels } \\
\text { King's } \\
\text { Revels }\end{array}$ & $\begin{array}{l}\text { STC } \\
6412\end{array}$ & $\begin{array}{l}23 \\
5\end{array}$ & $\begin{array}{l}\text { Induction, } \\
\text { prologue } \\
\text { and } \\
\text { epilogue }\end{array}$ \\
\hline $\begin{array}{l}16 \\
1 .\end{array}$ & $\begin{array}{l}\text { Dekker, } \\
\text { Thomas }\end{array}$ & $\begin{array}{l}\text { The Whore } \\
\text { of Babylon }\end{array}$ & $\begin{array}{l}1607 \\
\text { A } 1607\end{array}$ & $\begin{array}{l}\text { Allegoric } \\
\text { al } \\
\text { History }\end{array}$ & $\begin{array}{l}\text { Prince } \\
\text { Henry’s }\end{array}$ & $\begin{array}{l}\text { STC } \\
6532\end{array}$ & $\begin{array}{l}24 \\
1\end{array}$ & Prologue \\
\hline $\begin{array}{l}16 \\
2 .\end{array}$ & $\begin{array}{l}\text { Middleto } \\
\text { n, } \\
\text { Thomas }\end{array}$ & $\begin{array}{l}\text { Michaelm } \\
\text { as Term }\end{array}$ & $\begin{array}{l}1607 \\
\text { A } 1606\end{array}$ & Comedy & Paul's & $\begin{array}{l}\text { STC } \\
17890\end{array}$ & $\begin{array}{l}24 \\
4\end{array}$ & Induction \\
\hline $\begin{array}{l}16 \\
3 .\end{array}$ & $\begin{array}{l}\text { Day J., } \\
\text { W. } \\
\text { Rowley, } \\
\text { G. } \\
\text { Wilkins }\end{array}$ & $\begin{array}{l}\text { The } \\
\text { Travels of } \\
\text { Three } \\
\text { English } \\
\text { Brothers }\end{array}$ & $\begin{array}{l}1607 \\
\text { A } 1607\end{array}$ & Topical & $\begin{array}{l}\text { Queen } \\
\text { Anne's }\end{array}$ & $\begin{array}{l}\text { STC } \\
25635\end{array}$ & $\begin{array}{l}24 \\
8\end{array}$ & $\begin{array}{l}\text { Prologue } \\
\text { and } \\
\text { epilogue, } \\
\text { chorus }\end{array}$ \\
\hline $\begin{array}{l}16 \\
4 .\end{array}$ & $\begin{array}{l}\text { Marston, } \\
\text { John }\end{array}$ & $\begin{array}{l}\text { What You } \\
\text { Will }\end{array}$ & $\begin{array}{l}1607 \\
\text { A } \\
1601\end{array}$ & Comedy & Paul's & $\begin{array}{l}\text { STC } \\
17487\end{array}$ & $\begin{array}{l}25 \\
2\end{array}$ & $\begin{array}{l}\text { Induction, } \\
\text { prologue }\end{array}$ \\
\hline $\begin{array}{l}16 \\
5 .\end{array}$ & $\begin{array}{l}\text { Barnes, } \\
\text { B. }\end{array}$ & $\begin{array}{l}\text { The } \\
\text { Devil's } \\
\text { Charter }\end{array}$ & $\begin{array}{l}1607 \\
\text { A } 1606\end{array}$ & Tragedy & King's & $\begin{array}{l}\text { STC } \\
1466\end{array}$ & $\begin{array}{l}25 \\
4\end{array}$ & $\begin{array}{l}\text { Prologue } \\
\text { and } \\
\text { epilogue, } \\
\text { chorus }\end{array}$ \\
\hline $\begin{array}{l}16 \\
6 .\end{array}$ & $\begin{array}{l}\text { Jonson, } \\
\text { Ben }\end{array}$ & Volpone & $\begin{array}{l}1607 \\
\text { A } 1606\end{array}$ & Comedy & King's & $\begin{array}{l}\text { STC } \\
14783\end{array}$ & $\begin{array}{l}25 \\
9\end{array}$ & $\begin{array}{l}\text { Prologue } \\
+ \\
\text { Volpone's } \\
\text { final } \\
\text { speech } \\
\text { similar to } \\
\text { an } \\
\text { epilogue }\end{array}$ \\
\hline $\begin{array}{l}16 \\
7 .\end{array}$ & $\begin{array}{l}\text { Middleto } \\
\text { n, } \\
\text { Thomas } \\
\text { (and } \\
\text { Thomas } \\
\text { Dekker?) }\end{array}$ & $\begin{array}{l}\text { The } \\
\text { Family of } \\
\text { Love }\end{array}$ & $\begin{array}{l}1608 \\
\text { A } 1603\end{array}$ & Comedy & $\begin{array}{l}\text { Admiral's } \\
(?) \\
\text { (King's } \\
\text { Revels in } \\
1607 \text { ) }\end{array}$ & $\begin{array}{l}\text { STC } \\
17879\end{array}$ & $\begin{array}{l}26 \\
3\end{array}$ & $\begin{array}{l}\text { Prologue } \\
\text { and } \\
\text { epilogue }\end{array}$ \\
\hline $\begin{array}{l}16 \\
8 .\end{array}$ & $\begin{array}{l}\text { Anon. (T. } \\
\text { Dekker?) }\end{array}$ & $\begin{array}{l}\text { The Merry } \\
\text { Devil of } \\
\text { Edmonton }\end{array}$ & $\begin{array}{l}1608 \\
\text { A } 1602\end{array}$ & Comedy & $\begin{array}{l}\text { Chamberla } \\
\text { in's }\end{array}$ & $\begin{array}{l}\text { STC } \\
7493\end{array}$ & $\begin{array}{l}26 \\
4\end{array}$ & Prologue \\
\hline $\begin{array}{l}16 \\
9 .\end{array}$ & $\begin{array}{l}\text { Middleto } \\
\text { n, } \\
\text { Thomas }\end{array}$ & $\begin{array}{l}\text { Your Five } \\
\text { Gallants }\end{array}$ & $\begin{array}{l}1608 \\
\text { A } 1607\end{array}$ & Comedy & $\begin{array}{l}\text { Paul's } \\
\text { (S.R. : } \\
\text { Chapel) }\end{array}$ & $\begin{array}{l}\text { STC } \\
17907\end{array}$ & $\begin{array}{l}26 \\
6\end{array}$ & $\begin{array}{l}\text { Dumb } \\
\text { shows, } \\
\text { prologue }\end{array}$ \\
\hline $\begin{array}{l}17 \\
0 .\end{array}$ & $\begin{array}{l}\text { Day, John } \\
\text { (with }\end{array}$ & $\begin{array}{l}\text { Law } \\
\text { Tricks }\end{array}$ & 1608 & Comedy & $\begin{array}{l}\text { King's } \\
\text { Revels }\end{array}$ & $\begin{array}{l}\text { STC } \\
6416\end{array}$ & $\begin{array}{l}26 \\
7\end{array}$ & Epilogue \\
\hline
\end{tabular}




\begin{tabular}{|c|c|c|c|c|c|c|c|c|}
\hline & $\begin{array}{l}\text { Wilkins, } \\
\text { G ?) }\end{array}$ & & A 1604 & & & & & \\
\hline $\begin{array}{l}17 \\
1 .\end{array}$ & $\begin{array}{l}\text { Chapman, } \\
\text { George }\end{array}$ & $\begin{array}{l}\text { The } \\
\text { Conspirac } \\
\text { y of } \\
\text { Charles } \\
\text { Duke of } \\
\text { Byron }\end{array}$ & $\begin{array}{l}1608 \\
\text { A } 1608\end{array}$ & Tragedy & $\begin{array}{l}\text { Queen's } \\
\text { Revels }\end{array}$ & $\begin{array}{l}\text { STC } \\
4968\end{array}$ & $\begin{array}{l}27 \\
4\end{array}$ & Prologue \\
\hline $\begin{array}{l}17 \\
2 .\end{array}$ & $\begin{array}{l}\text { Greville, } \\
\text { Fulke }\end{array}$ & Mustapha & $\begin{array}{l}1609 \\
\text { A } 1596\end{array}$ & Tragedy & Closet & $\begin{array}{l}\text { STC } \\
12362\end{array}$ & $\begin{array}{l}27 \\
8\end{array}$ & Chorus \\
\hline $\begin{array}{l}17 \\
3 .\end{array}$ & $\begin{array}{l}\text { Anonymo } \\
\text { us }\end{array}$ & $\begin{array}{l}\text { Every } \\
\text { Woman in } \\
\text { her } \\
\text { Humour }\end{array}$ & $\begin{array}{l}1609 \\
\text { A } 1607\end{array}$ & Comedy & $\begin{array}{l}\text { King's } \\
\text { Revels (?) }\end{array}$ & $\begin{array}{l}\text { STC } \\
25948\end{array}$ & $\begin{array}{l}28 \\
3\end{array}$ & Prologue \\
\hline $\begin{array}{l}17 \\
4 .\end{array}$ & $\begin{array}{l}\text { Shakespe } \\
\text { are, } \\
\text { William }\end{array}$ & Pericles & $\begin{array}{l}1609 \\
\text { A } 1608\end{array}$ & $\begin{array}{l}\text { Tragicom } \\
\text { edy }\end{array}$ & King's & $\begin{array}{l}\text { STC } \\
22334\end{array}$ & $\begin{array}{l}28 \\
4\end{array}$ & $\begin{array}{l}\text { Chorus } \\
\text { (Gower) }\end{array}$ \\
\hline $\begin{array}{l}17 \\
5 .\end{array}$ & $\begin{array}{l}\text { Mason, } \\
\text { John }\end{array}$ & $\begin{array}{l}\text { The Turk } \\
\text { (Muleasse } \\
\text { es the } \\
\text { Turk) }\end{array}$ & $\begin{array}{l}1610 \\
\text { A } 1607\end{array}$ & Tragedy & $\begin{array}{l}\text { King's } \\
\text { Revels }\end{array}$ & $\begin{array}{l}\text { STC } \\
17617\end{array}$ & $\begin{array}{l}28 \\
6\end{array}$ & $\begin{array}{l}\text { Prologue } \\
\text { and } \\
\text { epilogue }\end{array}$ \\
\hline $\begin{array}{l}17 \\
6 .\end{array}$ & $\begin{array}{l}\text { Fletcher, } \\
\text { John }\end{array}$ & $\begin{array}{l}\text { The } \\
\text { Faithful } \\
\text { Shepherde } \\
\text { ss }\end{array}$ & 1608 & Pastoral & $\begin{array}{l}\text { Queen's } \\
\text { Revels? }\end{array}$ & $\begin{array}{l}\text { STC } \\
11070\end{array}$ & $\begin{array}{l}28 \\
7\end{array}$ & $\begin{array}{l}\text { Q 1634: } \\
\text { Prologue } \\
\text { in form of } \\
\text { a dialogue }\end{array}$ \\
\hline $\begin{array}{l}17 \\
7 .\end{array}$ & $\begin{array}{l}\text { Barry, } \\
\text { Lording }\end{array}$ & Ram Alley & $\begin{array}{l}1611 \\
\text { A1608 }\end{array}$ & Comedy & $\begin{array}{l}\text { King's } \\
\text { Revels }\end{array}$ & $\begin{array}{l}\text { STC } \\
1502\end{array}$ & $\begin{array}{l}29 \\
2\end{array}$ & $\begin{array}{l}\text { Prologue } \\
\text { and } \\
\text { epilogue }\end{array}$ \\
\hline $\begin{array}{l}17 \\
8 .\end{array}$ & $\begin{array}{l}\text { Heywood, } \\
\text { Thomas }\end{array}$ & $\begin{array}{l}\text { The } \\
\text { Golden } \\
\text { Age }\end{array}$ & $\begin{array}{l}1611 \\
\text { A } 1610\end{array}$ & $\begin{array}{l}\text { Classical } \\
\text { legend }\end{array}$ & $\begin{array}{l}\text { Queen's } \\
\text { Anne's }\end{array}$ & $\begin{array}{l}\text { STC } \\
13325\end{array}$ & $\begin{array}{l}29 \\
4\end{array}$ & $\begin{array}{l}\text { Chorus at } \\
\text { the end of } \\
\text { each act }\end{array}$ \\
\hline $\begin{array}{l}17 \\
9 .\end{array}$ & $\begin{array}{l}\text { Jonson, } \\
\text { Ben }\end{array}$ & $\begin{array}{l}\text { Catiline } \\
\text { his } \\
\text { Conspirac } \\
y\end{array}$ & $\begin{array}{l}1611 \\
\text { A } 1611\end{array}$ & Tragedy & King's & $\begin{array}{l}\text { STC } \\
14759\end{array}$ & $\begin{array}{l}29 \\
6\end{array}$ & $\begin{array}{l}\text { Chorus at } \\
\text { the end of } \\
\text { each act } \\
\text { except the } \\
\text { last one; } \\
\text { F } 1616 \\
\text { Chorus at } \\
\text { the end of } \\
\text { each act }\end{array}$ \\
\hline $\begin{array}{l}18 \\
0 .\end{array}$ & $\begin{array}{l}\text { Dekker, } \\
\text { Thomas, } \\
\text { Middleto } \\
\text { n, } \\
\text { Thomas }\end{array}$ & $\begin{array}{l}\text { The } \\
\text { Roaring } \\
\text { Girl }\end{array}$ & $\begin{array}{l}1611 \\
\text { A } 1611\end{array}$ & Comedy & $\begin{array}{l}\text { Prince } \\
\text { Henry's }\end{array}$ & $\begin{array}{l}\text { STC } \\
17908\end{array}$ & $\begin{array}{l}29 \\
8\end{array}$ & $\begin{array}{l}\text { Prologue } \\
\text { and } \\
\text { epilogue }\end{array}$ \\
\hline $\begin{array}{l}18 \\
1 .\end{array}$ & $\begin{array}{l}\text { Daborne, } \\
\text { Robert }\end{array}$ & $\begin{array}{l}\text { A } \\
\text { Christian }\end{array}$ & $\begin{array}{l}1612 \\
\text { A } 1610\end{array}$ & Tragedy & $\begin{array}{l}\text { King's (?), } \\
\text { Queen's } \\
\text { Revels (?) }\end{array}$ & $\begin{array}{l}\text { STC } \\
6184\end{array}$ & $\begin{array}{l}30 \\
0\end{array}$ & $\begin{array}{l}\text { Prologue } \\
\text { and } \\
\text { epilogue, }\end{array}$ \\
\hline
\end{tabular}




\begin{tabular}{|c|c|c|c|c|c|c|c|c|}
\hline & & $\begin{array}{l}\text { Turned } \\
\text { Turk }\end{array}$ & & & & & & $\begin{array}{l}\text { dumb } \\
\text { show }\end{array}$ \\
\hline $\begin{array}{l}18 \\
2 .\end{array}$ & $\begin{array}{l}\text { Jonson, } \\
\text { Ben }\end{array}$ & $\begin{array}{l}\text { The } \\
\text { Alchemist }\end{array}$ & $\begin{array}{l}1612 \\
\text { A } 1610\end{array}$ & Comedy & King's & $\begin{array}{l}\text { STC } \\
14755\end{array}$ & $\begin{array}{l}30 \\
3\end{array}$ & Prologue \\
\hline $\begin{array}{l}18 \\
3 .\end{array}$ & $\begin{array}{l}\text { Jonson, } \\
\text { Ben }\end{array}$ & Epicoene & $\begin{array}{l}1612 \\
\text { A } 1609\end{array}$ & Comedy & $\begin{array}{l}\text { Queen's } \\
\text { Revels }\end{array}$ & $\begin{array}{l}\text { STC } \\
14761\end{array}$ & $\begin{array}{l}30 \\
4\end{array}$ & $\begin{array}{l}\text { Two } \\
\text { prologues }\end{array}$ \\
\hline $\begin{array}{l}18 \\
4 .\end{array}$ & $\begin{array}{l}\text { Dekker, } \\
\text { Thomas }\end{array}$ & $\begin{array}{l}\text { If This Be } \\
\text { Not a } \\
\text { Good } \\
\text { Play, the } \\
\text { Devil Is in } \\
\text { It }\end{array}$ & $\begin{array}{l}1612 \\
\text { A } 1611\end{array}$ & Comedy & $\begin{array}{l}\text { Queen } \\
\text { Anne's }\end{array}$ & $\begin{array}{l}\text { STC } \\
6507\end{array}$ & $\begin{array}{l}30 \\
5\end{array}$ & $\begin{array}{l}\text { Induction } \\
\text { and } \\
\text { conclusion } \\
\text {, prologue } \\
\text { and } \\
\text { epilogue }\end{array}$ \\
\hline $\begin{array}{l}18 \\
5 .\end{array}$ & $\begin{array}{l}\text { Carey, } \\
\text { Elizabeth }\end{array}$ & Mariam & $\begin{array}{l}1613 \\
\text { A } 1604\end{array}$ & Tragedy & Closet & $\begin{array}{l}\text { STC } \\
4613\end{array}$ & $\begin{array}{l}30 \\
8\end{array}$ & $\begin{array}{l}\text { Chorus at } \\
\text { the end of } \\
\text { each act }\end{array}$ \\
\hline $\begin{array}{l}18 \\
6 .\end{array}$ & $\begin{array}{l}\text { Heywood, } \\
\text { Thomas }\end{array}$ & $\begin{array}{l}\text { The } \\
\text { Brazen } \\
\text { Age }\end{array}$ & $\begin{array}{l}1613 \\
\text { A } 1611\end{array}$ & $\begin{array}{l}\text { Classical } \\
\text { Legend }\end{array}$ & $\begin{array}{l}\text { Queen's } \\
\text { and King's }\end{array}$ & $\begin{array}{l}\text { STC } \\
13310\end{array}$ & $\begin{array}{l}31 \\
3\end{array}$ & $\begin{array}{l}\text { Prologue } \\
\text { and } \\
\text { epilogue }\end{array}$ \\
\hline $\begin{array}{l}18 \\
7 .\end{array}$ & $\begin{array}{l}\text { Beaumont } \\
\text {, Francis }\end{array}$ & $\begin{array}{l}\text { The } \\
\text { Knight of } \\
\text { the } \\
\text { Burning } \\
\text { Pestle }\end{array}$ & $\begin{array}{l}1613 \\
\text { A } 1607\end{array}$ & $\begin{array}{l}\text { Burlesqu } \\
\text { e } \\
\text { romance }\end{array}$ & $\begin{array}{l}\text { Queen's } \\
\text { Revels }\end{array}$ & $\begin{array}{l}\text { STC } \\
1674\end{array}$ & $\begin{array}{l}31 \\
6\end{array}$ & $\begin{array}{l}\text { Induction } \\
\text { and } \\
\text { epilogue } \\
\text { in form of } \\
\text { a dialogue }\end{array}$ \\
\hline $\begin{array}{l}18 \\
8 .\end{array}$ & $\begin{array}{l}\text { Heywood, } \\
\text { Thomas }\end{array}$ & $\begin{array}{l}\text { The Silver } \\
\text { Age }\end{array}$ & $\begin{array}{l}1613 \\
\text { A } 1611\end{array}$ & $\begin{array}{l}\text { Classical } \\
\text { Legend }\end{array}$ & $\begin{array}{l}\text { Queen's } \\
\text { and King's }\end{array}$ & $\begin{array}{l}\text { STC } \\
23248\end{array}$ & $\begin{array}{l}31 \\
7\end{array}$ & $\begin{array}{l}\text { Chorus, } \\
\text { dumb } \\
\text { show }\end{array}$ \\
\hline $\begin{array}{l}18 \\
9 .\end{array}$ & $\begin{array}{l}\text { Tailor, } \\
\text { Robert }\end{array}$ & $\begin{array}{l}\text { The Hog } \\
\text { hath Lost } \\
\text { his Pearl }\end{array}$ & $\begin{array}{l}1614 \\
\text { A } 1613\end{array}$ & Comedy & $\begin{array}{l}\text { Whitefriar } \\
\mathrm{s}\end{array}$ & $\begin{array}{l}\text { STC } \\
23658\end{array}$ & $\begin{array}{l}32 \\
1\end{array}$ & $\begin{array}{l}\text { Prologue } \\
\text { and } \\
\text { epilogue }\end{array}$ \\
\hline $\begin{array}{l}19 \\
0 .\end{array}$ & $\begin{array}{l}\text { Daniel, } \\
\text { Samuel }\end{array}$ & $\begin{array}{l}\text { Hymen's } \\
\text { Triumph }\end{array}$ & $\begin{array}{l}1615 \\
\text { A } 1614\end{array}$ & $\begin{array}{l}\text { Pastoral } \\
\text { court }\end{array}$ & Unknown. & $\begin{array}{l}\text { STC } \\
6257\end{array}$ & $\begin{array}{l}32 \\
5\end{array}$ & $\begin{array}{l}\text { Prologue } \\
\text { in form of } \\
\text { a dialogue }\end{array}$ \\
\hline $\begin{array}{l}19 \\
1 .\end{array}$ & $\begin{array}{l}\text { R. A. } \\
\text { (Robert } \\
\text { Armin? } \\
\text { Robert } \\
\text { Anton?) }\end{array}$ & $\begin{array}{l}\text { The } \\
\text { Valiant } \\
\text { Welshman }\end{array}$ & $\begin{array}{l}1615 \\
\text { A } 1612\end{array}$ & History & $\begin{array}{l}\text { Prince's } \\
\text { Men }\end{array}$ & $\begin{array}{l}\text { STC } \\
16\end{array}$ & $\begin{array}{l}32 \\
7\end{array}$ & Epilogue \\
\hline $\begin{array}{l}19 \\
2 .\end{array}$ & $\begin{array}{l}\text { Tomkins, } \\
\text { Thomas }\end{array}$ & Albumazar & $\begin{array}{l}1614 \\
\text { A } 1615\end{array}$ & Comedy & $\begin{array}{l}\text { Trinity } \\
\text { College } \\
\text { Cambridg } \\
\text { e }\end{array}$ & $\begin{array}{l}\text { STC } \\
24100\end{array}$ & $\begin{array}{l}33 \\
0\end{array}$ & $\begin{array}{l}\text { Prologue } \\
\text { and } \\
\text { epilogue }\end{array}$ \\
\hline $\begin{array}{l}19 \\
3 .\end{array}$ & $\begin{array}{l}\text { Heywood, } \\
\text { Thomas }\end{array}$ & $\begin{array}{l}\text { The Four } \\
\text { Prentices } \\
\text { of London }\end{array}$ & $\begin{array}{l}1615 \\
\text { A } 1594\end{array}$ & $\begin{array}{l}\text { Heroical } \\
\text { romance }\end{array}$ & Admiral's & $\begin{array}{l}\text { STC } \\
13321\end{array}$ & $\begin{array}{l}33 \\
3\end{array}$ & $\begin{array}{l}\text { Induction } \\
\text { (headed } \\
\text { "The } \\
\text { prologues } \\
\text { ") among }\end{array}$ \\
\hline
\end{tabular}




\begin{tabular}{|c|c|c|c|c|c|c|c|c|}
\hline & & & & & & & & $\begin{array}{l}\text { three } \\
\text { prologues }\end{array}$ \\
\hline $\begin{array}{l}19 \\
4 .\end{array}$ & S.S. & $\begin{array}{l}\text { The } \\
\text { Honest } \\
\text { Lawyer }\end{array}$ & $\begin{array}{l}1616 \\
\text { A } 1615\end{array}$ & Comedy & $\begin{array}{l}\text { Queen's } \\
\text { Anne's }\end{array}$ & $\begin{array}{l}\text { STC } \\
21519\end{array}$ & $\begin{array}{l}33 \\
7\end{array}$ & Epilogue \\
\hline $\begin{array}{l}19 \\
5 .\end{array}$ & $\begin{array}{l}\text { Holyday, } \\
\text { Barten }\end{array}$ & $\begin{array}{l}\text { Technoga } \\
\text { mia, or } \\
\text { The } \\
\text { Marriages } \\
\text { of the Arts }\end{array}$ & $\begin{array}{l}1618 \\
\text { A } 1618\end{array}$ & Moral & $\begin{array}{l}\text { Christ } \\
\text { Church, } \\
\text { Oxford }\end{array}$ & $\begin{array}{l}\text { STC } \\
13717\end{array}$ & $\begin{array}{l}35 \\
3\end{array}$ & $\begin{array}{l}\text { Prologue } \\
\text { and } \\
\text { epilogue }\end{array}$ \\
\hline $\begin{array}{l}19 \\
6 .\end{array}$ & $\begin{array}{l}\text { Belchier, } \\
\text { Daubridg } \\
\text { court }\end{array}$ & $\begin{array}{l}\text { Hans } \\
\text { Beer-Pot } \\
\text { (See me } \\
\text { and see me } \\
\text { not) }\end{array}$ & $\begin{array}{l}1618 \\
\text { A } 1618\end{array}$ & Dialogue & $\begin{array}{l}\text { Not } \\
\text { performed } \\
(?)\end{array}$ & $\begin{array}{l}\text { STC } \\
1803\end{array}$ & $\begin{array}{l}35 \\
4\end{array}$ & Prologue \\
\hline $\begin{array}{l}19 \\
7 .\end{array}$ & $\begin{array}{l}\text { Anonymo } \\
\text { us }\end{array}$ & $\begin{array}{l}\text { Two Wise } \\
\text { Men and } \\
\text { all the } \\
\text { Rest Fools }\end{array}$ & $\begin{array}{l}1619 \\
\text { A } 1619\end{array}$ & $\begin{array}{l}\text { Dialogue } \\
\mathrm{s}\end{array}$ & $\begin{array}{l}\text { Privately } \\
\text { acted (?) }\end{array}$ & $\begin{array}{l}\text { STC } \\
4991\end{array}$ & $\begin{array}{l}36 \\
1\end{array}$ & $\begin{array}{l}\text { Prologue, } \\
\text { two } \\
\text { epilogues }\end{array}$ \\
\hline $\begin{array}{l}19 \\
8 .\end{array}$ & $\begin{array}{l}\text { Anonymo } \\
\text { us }\end{array}$ & $\begin{array}{l}\text { Swetnam } \\
\text { Arraigned } \\
\text { by Women }\end{array}$ & $\begin{array}{l}1620 \\
\text { A } 1618\end{array}$ & Comedy & $\begin{array}{l}\text { Queen's } \\
\text { Anne's }\end{array}$ & $\begin{array}{l}\text { STC } \\
23544\end{array}$ & $\begin{array}{l}36 \\
2\end{array}$ & $\begin{array}{l}\text { Prologue } \\
\text { and } \\
\text { epilogue }\end{array}$ \\
\hline $\begin{array}{l}19 \\
9 .\end{array}$ & $\begin{array}{l}\text { Cumber, } \\
\text { John? (or } \\
\text { Cobbes, } \\
\text { James?) }\end{array}$ & $\begin{array}{l}\text { The Two } \\
\text { Merry } \\
\text { Milkmaids } \\
\text { or The } \\
\text { Best } \\
\text { Words } \\
\text { Wear the } \\
\text { Garland }\end{array}$ & $\begin{array}{l}1620 \\
\text { A } 1619\end{array}$ & Comedy & $\begin{array}{l}\text { Red Bull } \\
\text { Company } \\
\text { (Revels) }\end{array}$ & $\begin{array}{l}\text { STC } \\
4281\end{array}$ & $\begin{array}{l}36 \\
4\end{array}$ & Prologue \\
\hline $\begin{array}{l}20 \\
0 .\end{array}$ & $\begin{array}{l}\text { Middleto } \\
\mathrm{n} \text {, } \\
\text { Thomas } \\
\text { Rowley, } \\
\text { William }\end{array}$ & $\begin{array}{l}\text { The World } \\
\text { tossed at } \\
\text { tennis }\end{array}$ & $\begin{array}{l}1620 \\
\text { A } 1620\end{array}$ & Masque & $\begin{array}{l}\text { Prince's } \\
\text { men }\end{array}$ & $\begin{array}{l}\text { STC } \\
17909\end{array}$ & $\begin{array}{l}36 \\
5\end{array}$ & $\begin{array}{l}\text { Induction } \\
\text { and } \\
\text { prologue, } \\
\text { epilogue, } \\
\text { masque }\end{array}$ \\
\hline $\begin{array}{l}20 \\
1 .\end{array}$ & $\begin{array}{l}\text { Markham, } \\
\text { G., } \\
\text { Sampson, } \\
\text { W. }\end{array}$ & $\begin{array}{l}\text { Herod and } \\
\text { Antipater }\end{array}$ & $\begin{array}{l}1622 \\
\text { A } 1622\end{array}$ & Tragedy & $\begin{array}{l}\text { Red Bull } \\
\text { Company } \\
\text { (Revels) }\end{array}$ & $\begin{array}{l}\text { STC } \\
17401\end{array}$ & $\begin{array}{l}38 \\
2\end{array}$ & $\begin{array}{l}\text { Prologue } \\
\text { and } \\
\text { epilogue }\end{array}$ \\
\hline $\begin{array}{l}20 \\
2 .\end{array}$ & $\begin{array}{l}\text { May, } \\
\text { Thomas }\end{array}$ & The Heir & $\begin{array}{l}1622 \\
\text { A } 1620\end{array}$ & Comedy & $\begin{array}{l}\text { Red Bull } \\
\text { Company } \\
\text { (Revels) }\end{array}$ & $\begin{array}{l}\text { STC } \\
17713\end{array}$ & $\begin{array}{l}38 \\
4\end{array}$ & $\begin{array}{l}\text { Prologue } \\
\text { and } \\
\text { epilogue }\end{array}$ \\
\hline $\begin{array}{l}20 \\
3 .\end{array}$ & $\begin{array}{l}\text { Shakespe } \\
\text { are, } \\
\text { William }\end{array}$ & $\begin{array}{l}\text { The } \\
\text { Tempest }\end{array}$ & $\begin{array}{l}1623 \\
\text { collecti } \\
\text { on } \\
\text { A } 1611\end{array}$ & Comedy & King's & $\begin{array}{l}\text { STC } \\
22273\end{array}$ & $\begin{array}{l}39 \\
0\end{array}$ & Epilogue \\
\hline
\end{tabular}




\begin{tabular}{|c|c|c|c|c|c|c|c|c|}
\hline $\begin{array}{l}20 \\
4 .\end{array}$ & $\begin{array}{l}\text { Shakespe } \\
\text { are, } \\
\text { William }\end{array}$ & Henry VIII & $\begin{array}{l}1623 \\
\text { collecti } \\
\text { on } \\
\text { A } 1613\end{array}$ & History & King's & $\begin{array}{l}\text { STC } \\
22272\end{array}$ & $\begin{array}{l}40 \\
0\end{array}$ & $\begin{array}{l}\text { Prologue } \\
\text { and } \\
\text { epilogue }\end{array}$ \\
\hline $\begin{array}{l}20 \\
5 .\end{array}$ & $\begin{array}{l}\text { Middleto } \\
\text { n, } \\
\text { Thomas }\end{array}$ & $\begin{array}{l}\text { A Game at } \\
\text { Chess }\end{array}$ & $\begin{array}{l}1625 \\
\text { A } 1624\end{array}$ & $\begin{array}{l}\text { Political } \\
\text { satire }\end{array}$ & King's & $\begin{array}{l}\text { STC } \\
17882\end{array}$ & $\begin{array}{l}41 \\
2\end{array}$ & $\begin{array}{l}\text { Induction, } \\
\text { prologue } \\
\text { and } \\
\text { epilogue }\end{array}$ \\
\hline $\begin{array}{l}20 \\
6 .\end{array}$ & $\begin{array}{l}\text { Hawkins, } \\
\text { W. }\end{array}$ & $\begin{array}{l}\text { Apollo } \\
\text { Shroving }\end{array}$ & $\begin{array}{l}1627 \\
\text { A } 1627\end{array}$ & Comedy & $\begin{array}{l}\text { Hadleigh } \\
\text { School, } \\
\text { Suffolk }\end{array}$ & $\begin{array}{l}\text { STC } \\
12963\end{array}$ & $\begin{array}{l}41 \\
4\end{array}$ & $\begin{array}{l}\text { Introducti } \\
\text { on , } \\
\text { prologue } \\
\text { and } \\
\text { epilogue }\end{array}$ \\
\hline $\begin{array}{l}20 \\
7 .\end{array}$ & $\begin{array}{l}\text { Newman, } \\
\text { Thomas }\end{array}$ & $\begin{array}{l}\text { The } \\
\text { Andrian } \\
\text { Woman }\end{array}$ & $\begin{array}{l}1627 \\
\text { A } 1627\end{array}$ & Comedy & $\begin{array}{l}\text { For acting } \\
\text { in schools }\end{array}$ & $\begin{array}{l}\text { STC } \\
23897\end{array}$ & $\begin{array}{l}41 \\
5\end{array}$ & $\begin{array}{l}\text { Prologue } \\
\text { and } \\
\text { epilogue }\end{array}$ \\
\hline $\begin{array}{l}20 \\
8 .\end{array}$ & $\begin{array}{l}\text { Newman, } \\
\text { Thomas }\end{array}$ & $\begin{array}{l}\text { The } \\
\text { Eunuch }\end{array}$ & $\begin{array}{l}1627 \\
\text { collecti } \\
\text { on } \\
\text { A } 1627\end{array}$ & Comedy & $\begin{array}{l}\text { For acting } \\
\text { in schools }\end{array}$ & $\begin{array}{l}\text { STC } \\
23897\end{array}$ & $\begin{array}{l}41 \\
6\end{array}$ & $\begin{array}{l}\text { Prologue } \\
\text { and } \\
\text { epilogue }\end{array}$ \\
\hline $\begin{array}{l}20 \\
9 .\end{array}$ & $\begin{array}{l}\text { Reynolds, } \\
\text { Henry }\end{array}$ & Aminta & $\begin{array}{l}1628 \\
\text { A } 1628\end{array}$ & Pastoral & Closet & $\begin{array}{l}\text { STC } \\
23696\end{array}$ & $\begin{array}{l}41 \\
7\end{array}$ & $\begin{array}{l}\text { Chorus at } \\
\text { the end of } \\
\text { each act, } \\
\text { prologue } \\
\text { and } \\
\text { epilogue }\end{array}$ \\
\hline $\begin{array}{l}21 \\
0 .\end{array}$ & $\begin{array}{l}\text { Gomersal } \\
\text { 1, Robert }\end{array}$ & $\begin{array}{l}\text { Lodovick } \\
\text { Sforza }\end{array}$ & $\begin{array}{l}1628 \\
\text { A } 1628\end{array}$ & Tragedy & $\begin{array}{l}\text { Not } \\
\text { performed }\end{array}$ & $\begin{array}{l}\text { STC } \\
11995\end{array}$ & $\begin{array}{l}41 \\
8\end{array}$ & $\begin{array}{l}\text { Prologue } \\
\text { and } \\
\text { epilogue }\end{array}$ \\
\hline $\begin{array}{l}21 \\
1 .\end{array}$ & $\begin{array}{l}\text { Ford, } \\
\text { John }\end{array}$ & $\begin{array}{l}\text { The } \\
\text { Lover's } \\
\text { Melanchol } \\
y\end{array}$ & $\begin{array}{l}1629 \\
\text { A } 1628\end{array}$ & $\begin{array}{l}\text { Tragicom } \\
\text { edy }\end{array}$ & King's & $\begin{array}{l}\text { STC } \\
11163\end{array}$ & $\begin{array}{l}42 \\
0\end{array}$ & $\begin{array}{l}\text { Prologue } \\
\text { and } \\
\text { epilogue }\end{array}$ \\
\hline $\begin{array}{l}21 \\
2 .\end{array}$ & $\begin{array}{l}\text { Carlell, } \\
\text { Lodowick }\end{array}$ & $\begin{array}{l}\text { The } \\
\text { Deserving } \\
\text { Favourite }\end{array}$ & $\begin{array}{l}1629 \\
\text { A } 1629\end{array}$ & Comedy & $\begin{array}{l}\text { For acting } \\
\text { in schools }\end{array}$ & $\begin{array}{l}\text { STC } \\
4628\end{array}$ & $\begin{array}{l}42 \\
3\end{array}$ & $\begin{array}{l}\text { Prologue } \\
\text { and } \\
\text { epilogue }\end{array}$ \\
\hline $\begin{array}{l}21 \\
3 .\end{array}$ & $\begin{array}{l}\text { Shirley, } \\
\text { James }\end{array}$ & $\begin{array}{l}\text { The } \\
\text { Wedding }\end{array}$ & $\begin{array}{l}1629 \\
\text { A } 1626\end{array}$ & Comedy & $\begin{array}{l}\text { Queen } \\
\text { Henrietta' } \\
\text { s }\end{array}$ & $\begin{array}{l}\text { STC } \\
22460\end{array}$ & $\begin{array}{l}42 \\
5\end{array}$ & Epilogue \\
\hline $\begin{array}{l}21 \\
4 .\end{array}$ & $\begin{array}{l}\text { Randolph, } \\
\text { Thomas }\end{array}$ & $\begin{array}{l}\text { Aristippus, } \\
\text { or the } \\
\text { Jovial } \\
\text { Philosoph } \\
\text { er }\end{array}$ & $\begin{array}{l}1630 \\
\text { A } 1626\end{array}$ & $\begin{array}{l}\text { Comic } \\
\text { show } \\
\text { Comedy }\end{array}$ & $\begin{array}{l}\text { Trinity } \\
\text { College, } \\
\text { Cambridg } \\
\text { e }\end{array}$ & $\begin{array}{l}\text { STC } \\
20686\end{array}$ & $\begin{array}{l}43 \\
1\end{array}$ & $\begin{array}{l}\text { Praeludiu } \\
\text { m }\end{array}$ \\
\hline
\end{tabular}




\begin{tabular}{|c|c|c|c|c|c|c|c|c|}
\hline $\begin{array}{l}21 \\
5 .\end{array}$ & $\begin{array}{l}\text { Shirley, } \\
\text { James }\end{array}$ & $\begin{array}{l}\text { School of } \\
\text { complimen } \\
t \text { (Love } \\
\text { Tricks) }\end{array}$ & $\begin{array}{l}1631 \\
\text { A } 1625\end{array}$ & Comedy & $\begin{array}{l}\text { Lady } \\
\text { Elizabeth' } \\
\text { S }\end{array}$ & $\begin{array}{l}\text { STC } \\
22456\end{array}$ & $\begin{array}{l}44 \\
1\end{array}$ & $\begin{array}{l}\text { Prologue, } \\
\text { conclusion } \\
\text {, epilogue }\end{array}$ \\
\hline $\begin{array}{l}21 \\
6 .\end{array}$ & $\begin{array}{l}\text { Jonson, } \\
\text { Ben }\end{array}$ & $\begin{array}{l}\text { The New } \\
\text { Inn }\end{array}$ & $\begin{array}{l}1631 \\
\text { A } 1629\end{array}$ & Comedy & King's & $\begin{array}{l}\text { STC } \\
14780\end{array}$ & $\begin{array}{l}44 \\
2\end{array}$ & $\begin{array}{l}\text { Prologue, } \\
\text { two } \\
\text { epilogues }\end{array}$ \\
\hline $\begin{array}{l}21 \\
7 .\end{array}$ & $\begin{array}{l}\text { Fletcher, } \\
\text { Phineas }\end{array}$ & Sicelides & $\begin{array}{l}1631 \\
\text { A } 1615\end{array}$ & Piscatory & $\begin{array}{l}\text { King's } \\
\text { College, } \\
\text { Cambridg } \\
\text { e }\end{array}$ & $\begin{array}{l}\text { STC } \\
11083\end{array}$ & $\begin{array}{l}44 \\
3\end{array}$ & $\begin{array}{l}\text { Chorus at } \\
\text { the end of } \\
\text { each act } \\
\text { except the } \\
\text { first, } \\
\text { prologue } \\
\text { and } \\
\text { epilogue }\end{array}$ \\
\hline $\begin{array}{l}21 \\
8 .\end{array}$ & $\begin{array}{l}\text { Heywood, } \\
\text { Thomas }\end{array}$ & $\begin{array}{l}1 \text { The Fair } \\
\text { Maid of } \\
\text { West }\end{array}$ & $\begin{array}{l}1631 \\
\text { A } 1604\end{array}$ & Comedy & $\begin{array}{l}\text { Anne's } \\
\text { (Queen } \\
\text { Henrietta' } \\
\text { s in 1631) }\end{array}$ & $\begin{array}{l}\text { STC } \\
13320\end{array}$ & $\begin{array}{l}44 \\
5\end{array}$ & Prologue \\
\hline $\begin{array}{l}21 \\
9 .\end{array}$ & $\begin{array}{l}\text { Heywood, } \\
\text { Thomas }\end{array}$ & $\begin{array}{l}2 \text { The Fair } \\
\text { Maid of } \\
\text { West }\end{array}$ & $\begin{array}{l}1631 \\
\text { A } 1631\end{array}$ & Comedy & $\begin{array}{l}\text { Queen } \\
\text { Henrietta' } \\
\text { s }\end{array}$ & $\begin{array}{l}\text { STC } \\
13320\end{array}$ & $\begin{array}{l}44 \\
6\end{array}$ & $\begin{array}{l}\text { Chorus at } \\
\text { the end of } \\
\text { each act } \\
\text { except the } \\
\text { first, } \\
\text { dumb } \\
\text { show at } \\
\text { the end of } \\
\text { act } 3 \text {, } \\
\text { epilogue }\end{array}$ \\
\hline $\begin{array}{l}22 \\
0 .\end{array}$ & $\begin{array}{l}\text { Knevet, } \\
\text { Ralph }\end{array}$ & $\begin{array}{l}\text { Rhodon } \\
\text { and Iris }\end{array}$ & $\begin{array}{l}1631 \\
\text { A } 1631\end{array}$ & Pastoral & $\begin{array}{l}\text { Florists' } \\
\text { Feast, } \\
\text { Norwich }\end{array}$ & $\begin{array}{l}\text { STC } \\
15036\end{array}$ & $\begin{array}{l}44 \\
9\end{array}$ & $\begin{array}{l}\text { Prologue } \\
\text { and } \\
\text { epilogue }\end{array}$ \\
\hline $\begin{array}{l}22 \\
1 .\end{array}$ & $\begin{array}{l}\text { Jonson, } \\
\text { Ben }\end{array}$ & $\begin{array}{l}\text { Bartholom } \\
\text { ew Fair }\end{array}$ & $\begin{array}{l}1631 \\
\text { A } \\
1614\end{array}$ & Comedy & $\begin{array}{l}\text { Lady's } \\
\text { Elizabeth' } \\
\text { s }\end{array}$ & $\begin{array}{l}\text { STC } \\
14753- \\
5\end{array}$ & $\begin{array}{l}45 \\
5\end{array}$ & $\begin{array}{l}\text { Induction, } \\
\text { puppet } \\
\text { show }\end{array}$ \\
\hline $\begin{array}{l}22 \\
2 .\end{array}$ & $\begin{array}{l}\text { Jonson, } \\
\text { Ben }\end{array}$ & $\begin{array}{l}\text { The Staple } \\
\text { of News }\end{array}$ & 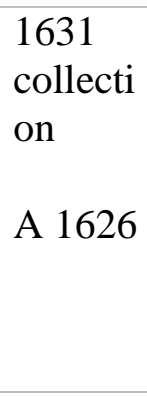 & Comedy & King's & $\begin{array}{l}\text { STC } \\
14753- \\
5\end{array}$ & $\begin{array}{l}45 \\
6\end{array}$ & $\begin{array}{l}\text { Induction, } \\
\text { prologue } \\
\text { for the } \\
\text { theatre, } \\
\text { prologue } \\
\text { for the } \\
\text { court, } \\
\text { epilogue }\end{array}$ \\
\hline $\begin{array}{l}22 \\
3 .\end{array}$ & $\begin{array}{l}\text { Jonson, } \\
\text { Ben }\end{array}$ & $\begin{array}{l}\text { The Devil } \\
\text { Is an Ass }\end{array}$ & $\begin{array}{l}1631 \\
\text { collecti } \\
\text { on } \\
\text { A } 1616\end{array}$ & Comedy & King's & $\begin{array}{l}\text { STC } \\
14753- \\
5\end{array}$ & $\begin{array}{l}45 \\
7\end{array}$ & $\begin{array}{l}\text { Prologue } \\
\text { and } \\
\text { epilogue }\end{array}$ \\
\hline
\end{tabular}




\begin{tabular}{|c|c|c|c|c|c|c|c|c|}
\hline $\begin{array}{l}22 \\
4 .\end{array}$ & $\begin{array}{l}\text { Goffe, } \\
\text { Thomas }\end{array}$ & $\begin{array}{l}\text { The } \\
\text { Courageo } \\
\text { us Turk }\end{array}$ & $\begin{array}{l}1632 \\
\text { A } 1619\end{array}$ & Tragedy & $\begin{array}{l}\text { Christ } \\
\text { Church, } \\
\text { Oxford }\end{array}$ & $\begin{array}{l}\text { STC } \\
11977\end{array}$ & $\begin{array}{l}45 \\
8\end{array}$ & Prologue \\
\hline $\begin{array}{l}22 \\
5 .\end{array}$ & $\begin{array}{l}\text { Massinge } \\
\text { r, Philip }\end{array}$ & $\begin{array}{l}\text { The } \\
\text { Emperor } \\
\text { of the East }\end{array}$ & $\begin{array}{l}1632 \\
\text { A } 1631\end{array}$ & $\begin{array}{l}\text { Tragicom } \\
\text { edy }\end{array}$ & King's & $\begin{array}{l}\text { STC } \\
17636\end{array}$ & $\begin{array}{l}45 \\
9\end{array}$ & $\begin{array}{l}\text { Two } \\
\text { prologues } \\
\text { and an } \\
\text { epilogue }\end{array}$ \\
\hline $\begin{array}{l}22 \\
6 .\end{array}$ & $\begin{array}{l}\text { Marmion, } \\
\text { Shakerly }\end{array}$ & $\begin{array}{l}\text { Holland's } \\
\text { Leaguer }\end{array}$ & $\begin{array}{l}1632 \\
\text { A } 1631\end{array}$ & Comedy & $\begin{array}{l}\text { Prince's } \\
\text { Charles }\end{array}$ & $\begin{array}{l}\text { STC } \\
17443\end{array}$ & $\begin{array}{l}46 \\
1\end{array}$ & Prologue \\
\hline $\begin{array}{l}22 \\
7 .\end{array}$ & $\begin{array}{l}\text { Shirley, } \\
\text { James }\end{array}$ & $\begin{array}{l}\text { Changes, } \\
\text { or Love in } \\
\text { a Maze }\end{array}$ & $\begin{array}{l}1632 \\
\text { A } 1632\end{array}$ & Comedy & $\begin{array}{l}\text { King's } \\
\text { Revels } \\
\text { (Prince } \\
\text { Charles's? } \\
\text { ) }\end{array}$ & STC & $\begin{array}{l}46 \\
2\end{array}$ & $\begin{array}{l}\text { Prologue } \\
\text { and } \\
\text { epilogue }\end{array}$ \\
\hline $\begin{array}{l}22 \\
8 .\end{array}$ & $\begin{array}{l}\text { Brome, } \\
\text { Richard }\end{array}$ & $\begin{array}{l}\text { The } \\
\text { Northern } \\
\text { Lass }\end{array}$ & $\begin{array}{l}1632 \\
\text { A } 1629\end{array}$ & Comedy & King's & $\begin{array}{l}\text { STC } \\
3819\end{array}$ & $\begin{array}{l}46 \\
3\end{array}$ & Prologue \\
\hline $\begin{array}{l}22 \\
9 .\end{array}$ & $\begin{array}{l}\text { Hausted, } \\
\text { Peter }\end{array}$ & $\begin{array}{l}\text { The Rival } \\
\text { Friends }\end{array}$ & $\begin{array}{l}1632 \\
\text { A } 1632\end{array}$ & $\begin{array}{l}\text { Tragicom } \\
\text { edy }\end{array}$ & $\begin{array}{l}\text { Queen's } \\
\text { College, } \\
\text { Cambridg } \\
\text { e }\end{array}$ & $\begin{array}{l}\text { STC } \\
12935\end{array}$ & $\begin{array}{l}46 \\
5\end{array}$ & $\begin{array}{l}\text { Introducti } \\
\text { on, } \\
\text { prologue } \\
\text { and } \\
\text { epilogue }\end{array}$ \\
\hline $\begin{array}{l}23 \\
0 .\end{array}$ & $\begin{array}{l}\text { Heywood, } \\
\text { Thomas }\end{array}$ & $\begin{array}{l}1 \text { The Iron } \\
\text { Age }\end{array}$ & $\begin{array}{l}1632 \\
\text { A } 1612\end{array}$ & $\begin{array}{l}\text { Classical } \\
\text { Legend }\end{array}$ & $\begin{array}{l}\text { Queen's } \\
\text { (and } \\
\text { King's?) }\end{array}$ & $\begin{array}{l}\text { STC } \\
13340\end{array}$ & $\begin{array}{l}46 \\
7\end{array}$ & Epilogue \\
\hline $\begin{array}{l}23 \\
1 .\end{array}$ & $\begin{array}{l}\text { Randolph, } \\
\text { Thomas }\end{array}$ & $\begin{array}{l}\text { The } \\
\text { Jealous } \\
\text { Lovers }\end{array}$ & $\begin{array}{l}1632 \\
\text { A } 1632\end{array}$ & Comedy & $\begin{array}{l}\text { Trinity } \\
\text { College, } \\
\text { Cambridg } \\
\text { e }\end{array}$ & $\begin{array}{l}\text { STC } \\
20692\end{array}$ & $\begin{array}{l}46 \\
9\end{array}$ & $\begin{array}{l}\text { Epilogue } \\
\text { in form of } \\
\text { a dialogue }\end{array}$ \\
\hline $\begin{array}{l}23 \\
2 .\end{array}$ & $\begin{array}{l}\text { Rowley, } \\
\text { William }\end{array}$ & $\begin{array}{l}\text { All's Lost } \\
\text { by Lust }\end{array}$ & $\begin{array}{l}1633 \\
\text { A } 1619\end{array}$ & Tragedy & $\begin{array}{l}\text { Prince's } \\
\text { (poi Lady } \\
\text { Elizabeth' } \\
\text { s) }\end{array}$ & $\begin{array}{l}\text { STC } \\
21425\end{array}$ & $\begin{array}{l}47 \\
1\end{array}$ & Prologue \\
\hline $\begin{array}{l}23 \\
3 .\end{array}$ & $\begin{array}{l}\text { Anonymo } \\
\text { us }\end{array}$ & $\begin{array}{l}\text { The Costly } \\
\text { Whire }\end{array}$ & $\begin{array}{l}1633 \\
\text { A } 1620\end{array}$ & $\begin{array}{l}\text { Pseudo- } \\
\text { history }\end{array}$ & $\begin{array}{l}\text { Red Bull } \\
\text { Company } \\
\text { (Revels) } \\
\text { (?), King's } \\
\text { Revels (?) }\end{array}$ & $\begin{array}{l}\text { STC } \\
25582\end{array}$ & $\begin{array}{l}47 \\
2\end{array}$ & Epilogue \\
\hline $\begin{array}{l}23 \\
4 .\end{array}$ & $\begin{array}{l}\text { Massinge } \\
\text { r, Philip }\end{array}$ & $\begin{array}{l}\text { A New } \\
\text { Way to } \\
\text { Pay Old } \\
\text { Debts }\end{array}$ & $\begin{array}{l}1633 \\
\text { A } 1625\end{array}$ & Comedy & $\begin{array}{l}\text { Red Bull } \\
\text { Company } \\
\text { (?) (poi } \\
\text { Queen } \\
\text { Henrietta' } \\
\text { s) }\end{array}$ & $\begin{array}{l}\text { STC } \\
17639\end{array}$ & $\begin{array}{l}47 \\
4\end{array}$ & Epilogue \\
\hline $\begin{array}{l}23 \\
5 .\end{array}$ & $\begin{array}{l}\text { Marlowe, } \\
\text { Christoph } \\
\text { er }\end{array}$ & $\begin{array}{l}\text { The Jew of } \\
\text { Malta }\end{array}$ & $\begin{array}{l}1633 \\
\text { A } 1589\end{array}$ & Tragedy & $\begin{array}{l}\text { Strange's } \\
\text { (by 1592) }\end{array}$ & $\begin{array}{l}\text { STC } \\
17412\end{array}$ & $\begin{array}{l}47 \\
5\end{array}$ & $\begin{array}{l}\text { Three } \\
\text { prologues } \\
\text { and an } \\
\text { epilogue }\end{array}$ \\
\hline
\end{tabular}




\begin{tabular}{|c|c|c|c|c|c|c|c|c|}
\hline $\begin{array}{l}23 \\
6 .\end{array}$ & $\begin{array}{l}\text { Ford, } \\
\text { John }\end{array}$ & $\begin{array}{l}\text { The } \\
\text { Broken } \\
\text { Heart }\end{array}$ & $\begin{array}{l}1633 \\
\text { A } 1630\end{array}$ & Tragedy & King's & $\begin{array}{l}\text { STC } \\
11156\end{array}$ & $\begin{array}{l}48 \\
0\end{array}$ & $\begin{array}{l}\text { Prologue } \\
\text { and } \\
\text { epilogue }\end{array}$ \\
\hline $\begin{array}{l}23 \\
7 .\end{array}$ & $\begin{array}{l}\text { Marmion, } \\
\text { Shackerly }\end{array}$ & $\begin{array}{l}\text { A Fine } \\
\text { Companio } \\
n\end{array}$ & $\begin{array}{l}1633 \\
\text { A } 1633\end{array}$ & Comedy & $\begin{array}{l}\text { Prince } \\
\text { Charles's }\end{array}$ & $\begin{array}{l}\text { STC } \\
17442\end{array}$ & $\begin{array}{l}48 \\
1\end{array}$ & $\begin{array}{l}\text { Prologue } \\
\text { in form of } \\
\text { a dialogue } \\
\text { (author + } \\
\text { critic) }\end{array}$ \\
\hline $\begin{array}{l}23 \\
8 .\end{array}$ & $\begin{array}{l}\text { Fisher, } \\
\text { Jasper }\end{array}$ & $\begin{array}{l}\text { Fuimus } \\
\text { Troes. } \\
\text { Aneid } 2 . \\
\text { The True } \\
\text { Troanes }\end{array}$ & $\begin{array}{l}1633 \\
\text { A } 1625\end{array}$ & History & $\begin{array}{l}\text { Magdalen } \\
\text { e Col. } \\
\text { Oxford }\end{array}$ & $\begin{array}{l}\text { STC } \\
10886\end{array}$ & $\begin{array}{l}48 \\
2\end{array}$ & $\begin{array}{l}\text { Induction } \\
\text { and } \\
\text { conclusion }\end{array}$ \\
\hline $\begin{array}{l}23 \\
9 .\end{array}$ & $\begin{array}{l}\text { Heywood, } \\
\text { Thomas }\end{array}$ & $\begin{array}{l}\text { The } \\
\text { English } \\
\text { Traveller }\end{array}$ & $\begin{array}{l}1633 \\
\text { A } 1627\end{array}$ & $\begin{array}{l}\text { Tragicom } \\
\text { edy }\end{array}$ & $\begin{array}{l}\text { Queen } \\
\text { Henrietta' } \\
\text { s }\end{array}$ & $\begin{array}{l}\text { STC } \\
13315\end{array}$ & $\begin{array}{l}48 \\
4\end{array}$ & Prologue \\
\hline $\begin{array}{l}24 \\
0 .\end{array}$ & $\begin{array}{l}\text { Goffe, } \\
\text { Thomas }\end{array}$ & Orestes & $\begin{array}{l}1633 \\
\text { A } 1617\end{array}$ & Tragedy & $\begin{array}{l}\text { Christ } \\
\text { Church, } \\
\text { Oxford }\end{array}$ & $\begin{array}{l}\text { STC } \\
11982\end{array}$ & $\begin{array}{l}48 \\
5\end{array}$ & Prologue \\
\hline $\begin{array}{l}24 \\
1 .\end{array}$ & $\begin{array}{l}\text { Greville, } \\
\text { Fulke }\end{array}$ & Alaham & $\begin{array}{l}1633 \\
\text { A } 1600\end{array}$ & Tragedy & Closet & $\begin{array}{l}\text { STC } \\
12361\end{array}$ & $\begin{array}{l}48 \\
9\end{array}$ & $\begin{array}{l}\text { Chorus } \\
\text { and } \\
\text { prologue }\end{array}$ \\
\hline $\begin{array}{l}24 \\
2 .\end{array}$ & $\begin{array}{l}\text { Ford, } \\
\text { John }\end{array}$ & $\begin{array}{l}\text { Perkin } \\
\text { Warbeck }\end{array}$ & $\begin{array}{l}1634 \\
\text { A } 1633\end{array}$ & History & $\begin{array}{l}\text { Queen } \\
\text { Henrietta' } \\
\text { s }\end{array}$ & $\begin{array}{l}\text { STC } \\
11157\end{array}$ & $\begin{array}{l}49 \\
1\end{array}$ & $\begin{array}{l}\text { Prologue } \\
\text { and } \\
\text { epilogue }\end{array}$ \\
\hline $\begin{array}{l}24 \\
3 .\end{array}$ & $\begin{array}{l}\text { Shakespe } \\
\text { are, } \\
\text { William e } \\
\text { Fletcher, } \\
\text { John }\end{array}$ & $\begin{array}{l}\text { The Two } \\
\text { Nobles } \\
\text { Kinsmen }\end{array}$ & $\begin{array}{l}1634 \\
\text { A } 1613\end{array}$ & $\begin{array}{l}\text { Tragicom } \\
\text { edy }\end{array}$ & King's & $\begin{array}{l}\text { STC } \\
11075\end{array}$ & $\begin{array}{l}49 \\
2\end{array}$ & $\begin{array}{l}\text { Prologue } \\
\text { and } \\
\text { epilogue }\end{array}$ \\
\hline $\begin{array}{l}24 \\
4 .\end{array}$ & $\begin{array}{l}\text { Heywood, } \\
\text { Thomas }\end{array}$ & $\begin{array}{l}\text { A } \\
\text { Maidenhe } \\
\text { ad well } \\
\text { Lost }\end{array}$ & $\begin{array}{l}1634 \\
\text { A } 1633\end{array}$ & Comedy & $\begin{array}{l}\text { Queen } \\
\text { Henrietta' } \\
\text { s }\end{array}$ & $\begin{array}{l}\text { STC } \\
13357\end{array}$ & $\begin{array}{l}49 \\
3\end{array}$ & $\begin{array}{l}\text { Prologue } \\
\text { and } \\
\text { epilogue }\end{array}$ \\
\hline $\begin{array}{l}24 \\
5 .\end{array}$ & $\begin{array}{l}\text { Rutter, } \\
\text { Joseph }\end{array}$ & $\begin{array}{l}\text { The } \\
\text { Shepherd' } \\
\text { s Holiday }\end{array}$ & $\begin{array}{l}1635 \\
\text { A } 1634\end{array}$ & Pastoral & $\begin{array}{l}\text { Queen } \\
\text { Henrietta' } \\
\text { S }\end{array}$ & $\begin{array}{l}\text { STC } \\
21470\end{array}$ & $\begin{array}{l}49 \\
9\end{array}$ & $\begin{array}{l}\text { Prologue } \\
\text { and } \\
\text { epilogue }\end{array}$ \\
\hline $\begin{array}{l}24 \\
6 .\end{array}$ & $\begin{array}{l}\text { Jones, } \\
\text { John }\end{array}$ & $\begin{array}{l}\text { Adrasta: } \\
\text { or the } \\
\text { Womans } \\
\text { Spleene, } \\
\text { and Loves } \\
\text { Conquest }\end{array}$ & $\begin{array}{l}1635 \\
\text { A } 1635\end{array}$ & $\begin{array}{l}\text { Tragicom } \\
\text { edy }\end{array}$ & $\begin{array}{l}\text { Not } \\
\text { performed }\end{array}$ & $\begin{array}{l}\text { STC } \\
14721\end{array}$ & $\begin{array}{l}50 \\
1\end{array}$ & $\begin{array}{l}\text { Induction, } \\
\text { including } \\
\text { prologue } \\
\text { and } \\
\text { epilogue }\end{array}$ \\
\hline $\begin{array}{l}24 \\
7 .\end{array}$ & $\begin{array}{l}\text { Heywood, } \\
\text { Thomas }\end{array}$ & $\begin{array}{l}\text { Love's } \\
\text { Mistress, } \\
\text { or The } \\
\text { Queen's } \\
\text { Mask }\end{array}$ & $\begin{array}{l}1636 \\
\text { A } 1634\end{array}$ & $\begin{array}{l}\text { Classical } \\
\text { Legend }\end{array}$ & $\begin{array}{l}\text { Queen } \\
\text { Henrietta' } \\
\text { s }\end{array}$ & $\begin{array}{l}\text { STC } \\
13352\end{array}$ & $\begin{array}{l}50 \\
4\end{array}$ & $\begin{array}{l}\text { Three } \\
\text { prologues, } \\
\text { one } \\
\text { epilogue }\end{array}$ \\
\hline
\end{tabular}




\begin{tabular}{|c|c|c|c|c|c|c|c|c|}
\hline $\begin{array}{l}24 \\
8 .\end{array}$ & $\begin{array}{l}\text { Davenant, } \\
\text { William }\end{array}$ & $\begin{array}{l}\text { The } \\
\text { Platonic } \\
\text { Lovers }\end{array}$ & $\begin{array}{l}1636 \\
\text { A } 1635\end{array}$ & Comedy & King's & $\begin{array}{l}\text { STC } \\
6305\end{array}$ & $\begin{array}{l}50 \\
6\end{array}$ & $\begin{array}{l}\text { Prologue } \\
\text { and } \\
\text { epilogue }\end{array}$ \\
\hline $\begin{array}{l}24 \\
9 .\end{array}$ & $\begin{array}{l}\text { Davenant, } \\
\text { William }\end{array}$ & The Wits & $\begin{array}{l}1636 \\
\text { A } 1634\end{array}$ & Comedy & King's & $\begin{array}{l}\text { STC } \\
6309\end{array}$ & $\begin{array}{l}50 \\
7\end{array}$ & $\begin{array}{l}\text { Prologue } \\
\text { and } \\
\text { epilogue }\end{array}$ \\
\hline $\begin{array}{l}25 \\
0 .\end{array}$ & $\begin{array}{l}\text { Dekker, } \\
\text { Thomas } \\
\text { (\& Day, } \\
\text { John?) }\end{array}$ & $\begin{array}{l}\text { The } \\
\text { Wonder of } \\
\text { a Kingdom }\end{array}$ & $\begin{array}{l}1636 \\
\text { A } 1631\end{array}$ & Comedy & $\begin{array}{l}\text { Queen } \\
\text { Henrietta' } \\
\text { s }\end{array}$ & $\begin{array}{l}\text { STC } \\
6533\end{array}$ & $\begin{array}{l}50 \\
8\end{array}$ & Epilogue \\
\hline $\begin{array}{l}25 \\
1 .\end{array}$ & $\begin{array}{l}\text { Heywood, } \\
\text { Thomas }\end{array}$ & $\begin{array}{l}\text { A } \\
\text { Challenge } \\
\text { for Beauty }\end{array}$ & $\begin{array}{l}1636 \\
\text { A } 1635\end{array}$ & $\begin{array}{l}\text { Tragicom } \\
\text { edy }\end{array}$ & King's & $\begin{array}{l}\text { STC } \\
13311\end{array}$ & $\begin{array}{l}50 \\
9\end{array}$ & $\begin{array}{l}\text { Prologue } \\
\text { and } \\
\text { epilogue }\end{array}$ \\
\hline $\begin{array}{l}25 \\
2 .\end{array}$ & $\begin{array}{l}\text { Sampson, } \\
\text { William }\end{array}$ & $\begin{array}{l}\text { The Vow } \\
\text { Breaker, } \\
\text { or The } \\
\text { Fair Maid } \\
\text { of Clifton }\end{array}$ & $\begin{array}{l}1636 \\
\text { A } 1625\end{array}$ & $\begin{array}{l}\text { Tragedy } \\
\text { and } \\
\text { history }\end{array}$ & Unknown & $\begin{array}{l}\text { STC } \\
21688\end{array}$ & $\begin{array}{l}51 \\
0\end{array}$ & Prologue \\
\hline $\begin{array}{l}25 \\
3 .\end{array}$ & $\begin{array}{l}\text { Nabbes, } \\
\text { Thomas }\end{array}$ & $\begin{array}{l}\text { Hannibal } \\
\text { and Scipio }\end{array}$ & $\begin{array}{l}1637 \\
\text { A } 1635\end{array}$ & Tragedy & $\begin{array}{l}\text { Queen's } \\
\text { Henrietta }\end{array}$ & $\begin{array}{l}\text { STC } \\
18341\end{array}$ & $\begin{array}{l}51 \\
3\end{array}$ & $\begin{array}{l}\text { Prologue } \\
\text { and } \\
\text { epilogue }\end{array}$ \\
\hline $\begin{array}{l}25 \\
4 .\end{array}$ & $\begin{array}{l}\text { Fletcher, } \\
\text { John } \\
\text { (revised } \\
\text { by } \\
\text { Massinge } \\
\text { r?) }\end{array}$ & $\begin{array}{l}\text { The Elder } \\
\text { Brother }\end{array}$ & $\begin{array}{l}1637 \\
\text { A } 1625\end{array}$ & Comedy & King's & $\begin{array}{l}\text { STC } \\
11066\end{array}$ & $\begin{array}{l}51 \\
5\end{array}$ & $\begin{array}{l}\text { Prologue } \\
\text { and } \\
\text { epilogue }\end{array}$ \\
\hline $\begin{array}{l}25 \\
5 .\end{array}$ & $\begin{array}{l}\text { Heywood, } \\
\text { Thomas } \\
\text { (\& Smith, } \\
\text { Went. ?) }\end{array}$ & $\begin{array}{l}\text { The Royal } \\
\text { King and } \\
\text { the Loyal } \\
\text { Subject }\end{array}$ & $\begin{array}{l}1637 \\
\text { A } 1602\end{array}$ & $\begin{array}{l}\text { Tragicom } \\
\text { edy }\end{array}$ & $\begin{array}{l}\text { Worcester } \\
\text { 's (?) } \\
\text { (Queen } \\
\text { Henrietta' } \\
\text { s nel1637) }\end{array}$ & $\begin{array}{l}\text { STC } \\
13364\end{array}$ & $\begin{array}{l}51 \\
6\end{array}$ & $\begin{array}{l}\text { Prologue } \\
\text { and } \\
\text { epilogue }\end{array}$ \\
\hline $\begin{array}{l}25 \\
6 .\end{array}$ & $\begin{array}{l}\text { Shirley, } \\
\text { James }\end{array}$ & $\begin{array}{l}\text { The } \\
\text { Example }\end{array}$ & $\begin{array}{l}1637 \\
\text { A } 1634\end{array}$ & Comedy & $\begin{array}{l}\text { Queen } \\
\text { Henrietta' } \\
\text { s }\end{array}$ & $\begin{array}{l}\text { STC } \\
22442\end{array}$ & $\begin{array}{l}52 \\
1\end{array}$ & $\begin{array}{l}\text { Prologue } \\
\text { and } \\
\text { epilogue }\end{array}$ \\
\hline $\begin{array}{l}25 \\
7 .\end{array}$ & $\begin{array}{l}\text { Ford, } \\
\text { John }\end{array}$ & $\begin{array}{l}\text { The } \\
\text { Fancies } \\
\text { Chaste } \\
\text { and Noble }\end{array}$ & $\begin{array}{l}1638 \\
\text { A } 1635\end{array}$ & Comedy & $\begin{array}{l}\text { Queen } \\
\text { Henrietta' } \\
\text { s }\end{array}$ & $\begin{array}{l}\text { STC } \\
11159\end{array}$ & $\begin{array}{l}53 \\
2\end{array}$ & $\begin{array}{l}\text { Prologue, } \\
\text { epilogue } \\
\text { in form of } \\
\text { a dialogue }\end{array}$ \\
\hline $\begin{array}{l}25 \\
8 .\end{array}$ & $\begin{array}{l}\text { Shirley, } \\
\text { H. (\& } \\
\text { Heywood, } \\
\text { Thomas?) }\end{array}$ & $\begin{array}{l}\text { The } \\
\text { Martyred } \\
\text { Soldier }\end{array}$ & $\begin{array}{l}1638 \\
\text { A } 1618\end{array}$ & Tragedy & $\begin{array}{l}\text { Queen } \\
\text { Anne's (?) }\end{array}$ & $\begin{array}{l}\text { STC } \\
22435\end{array}$ & $\begin{array}{l}53 \\
3\end{array}$ & Epilogue \\
\hline $\begin{array}{l}25 \\
9 .\end{array}$ & $\begin{array}{l}\text { Shirley, } \\
\text { James }\end{array}$ & $\begin{array}{l}\text { The } \\
\text { Duke's } \\
\text { Mistress }\end{array}$ & $\begin{array}{l}1638 \\
\text { A } 1636\end{array}$ & $\begin{array}{l}\text { Tragicom } \\
\text { edy }\end{array}$ & $\begin{array}{l}\text { Queen } \\
\text { Henrietta' } \\
\text { s }\end{array}$ & $\begin{array}{l}\text { STC } \\
22441\end{array}$ & $\begin{array}{l}53 \\
6\end{array}$ & $\begin{array}{l}\text { Prologue } \\
\text { and } \\
\text { epilogue }\end{array}$ \\
\hline $\begin{array}{l}26 \\
0 .\end{array}$ & $\begin{array}{l}\text { Killigrew, } \\
\text { Henry }\end{array}$ & $\begin{array}{l}\text { The } \\
\text { Conspirac } \\
y \\
\text { (Pallantus }\end{array}$ & $\begin{array}{l}1638 \\
\text { A } 1635\end{array}$ & $\begin{array}{l}\text { Tragicom } \\
\text { edy }\end{array}$ & $\begin{array}{l}\text { York } \\
\text { House (?) } \\
\text { \& King’s }\end{array}$ & $\begin{array}{l}\text { STC } \\
14958\end{array}$ & $\begin{array}{l}53 \\
7\end{array}$ & $\begin{array}{l}\text { Introducti } \\
\text { on, chorus } \\
\text { at the end } \\
\text { of each }\end{array}$ \\
\hline
\end{tabular}




\begin{tabular}{|c|c|c|c|c|c|c|c|c|}
\hline & & $\begin{array}{l}\text { and } \\
\text { Eudora) }\end{array}$ & & & & & & $\begin{array}{l}\text { act, } \\
\text { prologue } \\
\text { and } \\
\text { epilogue }\end{array}$ \\
\hline $\begin{array}{l}26 \\
1 .\end{array}$ & $\begin{array}{l}\text { Shirley, } \\
\text { James }\end{array}$ & $\begin{array}{l}\text { The Royal } \\
\text { Master }\end{array}$ & $\begin{array}{l}1638 \\
\text { A } 1637\end{array}$ & Comedy & $\begin{array}{l}\text { I Ogilby’s } \\
\text { Men \& } \\
\text { Queen's }\end{array}$ & $\begin{array}{l}\text { STC } \\
22454\end{array}$ & $\begin{array}{l}53 \\
8\end{array}$ & Epilogue \\
\hline $\begin{array}{l}26 \\
2 .\end{array}$ & $\begin{array}{l}\text { Cowley, } \\
\text { Abraham }\end{array}$ & $\begin{array}{l}\text { Love's } \\
\text { Riddle }\end{array}$ & $\begin{array}{l}1638 \\
\text { A } 1633\end{array}$ & Pastoral & $\begin{array}{l}\text { Not } \\
\text { performed }\end{array}$ & $\begin{array}{l}\text { STC } \\
5904\end{array}$ & $\begin{array}{l}53 \\
9\end{array}$ & Epilogue \\
\hline $\begin{array}{l}26 \\
3 .\end{array}$ & $\begin{array}{l}\text { Nabbes, } \\
\text { Thomas }\end{array}$ & $\begin{array}{l}\text { Tottenham } \\
\text { Court }\end{array}$ & $\begin{array}{l}1638 \\
\text { A } 1634\end{array}$ & Comedy & $\begin{array}{l}\text { Prince's } \\
\text { Men, or } \\
\text { King's } \\
\text { Revels }\end{array}$ & $\begin{array}{l}\text { STC } \\
18344\end{array}$ & $\begin{array}{l}54 \\
0\end{array}$ & $\begin{array}{l}\text { Prologue } \\
\text { and } \\
\text { epilogue }\end{array}$ \\
\hline $\begin{array}{l}26 \\
4 .\end{array}$ & $\begin{array}{l}\text { Suckling, } \\
\text { John }\end{array}$ & Aglaura & $\begin{array}{l}1638 \\
\text { A } 1637\end{array}$ & Tragedy & King's & $\begin{array}{l}\text { STC } \\
23420\end{array}$ & $\begin{array}{l}54 \\
1\end{array}$ & $\begin{array}{l}\text { Two } \\
\text { prologues } \\
\text { e two } \\
\text { epilogues }\end{array}$ \\
\hline $\begin{array}{l}26 \\
5 .\end{array}$ & $\begin{array}{l}\text { Nabbes, } \\
\text { Thomas }\end{array}$ & $\begin{array}{l}\text { Covent } \\
\text { Garden }\end{array}$ & $\begin{array}{l}1638 \\
\text { A } 1633\end{array}$ & Comedy & $\begin{array}{l}\text { Queen } \\
\text { Henrietta' } \\
\text { s }\end{array}$ & $\begin{array}{l}\text { STC } \\
18339\end{array}$ & $\begin{array}{l}54 \\
2\end{array}$ & $\begin{array}{l}\text { Prologue } \\
\text { and } \\
\text { epilogue }\end{array}$ \\
\hline $\begin{array}{l}26 \\
6 .\end{array}$ & $\begin{array}{l}\text { Nabbes, } \\
\text { Thomas }\end{array}$ & $\begin{array}{l}\text { The } \\
\text { Spring's } \\
\text { Glory }\end{array}$ & $\begin{array}{l}1638 \\
\text { A } 1637\end{array}$ & Mask & $\begin{array}{l}\text { Not } \\
\text { performed } \\
(?)\end{array}$ & $\begin{array}{l}\text { STC } \\
18343\end{array}$ & $\begin{array}{l}54 \\
3\end{array}$ & Epilogue \\
\hline $\begin{array}{l}26 \\
7 .\end{array}$ & $\begin{array}{l}\text { Randolph, } \\
\text { Thomas }\end{array}$ & $\begin{array}{l}\text { The Muses } \\
\text { Looking-G } \\
\text { lass }\end{array}$ & $\begin{array}{l}1638 \\
\text { collecti } \\
\text { on } \\
\text { A } 1630\end{array}$ & Comedy & $\begin{array}{l}\text { King's } \\
\text { Revels }\end{array}$ & $\begin{array}{l}\text { STC } \\
20694\end{array}$ & $\begin{array}{l}54 \\
7\end{array}$ & Epilogue \\
\hline $\begin{array}{l}26 \\
8 .\end{array}$ & $\begin{array}{l}\text { Randolph, } \\
\text { Thomas }\end{array}$ & Amyntas & $\begin{array}{l}1638 \\
\text { collecti } \\
\text { on } \\
\text { A } 1630\end{array}$ & Pastoral & $\begin{array}{l}\text { King's } \\
\text { Revels }\end{array}$ & $\begin{array}{l}\text { STC } \\
20694\end{array}$ & $\begin{array}{l}54 \\
8\end{array}$ & $\begin{array}{l}\text { Prologue } \\
\text { in form of } \\
\text { a } \\
\text { dialogue, } \\
\text { epilogue }\end{array}$ \\
\hline $\begin{array}{l}26 \\
9 .\end{array}$ & $\begin{array}{l}\text { Carlell, } \\
\text { Lodowick }\end{array}$ & $\begin{array}{l}1 \\
\text { Arviragus } \\
\text { and } \\
\text { Philicia }\end{array}$ & $\begin{array}{l}1639 \\
\text { A } 1636\end{array}$ & $\begin{array}{l}\text { Tragicom } \\
\text { edy }\end{array}$ & King's & $\begin{array}{l}\text { STC } \\
4627\end{array}$ & $\begin{array}{l}55 \\
1\end{array}$ & $\begin{array}{l}\text { Prologue } \\
\text { and } \\
\text { epilogue }\end{array}$ \\
\hline $\begin{array}{l}27 \\
0 .\end{array}$ & $\begin{array}{l}\text { Carlell, } \\
\text { Lodowick }\end{array}$ & $\begin{array}{l}2 \\
\text { Arviragus } \\
\text { and } \\
\text { Philicia }\end{array}$ & $\begin{array}{l}1639 \\
\text { A } 1636\end{array}$ & $\begin{array}{l}\text { Tragicom } \\
\text { edy }\end{array}$ & King's & $\begin{array}{l}\text { STC } \\
4627\end{array}$ & $\begin{array}{l}55 \\
2\end{array}$ & Epilogue \\
\hline $\begin{array}{l}27 \\
1 .\end{array}$ & $\begin{array}{l}\text { May, } \\
\text { Thomas }\end{array}$ & $\begin{array}{l}\text { Julia } \\
\text { Agrippina }\end{array}$ & $\begin{array}{l}1639 \\
\text { A } 1628\end{array}$ & Tragedy & unknown & $\begin{array}{l}\text { STC } \\
17718\end{array}$ & $\begin{array}{l}55 \\
4\end{array}$ & Induction \\
\hline $\begin{array}{l}27 \\
2 .\end{array}$ & $\begin{array}{l}\text { Ford, } \\
\text { John }\end{array}$ & $\begin{array}{l}\text { The } \\
\text { Lady's } \\
\text { Trial }\end{array}$ & $\begin{array}{l}1639 \\
\text { A } 1638\end{array}$ & Comedy & $\begin{array}{l}\text { Beeston's } \\
\text { Boys }\end{array}$ & $\begin{array}{l}\text { STC } \\
11161\end{array}$ & $\begin{array}{l}55 \\
5\end{array}$ & $\begin{array}{l}\text { Prologue } \\
\text { and } \\
\text { epilogue }\end{array}$ \\
\hline
\end{tabular}




\begin{tabular}{|c|c|c|c|c|c|c|c|c|}
\hline $\begin{array}{l}27 \\
3 .\end{array}$ & $\begin{array}{l}\text { Zouche, } \\
\text { Richard }\end{array}$ & $\begin{array}{l}\text { The } \\
\text { Sophister } \\
\text { (Fallacy, } \\
\text { or The } \\
\text { Troubles } \\
\text { of Great } \\
\text { Hermenia) }\end{array}$ & $\begin{array}{l}1639 \\
\text { A } 1614\end{array}$ & Moral & Oxford & $\begin{array}{l}\text { STC } \\
26133\end{array}$ & $\begin{array}{l}55 \\
6\end{array}$ & $\begin{array}{l}\text { Prologue } \\
\text { and } \\
\text { epilogue }\end{array}$ \\
\hline $\begin{array}{l}27 \\
4 .\end{array}$ & $\begin{array}{l}\text { T. D. } \\
\text { (Thomas. } \\
\text { Drue?) }\end{array}$ & $\begin{array}{l}\text { The } \\
\text { Bloody } \\
\text { Banquet }\end{array}$ & $\begin{array}{l}1639 \\
\text { A } 1639\end{array}$ & Tragedy & $\begin{array}{l}\text { Beeston's } \\
\text { Boys }\end{array}$ & $\begin{array}{l}\text { STC } \\
6181\end{array}$ & $\begin{array}{l}56 \\
7\end{array}$ & $\begin{array}{l}\text { Induction } \\
\text { (dumb } \\
\text { show), } \\
\text { chorus }\end{array}$ \\
\hline $\begin{array}{l}27 \\
5 .\end{array}$ & $\begin{array}{l}\text { Myne, } \\
\text { Jasper }\end{array}$ & $\begin{array}{l}\text { The City } \\
\text { Match }\end{array}$ & $\begin{array}{l}1639 \\
\text { A } 1637\end{array}$ & Comedy & King's & $\begin{array}{l}\text { STC } \\
17750\end{array}$ & $\begin{array}{l}56 \\
8\end{array}$ & $\begin{array}{l}\text { Prologue } \\
\text { and } \\
\text { epilogue }\end{array}$ \\
\hline $\begin{array}{l}27 \\
6 .\end{array}$ & $\begin{array}{l}\text { Lower, } \\
\text { William }\end{array}$ & $\begin{array}{l}\text { The } \\
\text { Phoenix in } \\
\text { her } \\
\text { Flames }\end{array}$ & $\begin{array}{l}1639 \\
\text { A } 1639\end{array}$ & Tragedy & $\begin{array}{l}\text { Not } \\
\text { performed } \\
(?)\end{array}$ & $\begin{array}{l}\text { STC } \\
16873\end{array}$ & $\begin{array}{l}56 \\
9\end{array}$ & $\begin{array}{l}\text { Prologue } \\
\text { and } \\
\text { epilogue }\end{array}$ \\
\hline $\begin{array}{l}27 \\
7 .\end{array}$ & $\begin{array}{l}\text { Cartwrigh } \\
\text { t, William }\end{array}$ & $\begin{array}{l}\text { The Royal } \\
\text { Slave }\end{array}$ & $\begin{array}{l}1639 \\
\text { A } 1636\end{array}$ & $\begin{array}{l}\text { Tragicom } \\
\text { edy }\end{array}$ & $\begin{array}{l}\text { Christ } \\
\text { Church, } \\
\text { Oxford }\end{array}$ & $\begin{array}{l}\text { STC } \\
4717\end{array}$ & $\begin{array}{l}57 \\
0\end{array}$ & $\begin{array}{l}\text { Three } \\
\text { prologues } \\
\text { e three } \\
\text { epilogues }\end{array}$ \\
\hline $\begin{array}{l}27 \\
8 .\end{array}$ & $\begin{array}{l}\text { Shirley, } \\
\text { James }\end{array}$ & $\begin{array}{l}\text { The } \\
\text { Chorusnat } \\
\text { ion }\end{array}$ & $\begin{array}{l}1640 \\
\text { A } 1635\end{array}$ & Comedy & $\begin{array}{l}\text { Queen } \\
\text { Henrietta' } \\
\text { s }\end{array}$ & $\begin{array}{l}\text { STC } \\
22440\end{array}$ & $\begin{array}{l}57 \\
2\end{array}$ & $\begin{array}{l}\text { Prologue } \\
\text { and } \\
\text { epilogue }\end{array}$ \\
\hline $\begin{array}{l}27 \\
9 .\end{array}$ & $\begin{array}{l}\text { Nabbes, } \\
\text { Thomas }\end{array}$ & The Bride & $\begin{array}{l}1640 \\
\text { A } 1638\end{array}$ & Comedy & $\begin{array}{l}\text { Beeston's } \\
\text { Boys }\end{array}$ & $\begin{array}{l}\text { STC } \\
18338\end{array}$ & $\begin{array}{l}57 \\
6\end{array}$ & Prologue \\
\hline $\begin{array}{l}28 \\
0 .\end{array}$ & $\begin{array}{l}\text { Shirley, } \\
\text { James }\end{array}$ & $\begin{array}{l}\text { The } \\
\text { Humorous } \\
\text { Courtier }\end{array}$ & $\begin{array}{l}1640 \\
\text { A } 1631\end{array}$ & Comedy & $\begin{array}{l}\text { Queen } \\
\text { Henrietta' } \\
\text { s }\end{array}$ & $\begin{array}{l}\text { STC } \\
22447\end{array}$ & $\begin{array}{l}57 \\
7\end{array}$ & $\begin{array}{l}\text { Prologue } \\
\text { and } \\
\text { epilogue }\end{array}$ \\
\hline $\begin{array}{l}28 \\
1 .\end{array}$ & $\begin{array}{l}\text { Sandys, } \\
\text { George }\end{array}$ & $\begin{array}{l}\text { Christ's } \\
\text { Passion }\end{array}$ & $\begin{array}{l}1640 \\
\text { A } 1640\end{array}$ & $\begin{array}{l}\text { Neo- } \\
\text { miracle }\end{array}$ & Closet & $\begin{array}{l}\text { STC } \\
12397\end{array}$ & $\begin{array}{l}57 \\
9\end{array}$ & $\begin{array}{l}\text { Chorus at } \\
\text { the end of } \\
\text { each act } \\
\text { except the } \\
\text { last one }\end{array}$ \\
\hline $\begin{array}{l}28 \\
2 .\end{array}$ & $\begin{array}{l}\text { Gough, } \\
\text { John }\end{array}$ & $\begin{array}{l}\text { The } \\
\text { Strange } \\
\text { Discovery }\end{array}$ & $\begin{array}{l}1640 \\
\text { A } 1640\end{array}$ & $\begin{array}{l}\text { Tragicom } \\
\text { edy }\end{array}$ & Closet & $\begin{array}{l}\text { STC } \\
12133\end{array}$ & $\begin{array}{l}58 \\
4\end{array}$ & Prologue \\
\hline $\begin{array}{l}28 \\
3 .\end{array}$ & $\begin{array}{l}\text { Jonson, } \\
\text { Ben }\end{array}$ & $\begin{array}{l}\text { The } \\
\text { Gipsies } \\
\text { Metamorp } \\
\text { hosed }\end{array}$ & $\begin{array}{l}1640 \\
\text { A } 1621\end{array}$ & Mask & $\begin{array}{l}\text { Burley, } \\
\text { Belvoir, e } \\
\text { Windsor }\end{array}$ & $\begin{array}{l}\text { STC } \\
14777 \\
\text { a }\end{array}$ & $\begin{array}{l}58 \\
5\end{array}$ & Prologue \\
\hline $\begin{array}{l}28 \\
4 .\end{array}$ & $\begin{array}{l}\text { Brome, } \\
\text { Richard }\end{array}$ & $\begin{array}{l}\text { The } \\
\text { Antipodes }\end{array}$ & $\begin{array}{l}1640 \\
\text { A } 1638\end{array}$ & Comedy & Queen's & $\begin{array}{l}\text { STC } \\
3818\end{array}$ & $\begin{array}{l}58 \\
6\end{array}$ & $\begin{array}{l}\text { Prologue } \\
\text { and } \\
\text { epilogue } \\
\text { in form of } \\
\text { a dialogue }\end{array}$ \\
\hline
\end{tabular}




\begin{tabular}{|c|c|c|c|c|c|c|c|c|}
\hline $\begin{array}{l}28 \\
5 .\end{array}$ & $\begin{array}{l}\text { Brome, } \\
\text { Richard }\end{array}$ & $\begin{array}{l}\text { The } \\
\text { Sparagus } \\
\text { Garden }\end{array}$ & $\begin{array}{l}1640 \\
\text { A } 1635\end{array}$ & Comedy & $\begin{array}{l}\text { King's } \\
\text { Revels }\end{array}$ & $\begin{array}{l}\text { STC } \\
3820\end{array}$ & $\begin{array}{l}58 \\
7\end{array}$ & $\begin{array}{l}\text { Prologue } \\
\text { and } \\
\text { epilogue }\end{array}$ \\
\hline $\begin{array}{l}28 \\
6 .\end{array}$ & $\begin{array}{l}\text { Habingto } \\
\mathrm{n}, \\
\text { William }\end{array}$ & $\begin{array}{l}\text { The Queen } \\
\text { of Aragon }\end{array}$ & $\begin{array}{l}1640 \\
\text { A } 1640\end{array}$ & $\begin{array}{l}\text { Tragicom } \\
\text { edy }\end{array}$ & $\begin{array}{l}\text { Amateurs } \\
\text { at Court, } \\
\text { \& King's }\end{array}$ & $\begin{array}{l}\text { STC } \\
12587\end{array}$ & $\begin{array}{l}58 \\
8\end{array}$ & $\begin{array}{l}\text { Two } \\
\text { prologues } \\
\text { and one } \\
\text { epilogue }\end{array}$ \\
\hline $\begin{array}{l}28 \\
7 .\end{array}$ & $\begin{array}{l}\text { Chamberl } \\
\text { ain, } \\
\text { Robert }\end{array}$ & $\begin{array}{l}\text { The } \\
\text { Swaggerin } \\
\text { g Damsel }\end{array}$ & $\begin{array}{l}1640 \\
\text { A } 1640\end{array}$ & Comedy & $\begin{array}{l}\text { Beeston's } \\
\text { Boys }\end{array}$ & $\begin{array}{l}\text { STC } \\
4946\end{array}$ & $\begin{array}{l}58 \\
9\end{array}$ & Prologue \\
\hline $\begin{array}{l}28 \\
8 .\end{array}$ & $\begin{array}{l}\text { Glapthorn } \\
\text { e, Henry }\end{array}$ & $\begin{array}{l}\text { The } \\
\text { Ladies, } \\
\text { Privilege }\end{array}$ & $\begin{array}{l}1640 \\
\text { A } 1637\end{array}$ & $\begin{array}{l}\text { Tragicom } \\
\text { edy }\end{array}$ & $\begin{array}{l}\text { Beeston's } \\
\text { Boys }\end{array}$ & $\begin{array}{l}\text { STC } \\
11910\end{array}$ & $\begin{array}{l}59 \\
0\end{array}$ & $\begin{array}{l}\text { Prologue } \\
\text { and } \\
\text { epilogue }\end{array}$ \\
\hline $\begin{array}{l}28 \\
9 .\end{array}$ & $\begin{array}{l}\text { Glapthorn } \\
\text { e, Henry }\end{array}$ & $\begin{array}{l}\text { Wit in a } \\
\text { Constable }\end{array}$ & $\begin{array}{l}1640 \\
\text { A } 1638\end{array}$ & Comedy & $\begin{array}{l}\text { Beeston's } \\
\text { Boys }\end{array}$ & $\begin{array}{l}\text { STC } \\
11914\end{array}$ & $\begin{array}{l}59 \\
1\end{array}$ & $\begin{array}{l}\text { Prologue } \\
\text { and } \\
\text { epilogue }\end{array}$ \\
\hline $\begin{array}{l}29 \\
0 .\end{array}$ & $\begin{array}{l}\text { Shirley, } \\
\text { James }\end{array}$ & $\begin{array}{l}1 \text { Saint } \\
\text { Patrick for } \\
\text { Ireland }\end{array}$ & $\begin{array}{l}1640 \\
\text { A } 1639\end{array}$ & $\begin{array}{l}\text { Neo- } \\
\text { miracle }\end{array}$ & $\begin{array}{l}\text { I Ogilby's } \\
\text { Men, } \\
\text { Dublin }\end{array}$ & $\begin{array}{l}\text { STC } \\
22455\end{array}$ & $\begin{array}{l}59 \\
3\end{array}$ & $\begin{array}{l}\text { Prologue } \\
\text { and } \\
\text { epilogue }\end{array}$ \\
\hline $\begin{array}{l}29 \\
1 .\end{array}$ & $\begin{array}{l}\text { Sharpe, } \\
\text { Lewis }\end{array}$ & $\begin{array}{l}\text { The Noble } \\
\text { Stranger }\end{array}$ & $\begin{array}{l}1640 \\
\text { A } 1639\end{array}$ & $\begin{array}{l}\text { Tragicom } \\
\text { edy }\end{array}$ & Queen's & $\begin{array}{l}\text { STC } \\
22377\end{array}$ & $\begin{array}{l}59 \\
7\end{array}$ & $\begin{array}{l}\text { Prologue } \\
\text { and } \\
\text { epilogue }\end{array}$ \\
\hline $\begin{array}{l}29 \\
2 .\end{array}$ & $\begin{array}{l}\text { Fletcher, } \\
\text { John }\end{array}$ & $\begin{array}{l}\text { Rule A } \\
\text { wife and } \\
\text { Have a } \\
\text { Wife }\end{array}$ & $\begin{array}{l}1640 \\
\text { A } 1624\end{array}$ & Comedy & King's & $\begin{array}{l}\text { STC } \\
11073\end{array}$ & $\begin{array}{l}59 \\
8\end{array}$ & $\begin{array}{l}\text { Prologue } \\
\text { and } \\
\text { epilogue }\end{array}$ \\
\hline $\begin{array}{l}29 \\
3 .\end{array}$ & $\begin{array}{l}\text { Harding, } \\
\text { Samuel }\end{array}$ & $\begin{array}{l}\text { Sicily and } \\
\text { Naples }\end{array}$ & $\begin{array}{l}1640 \\
\text { A } 1640\end{array}$ & Tragedy & $\begin{array}{l}\text { Not } \\
\text { performed }\end{array}$ & $\begin{array}{l}\text { STC } \\
12757\end{array}$ & $\begin{array}{l}59 \\
9\end{array}$ & Epilogue \\
\hline $\begin{array}{l}29 \\
4 .\end{array}$ & $\begin{array}{l}\text { Tatham, } \\
\text { John }\end{array}$ & $\begin{array}{l}\text { Love } \\
\text { Crows the } \\
\text { End }\end{array}$ & $\begin{array}{l}1640 \\
\text { collecti } \\
\text { on } \\
\text { A } 1632\end{array}$ & Pastoral & $\begin{array}{l}\text { Bingham } \\
\text { School, } \\
\text { Nottingha } \\
\text { mshire }\end{array}$ & $\begin{array}{l}\text { STC } \\
23704\end{array}$ & $\begin{array}{l}60 \\
0\end{array}$ & Prologue \\
\hline $\begin{array}{l}29 \\
5 .\end{array}$ & $\begin{array}{l}\text { Burnell, } \\
\text { Henry }\end{array}$ & $\begin{array}{l}\text { Landgarth } \\
a\end{array}$ & $\begin{array}{l}1641 \\
\text { A } 1640\end{array}$ & $\begin{array}{l}\text { Tragicom } \\
\text { edy }\end{array}$ & $\begin{array}{l}\text { I Ogilby's } \\
\text { Men, } \\
\text { Dublin }\end{array}$ & $\begin{array}{l}\text { STC } \\
\text { B5751 }\end{array}$ & $\begin{array}{l}60 \\
4\end{array}$ & $\begin{array}{l}\text { Prologue } \\
\text { and } \\
\text { epilogue }\end{array}$ \\
\hline $\begin{array}{l}29 \\
6 .\end{array}$ & $\begin{array}{l}\text { Brathwait } \\
\text {, Richard }\end{array}$ & $\begin{array}{l}\text { Mercurius } \\
\text { Britannicu } \\
\text { s, or the } \\
\text { English } \\
\text { Intelligenc } \\
\text { er }\end{array}$ & $\begin{array}{l}1641 \\
\text { A } 1641\end{array}$ & $\begin{array}{l}\text { Latin } \\
\text { Political } \\
\text { Comedy }\end{array}$ & Closet & $\begin{array}{l}\text { STC } \\
\text { B4270 }\end{array}$ & $\begin{array}{l}60 \\
5\end{array}$ & Epilogue \\
\hline $\begin{array}{l}29 \\
7 .\end{array}$ & $\begin{array}{l}\text { Jonson, } \\
\text { Ben }\end{array}$ & $\begin{array}{l}\text { The } \\
\text { Magnetic } \\
\text { Lady }\end{array}$ & $\begin{array}{l}1641 \\
\text { collecti } \\
\text { on } \\
\text { A } 1632\end{array}$ & Comedy & King's & $\begin{array}{l}\text { STC } \\
14754\end{array}$ & $\begin{array}{l}61 \\
6\end{array}$ & $\begin{array}{l}\text { Induction, } \\
\text { chorus at } \\
\text { the end of } \\
\text { each act. } \\
\text { The } \\
\text { chorus of }\end{array}$ \\
\hline
\end{tabular}




\begin{tabular}{|c|c|c|c|c|c|c|c|c|}
\hline & & & & & & & & $\begin{array}{l}\text { act } 5 \\
\text { "changed } \\
\text { into an } \\
\text { epilogue } \\
\text { to the } \\
\text { King for a } \\
\text { court } \\
\text { performan } \\
\text { ce". }\end{array}$ \\
\hline $\begin{array}{l}29 \\
8 .\end{array}$ & $\begin{array}{l}\text { Jonson, } \\
\text { Ben }\end{array}$ & $\begin{array}{l}\text { A Tale of } a \\
\text { Tub }\end{array}$ & $\begin{array}{l}1641 \\
\begin{array}{l}\text { collecti } \\
\text { on }\end{array} \\
\text { A } \\
1596- \\
1633\end{array}$ & Comedy & Admiral's & $\begin{array}{l}\text { STC } \\
14754\end{array}$ & $\begin{array}{l}61 \\
7\end{array}$ & $\begin{array}{l}\text { Prologue } \\
\text { and } \\
\text { epilogue }\end{array}$ \\
\hline $\begin{array}{l}29 \\
9 .\end{array}$ & $\begin{array}{l}\text { Jonson, } \\
\text { Ben }\end{array}$ & $\begin{array}{l}\text { The Sad } \\
\text { Shepherd }\end{array}$ & $\begin{array}{l}1641 \\
\text { collecti } \\
\text { on } \\
\text { A } 1637\end{array}$ & $\begin{array}{l}\text { Comic } \\
\text { pastoral }\end{array}$ & $\begin{array}{l}\text { Not } \\
\text { performed }\end{array}$ & $\begin{array}{l}\text { STC } \\
14754\end{array}$ & $\begin{array}{l}61 \\
8\end{array}$ & Prologue \\
\hline $\begin{array}{l}30 \\
0 .\end{array}$ & $\begin{array}{l}\text { Denham, } \\
\text { John }\end{array}$ & The Sophy & $\begin{array}{l}1642 \\
\text { A } 1641\end{array}$ & Tragedy & King's & $\begin{array}{l}\text { STC } \\
\text { D1000 } \\
9\end{array}$ & $\begin{array}{l}62 \\
2\end{array}$ & $\begin{array}{l}\text { Prologue } \\
\text { and } \\
\text { epilogue }\end{array}$ \\
\hline $\begin{array}{l}30 \\
1 .\end{array}$ & $\begin{array}{l}\text { Fletcher, } \\
\text { John }\end{array}$ & $\begin{array}{l}\text { The Noble } \\
\text { Gentleman }\end{array}$ & $\begin{array}{l}1647 \\
\text { collecti } \\
\text { on } \\
\text { A } 1606\end{array}$ & Comedy & King's & $\begin{array}{l}\text { STC } \\
\text { B1581 }\end{array}$ & $\begin{array}{l}64 \\
1\end{array}$ & $\begin{array}{l}\text { Prologue } \\
\text { and } \\
\text { epilogue }\end{array}$ \\
\hline $\begin{array}{l}30 \\
2 .\end{array}$ & $\begin{array}{l}\text { Fletcher, } \\
\text { John }\end{array}$ & $\begin{array}{l}\text { The } \\
\text { Captain }\end{array}$ & $\begin{array}{l}1647 \\
\text { collecti } \\
\text { on } \\
\text { A } 1612\end{array}$ & & & $\begin{array}{l}\text { STC } \\
\text { SB158 } \\
1\end{array}$ & $\begin{array}{l}64 \\
2\end{array}$ & $\begin{array}{l}\text { Prologue } \\
\text { and } \\
\text { epilogue }\end{array}$ \\
\hline $\begin{array}{l}30 \\
3 .\end{array}$ & $\begin{array}{l}\text { Beaumont } \\
\text { Francis } \\
\\
\text { or N. } \\
\text { Field and } \\
J . \\
\text { Fletcher } \\
\text { (induction } \\
\text { by } \\
\text { Beaumont } \\
\text { or Field) }\end{array}$ & $\begin{array}{l}\text { Four plays } \\
\text { in one (for } \\
\text { Moral } \\
\text { Represent } \\
\text { ations) }\end{array}$ & $\begin{array}{l}1647 \\
\text { A } 1613\end{array}$ & Moral & Unknown & $\begin{array}{l}\text { STC } \\
\text { B1581 }\end{array}$ & $\begin{array}{l}67 \\
0\end{array}$ & $\begin{array}{l}\text { Induction, } \\
\text { dumb } \\
\text { show, } \\
\text { final song, } \\
\text { epilogue }\end{array}$ \\
\hline
\end{tabular}




\begin{tabular}{|c|c|c|c|c|c|c|c|c|}
\hline $\begin{array}{l}30 \\
4 .\end{array}$ & $\begin{array}{l}\text { Randolph } \\
\text { Thomas } \\
\text { (revised } \\
\text { by 'T. J.”) }\end{array}$ & $\begin{array}{l}\text { Plutophtal } \\
\text { mia } \\
\text { Plutogami } \\
\text { a } \\
\text { Hey for } \\
\text { Honesty, } \\
\text { Down with } \\
\text { Knavery }\end{array}$ & $\begin{array}{l}1651 \\
\text { A } 1627\end{array}$ & Comedy & $\begin{array}{l}\text { Trinity } \\
\text { Col, } \\
\text { Cambridg } \\
\text { e? }\end{array}$ & $\begin{array}{l}\text { A3685 } \\
\text { Wing }\end{array}$ & $\begin{array}{l}69 \\
9\end{array}$ & $\begin{array}{l}\text { Induction, } \\
\text { epilogue } \\
\text { and } \\
\text { argument }\end{array}$ \\
\hline $\begin{array}{l}30 \\
5 .\end{array}$ & $\begin{array}{l}\text { Goffe, } \\
\text { Thomas }\end{array}$ & $\begin{array}{l}\text { The } \\
\text { Careless } \\
\text { Shepherde } \\
\text { ss }\end{array}$ & $\begin{array}{l}1656 \\
\text { A } 1619\end{array}$ & Pastoral & $\begin{array}{l}\text { Christ } \\
\text { Church, } \\
\text { Oxford (?) }\end{array}$ & $\begin{array}{l}\text { G } \\
1005 \\
\text { Wing }\end{array}$ & $\begin{array}{l}76 \\
1\end{array}$ & $\begin{array}{l}\text { Induction } \\
\text { (praeludiu } \\
\text { m), } \\
\text { Masque of } \\
\text { Apollo } \\
\text { (II,6), } \\
\text { epilogue }\end{array}$ \\
\hline $\begin{array}{l}30 \\
6 .\end{array}$ & T. W. & $\begin{array}{l}\text { Thorney } \\
\text { Abbey }\end{array}$ & $\begin{array}{l}1662 \\
\text { collecti } \\
\text { on } \\
\text { Probab } \\
\text { ly a } \\
17^{\text {th }} \\
\text { cent. } \\
\text { play } \\
\text { with } \\
\text { later } \\
\text { additio } \\
\text { ns }\end{array}$ & History & unknown & $\begin{array}{l}\text { G } \\
1580 \\
\text { Wing }\end{array}$ & $\begin{array}{l}82 \\
4\end{array}$ & $\begin{array}{l}\text { Prelude } \\
\text { (Prologue } \\
\text { in } \\
\text { dialogue } \\
\text { form } \\
\text { between } \\
\text { the Fool } \\
\text { and the } \\
\text { prompter) }\end{array}$ \\
\hline $\begin{array}{l}30 \\
7 .\end{array}$ & $\begin{array}{l}\text { Haughton } \\
\text { W. (rev. } \\
\text { for press } \\
\text { by "I.T.") }\end{array}$ & $\begin{array}{l}\text { Grim the } \\
\text { Collier of } \\
\text { Croydon }\end{array}$ & $\begin{array}{l}1662 \\
\text { collecti } \\
\text { on } \\
\text { A } 1600\end{array}$ & Comedy & $\begin{array}{l}\text { Admiral's } \\
\text { ? }\end{array}$ & $\begin{array}{l}\text { G1580 } \\
\text { Wing }\end{array}$ & $\begin{array}{l}82 \\
6\end{array}$ & Prologue \\
\hline $\begin{array}{l}30 \\
8 .\end{array}$ & $\begin{array}{l}\text { Wild } \\
\text { Robert }\end{array}$ & $\begin{array}{l}\text { The } \\
\text { Benefice }\end{array}$ & $\begin{array}{l}1689 \\
\text { A } \\
1641 ?\end{array}$ & Comedy & $\begin{array}{l}\text { Cambridg } \\
\text { e? }\end{array}$ & & $\begin{array}{l}83 \\
6\end{array}$ & $\begin{array}{l}\text { Induction } \\
\text { (act 1)- } \\
\text { characters: } \\
\text { Shakespea } \\
\text { re, } \\
\text { Beaumont } \\
\text { and } \\
\text { Flecther, } \\
\text { Comedy- } \\
\text { songs, } \\
\text { prologue } \\
\text { and } \\
\text { epilogue }\end{array}$ \\
\hline
\end{tabular}


[1] See the appendix for tables that chart the presence of introductory scenes (such as induction, dumb shows, choruses, prologues, epilogues, etc.) in early modern English drama from 1516 to 1642 .

[2] Richard Hosley, “Was There a 'Dramatic Epilogue' to The Taming of the Shrew?, Studies in English Literature, 1500-1900, 1 (1961), pp. 17-34, p. 21 . On induction in Elizabethan drama, see Thelma Greenfield, The Induction in Elizabethan Drama, Eugene, The University of Oregon Press, 1969.

[3] Alfred Harbage, Annals of English Drama, Philadelphia, University of Pennsylvania Press, 1940.

[4] On dumb show in Elizabethan theatre see Dieter Mehl, The Elizabethan Dumb Show, Cambridge (Mass.), Harvard University Press, 1966.

[5] "These inductions characteristically account for and 'present' the plays. They explain why it appears; they sometimes provide onlookers". (Thelma Greenfield, The Induction in Elizabethan Drama, cit. p. 39).

[6]Ibid., p. 67.

[7] Louise George Clubb, Italian Drama in Shakespeare's Time, New Haven and London, Yale University Press, 1989, p.5).

[8] Philippe Fabia, Les Prologues de Terence, Ernest Thorin, Paris 1888, and Emilio Goggio, "The Prologue in the Commedie Erudite of the Sixteenth Century", Italica, 18 (1941) pp. 124132.

[9]Curculio, Epidicus, Persa e Stichus.

[10]Amphitri, Mercalor, Miles Gloriosus, Mostellaria, Aulularia, Rudens, Trinummus e Cistellaria.

[11]Asinaria, Casina, Captivi, Menoechmi, Poenulus, Pseudolus e Truculentus.

[12] Giovan Battista Giraldi Cinthio, Intorno al comporre delle commedie e delle tragedie (1543), in Commedie del Cinquecento, edited by Aldo Borlenghi, Rizzoli, Milano 1959, vol. I, pp. 1020-1021 (my translation).

[13]Ibid., p. 1021.

[14] The play, begun in 1509, was completed by Ariosto to accomplish Pope Leo X. See Ariosto's letter to the Pope (16 January 1520) where the dramatist thanks him for having being invited to perform the play for Carnival (Ludovico Ariosto, Opere Minori, edited by Cesare Segre, Milano-Napoli, Ricciardi, 1964, p. 766-7). Eventually, the Pope did not authorize the performance of the play.

[15] Ludovico Ariosto, Opere minori, edited by Luigi Polidori, Firenze, Le Monnier, 1857, vol. II, p. 352. 
[16]Ibid., p. 354-355.

[17] Giovanni Francesco Loredano, Lo Incendio, Venezia, 1597, p. 1-3 (my translation).

[18] Ludovico Dolce, Fabritia, Venezia, 1549, pp. 4-7 (my translation).

[19] See Giovanni Della Porta's La Fantesca (1592), Giovan Battista Cini's La Vedova (1567), Luigi Alamanni's La Flora (1555), Giovanni Della Porta's La Furiosa (1600), Alessandro Piccolomini's L'Hortensio (1560), La Strega (1546) by Lasca respectively.

[20] Allegorical characters can be found in dumb shows. Thelma Greenfield, who classifies the inductions in four categories ("The inductive dumb show", "The occasional induction", "The critical induction" and "The frame play") identifies allegorical characters in the first three categories (Thelma Greenfield, The Induction in Elizabethan Drama, cit. pp. 23-27, 4044 e 116-117).

[21] See Willheim Creizenach, The English drama in the age of Shakespeare, London, Sidwick \& Jackson, 1916, pp. 276-277. Beyond Creizenach a hundred years ago, no recent critics has analyzed these conventions from the point of view of influence.

[22] Anonymous, A Warning to Fair Women, London 1599, A2 ${ }^{\mathrm{r}}-\mathrm{A} 3^{\mathrm{v}}$.

[23] Anonymous, The True Tragedy of Richard III, London 1594, A3 ${ }^{\mathrm{v}}-\mathrm{A} 4^{\mathrm{r}}$.

[24] "Hilary was the winter term, Easter the early spring term, Trinity the late spring term. Michaelmas was the autumn term (beginning on 9 October), the first one of the legal year, and the longest). It was also the busiest of the four terms because of the harvest and the endof-the-year litigations. Country litigants would come to London after bringing in the harvest; the money they earned from it would finance their lawsuit. (Michael Taylor, "Notes", in Thomas Middleton, A Mad World, My Master and other plays, edited by Michael Taylor, Oxford, Oxford University Press, 1995, p. 318).

[25] Thomas Middleton, Michaelmas Term (1604), in edited by Theodore B. Leinwand, in The Collected Works, edited by Gary Taylor and John Lavagnino, Oxford, Clarendon Press, 2007, p. 338.

[26] Ben Jonson, Every Man Out of His Humour, London 1600, B4 ${ }^{\mathrm{r}}$.

[27]Ibid., B4 .

[28] Marvin T. Herrick, Italian comedy in the Renaissance, Urbana, Illinois University Press, 1960, p. 137.

[29] On University Drama, see Frederick S. Boas, University drama in the Tudor age, Oxford, Oxford University Press, 1914; George C. Moore Smith, College plays performed in the university of Cambridge, Cambridge, Cambridge University Press, 1923.

[30] See Fernando Cioni, Stages at the University of Cambridge in Tudor England, in English Renaissance Scenes, edited by Paola Pugliatti and Alessandro Serpieri, Oxford, Peter Lang, 2006, pp. 127-154. 
[31] The manuscript, housed in the Lambeth Library (London), was reproduced by HorstDieter Blume for the series Renaissance Latin Drama in England, Georg Olms Verlag, Hildesheim 1991.

[32] Anonymous, Laelia, edited by George C. Moore Smith, Cambridge, Cambridge University Press, 1910, p. 3, v. 3.

[33]Ibid., p. 92 vv. 78 e 81-83.

[34] The text of the play was transcribed by Frederick S. Boas in The Christmas Prince, The Malone Society reprints, Oxford, Oxford University Press, 1922, pp. 56-101.

[35] The manuscripts of William Percy's plays are housed in the Huntington Library, San Marino (California). Percy's plays, even if probably not meant to be performed, reveal interesting evidences of Elizabethn stage practice. See Harold N. Hillebrand, "William Percy: An Elizabethan Amateur", in The Huntington Library Quarterly 1 (1938), pp. 391-416.

[36] The tragedy is extant in a manuscript housed in St. John's College Library at Oxford. Frederick S. Boas transcribed the text in The Christmas Prince, cit., pp. 229-287.

[37]Ibid., p. 231. 